University of Tennessee Health Science Center UTHSC Digital Commons

\title{
The Role of Drak2 in T Cell Function and Autoimmunity
}

Tarsha L. Harris

University of Tennessee Health Science Center

Follow this and additional works at: https://dc.uthsc.edu/dissertations

Part of the Endocrine System Diseases Commons, Immune System Diseases Commons, and the Medical Immunology Commons

\section{Recommended Citation}

Harris, Tarsha L. , "The Role of Drak2 in T Cell Function and Autoimmunity" (2016). Theses and Dissertations (ETD). Paper 386. http://dx.doi.org/10.21007/etd.cghs.2016.0407.

This Dissertation is brought to you for free and open access by the College of Graduate Health Sciences at UTHSC Digital Commons. It has been accepted for inclusion in Theses and Dissertations (ETD) by an authorized administrator of UTHSC Digital Commons. For more information, please contact jwelch30@uthsc.edu. 


\title{
The Role of Drak2 in T Cell Function and Autoimmunity
}

\begin{abstract}
The immune system utilizes many regulatory mechanisms to limit immune responses and ensure that immune cells target foreign pathogens and not healthy cells of the body. However, some immune cells can escape these checkpoints and attack the body's healthy cells, leading to tissue destruction and devastating autoimmune disorders. For example, multiple sclerosis (MS) occurs when immune cells attack the myelin sheath surrounding neurons of the central nervous system (CNS). Likewise, the destruction of pancreatic islet cells by dysregulated immune cells leads to type 1 diabetes (T1D). Remarkably, there are more than 80 types of autoimmune diseases. An estimated 50 million Americans suffer from autoimmune disease, and the prevalence continues to increase. These diseases are chronic and potentially life threatening, with associated healthcare costs estimated at $\$ 100$ billion annually. Current therapies to limit autoimmune diseases often include immunosuppressant medications that also increase susceptibility to infections and tumors. Therefore, therapeutic treatments which specifically inhibit autoreactive immune cells, while sparing immune cells required for pathogen or tumor clearance would significantly improve treatment options.
\end{abstract}

Drak2, a serine-threonine kinase, expressed abundantly in T and B cells, is a negative regulator of $\mathrm{T}$ cell activation. However, unlike other negative regulators, Drak2 plays an important role in eliciting autoimmunity, rather than preventing it. This is demonstrated by the finding that $D$ rak $2^{-/}$mice are resistant to autoimmune disease in mouse models of T1D and MS. This resistance is due to reduced accumulation of Drak2 ${ }^{-/-}$autoreactive T cells in the pancreas and CNS compared to wildtype mice. The decreased accumulation of autoreactive T cells in the target organs of $D r a k 2^{-/}$mice is partly due to diminished survival. Interestingly, despite Drak $^{-/-} \mathrm{T}$ cells being more sensitive to death, pathogen clearance and tumor surveillance are maintained in $D r a k 2^{--}$mice. Therefore, inhibiting Drak2 is a potential alternative therapeutic approach to inhibit autoreactive $T$ cells without suppressing the entire immune system. Thus, there is major interest in identifying the mechanisms by which Drak2 inhibits autoimmunity. This dissertation discusses the current knowledge of Drak2, its role in autoimmunity, and its potential as an inhibitory target to treat disease.

We utilized several in vivo T cell adoptive transfer models to show that resistance to T1D was due to the absence of Drak2 in T cells rather than pancreatic $\beta$-cells, and that regulatory T cells (Tregs) were required to elicit resistance. Further analysis revealed that in the absence of Drak2, IL-2 signaling and Treg development increased and likely contributes to disease resistance. We also determined that Drak2 is not a negative regulator of TGF- $\beta$ signaling in primary T cells, opposing a previous report. Thus it is unlikely that alterations in the TGF- $\beta$ signaling pathway mediate autoimmune disease resistance in the absence of Drak2. Finally, to advance our understanding of how Drak2 contributes to T cell accumulation, and ultimately to T1D and MS, we established in vitro culture methods to recapitulate the survival defect observed in the absence of Drak2 in vivo. Interestingly, we discovered that Drak2 modifies the actin polymerization pathway either directly or indirectly, and that Drak2 ${ }^{-/-} \mathrm{T}$ cells exhibited defects in cell cycle progression, proliferation, and other actin-mediated $\mathrm{T}$ cell functions that impair $\mathrm{T}$ cell accumulation. Together, these data highlight novel insights into the roles of Drak2 in T cell function and autoimmunity, and suggest that subtle changes within these diverse processes may cooperate to contribute to autoimmune disease resistance in the absence of Drak2.

\section{Document Type}

Dissertation 


\section{Degree Name}

Doctor of Philosophy (PhD)

\section{Program}

Biomedical Sciences

\section{Research Advisor}

Maureen A. McGargill, Ph.D.

\section{Keywords}

Actin Polymerization; Autoimmunity; Drak2; IL-2 Signaling; T cells; Type 1 Diabetes

\section{Subject Categories}

Diseases | Endocrine System Diseases | Immune System Diseases | Medical Immunology | Medical Sciences | Medicine and Health Sciences 


\title{
THE ROLE OF DRAK2 IN T CELL FUNCTION AND AUTOIMMUNITY
}

\author{
A Dissertation \\ Presented for \\ The Graduate Studies Council \\ The University of Tennessee \\ Health Science Center
}

\author{
In Partial Fulfillment \\ Of the Requirements for the Degree \\ Doctor of Philosophy \\ From The University of Tennessee
}

By

Tarsha L. Harris

August 2016 
Chapter 4 (C) 2015 by Harris, McGargill.

All other material $\odot 2016$ by Tarsha L. Harris.

All rights reserved. 


\section{DEDICATION}

To my mother, Ella M. Harris, I appreciate the encouragement that you have given me throughout my life. Thank you for instilling in me the strength and tenacity to continuously strive towards my goals.

To my older siblings, Audray, Songia, Vye, and Marvin, you all have always shown pride in my accomplishments and have made me feel that I can achieve anything. Thank you for the inspiration. To my oldest sister, Latonga, I know you are smiling down from heaven, and your support of me before your departure will never be forgotten. To my oldest nephew, Cortez, thank you for the positive vibes.

To my greatest supporter, Charles H. Lott, thank you for providing me with an unwavering support system and encouraging me over the past 11 years. You have been an awesome partner and a great dad. I appreciate you for making sure our children were well taken care of when I had long days at the research lab. To my children, Zaria, Mikel, Aaliyah, and the new addition arriving in September 2016, you all are my constant source of motivation and I feel blessed to be your mother. Thank you for being sweethearts and making it easy to be a mom and student simultaneously!

To my other family members and all of my special friends that I have known since childhood and college, thank you all for the motivational words throughout the years. Your inspiration has fueled my drive.

Again, thanks to each and every one of you. I love you all and cherish the support that each of you provided! 


\section{ACKNOWLEDGEMENTS}

I would like to express my sincere gratitude to my advisor, Dr. Maureen A. McGargill. Your willingness to allow me the opportunity to complete my graduate training in your lab is greatly appreciated and the experience is highly valued. Thank you for always encouraging me to accomplish more and push forward. You have done an awesome job of finding the perfect balance between allowing me to learn how to think independently, while also offering valuable advice and guidance. Your mentorship is invaluable.

I must express great appreciation to my committee members, Drs. Hongbo Chi, Elizabeth Fitzpatrick, Tony Marion, and Brian Sorrentino, for challenging me to think critically about my research. Your thought-provoking questions and suggestions have been a great asset during my graduate experience. Thank you for your time and input towards my project.

I would also like to acknowledge former and current fellow lab members, Ashley Castellaw, Ben Edwards, and Carlessia Lewis, for outstanding technical support and for ensuring that the lab runs smoothly. To Drs. Blaine Creasy, Jenny Johnson, Rachael Keating, Meenu Pillai, and Marie Wehenkel, thank you for your great advice, suggestions, and willingness to share your vast knowledge. You all have contributed to making the McGargill Lab an outstanding work environment.

I want to especially thank the University of Tennessee Health Center, Integrated Biomedical Sciences Program, and the Microbiology, Immunology, and Biochemistry track (formerly the Microbial Pathogenesis, Immunology, and Inflammation track) for allowing me the opportunity to pursue the Ph.D. degree. Furthermore, much appreciation to St. Jude Children's Research Hospital, ALSAC, and the Immunology Department for allowing me the support and access to conduct research on their illustrious campus. Thanks to the faculty and staff of the Immunology Flow Core, Cell and Tissue Imaging Core, and the Animal Resource Center at St. Jude for providing exceptional services and assistance.

Lastly, I want to acknowledge my fellow graduate classmates, Drs. Sandra Lester and Felicia Emery for endless support and encouragement. We have had many laughs and have seen each other through some challenging times. Sharing this experience with you has been my pleasure. 


\begin{abstract}
The immune system utilizes many regulatory mechanisms to limit immune responses and ensure that immune cells target foreign pathogens and not healthy cells of the body. However, some immune cells can escape these checkpoints and attack the body's healthy cells, leading to tissue destruction and devastating autoimmune disorders. For example, multiple sclerosis (MS) occurs when immune cells attack the myelin sheath surrounding neurons of the central nervous system (CNS). Likewise, the destruction of pancreatic islet cells by dysregulated immune cells leads to type 1 diabetes (T1D). Remarkably, there are more than 80 types of autoimmune diseases. An estimated 50 million Americans suffer from autoimmune disease, and the prevalence continues to increase. These diseases are chronic and potentially life threatening, with associated healthcare costs estimated at $\$ 100$ billion annually. Current therapies to limit autoimmune diseases often include immunosuppressant medications that also increase susceptibility to infections and tumors. Therefore, therapeutic treatments which specifically inhibit autoreactive immune cells, while sparing immune cells required for pathogen or tumor clearance would significantly improve treatment options.

Drak2, a serine-threonine kinase, expressed abundantly in T and B cells, is a negative regulator of $\mathrm{T}$ cell activation. However, unlike other negative regulators, Drak2 plays an important role in eliciting autoimmunity, rather than preventing it. This is demonstrated by the finding that $\operatorname{Drak} 2^{-/}$mice are resistant to autoimmune disease in mouse models of T1D and MS. This resistance is due to reduced accumulation of Drak $2^{-/}$ autoreactive T cells in the pancreas and CNS compared to wildtype mice. The decreased accumulation of autoreactive T cells in the target organs of Drak2 $2^{-/}$mice is partly due to diminished survival. Interestingly, despite $\operatorname{Drak}^{-/-} \mathrm{T}$ cells being more sensitive to death, pathogen clearance and tumor surveillance are maintained in Drak2 $2^{-/}$mice. Therefore, inhibiting Drak2 is a potential alternative therapeutic approach to inhibit autoreactive $\mathrm{T}$ cells without suppressing the entire immune system. Thus, there is major interest in identifying the mechanisms by which Drak2 inhibits autoimmunity. This dissertation discusses the current knowledge of Drak2, its role in autoimmunity, and its potential as an inhibitory target to treat disease.
\end{abstract}

We utilized several in vivo T cell adoptive transfer models to show that resistance to T1D was due to the absence of Drak2 in T cells rather than pancreatic $\beta$-cells, and that regulatory $\mathrm{T}$ cells (Tregs) were required to elicit resistance. Further analysis revealed that in the absence of Drak2, IL-2 signaling and Treg development increased and likely contributes to disease resistance. We also determined that Drak2 is not a negative regulator of TGF- $\beta$ signaling in primary T cells, opposing a previous report. Thus it is unlikely that alterations in the TGF- $\beta$ signaling pathway mediate autoimmune disease resistance in the absence of Drak2. Finally, to advance our understanding of how Drak2 contributes to $\mathrm{T}$ cell accumulation, and ultimately to T1D and MS, we established in vitro culture methods to recapitulate the survival defect observed in the absence of Drak2 in vivo. Interestingly, we discovered that Drak2 modifies the actin polymerization pathway either directly or indirectly, and that $\operatorname{Drak} 2^{--} \mathrm{T}$ cells exhibited defects in cell cycle 
progression, proliferation, and other actin-mediated $\mathrm{T}$ cell functions that impair $\mathrm{T}$ cell accumulation. Together, these data highlight novel insights into the roles of Drak2 in T cell function and autoimmunity, and suggest that subtle changes within these diverse processes may cooperate to contribute to autoimmune disease resistance in the absence of Drak2. 


\section{TABLE OF CONTENTS}

CHAPTER 1. INTRODUCTION ......................................................................................1

Expression

CHAPTER 2. MATERIALS AND METHODS.......................................................10

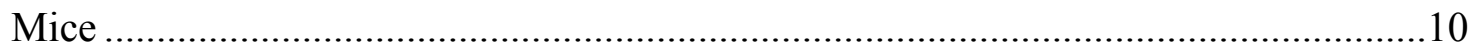

Fluorescence-Activated Cell Sorting and Purification of Lymphoid Populations ........10

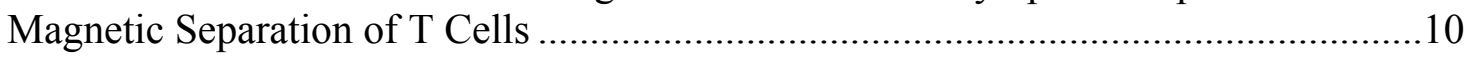

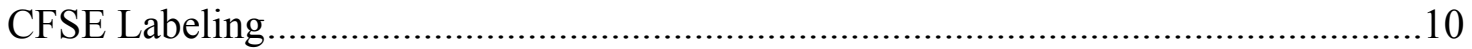

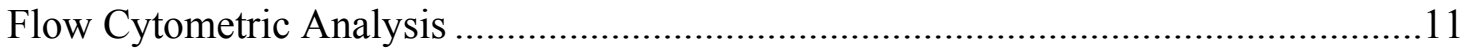

Anti- CD3 and Soluble Anti-CD28 Stimulation....................................................... 11

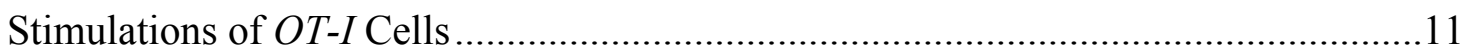

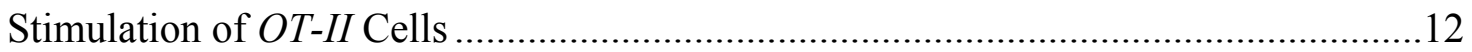

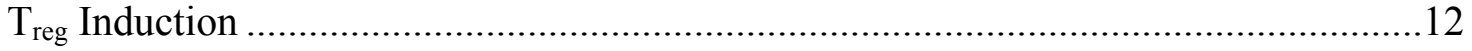

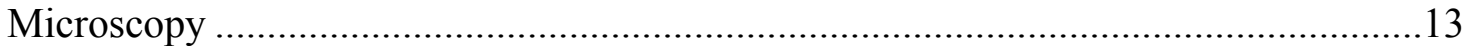

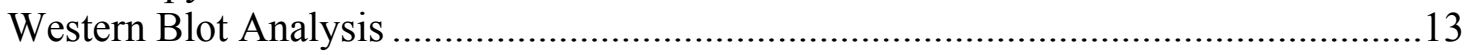

T Cell Adoptive Transfer .................................................................................... 13

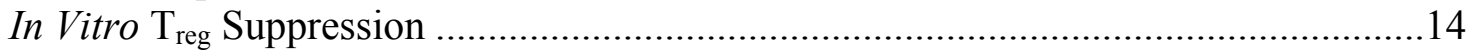

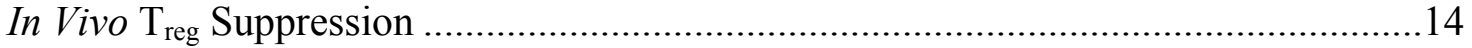

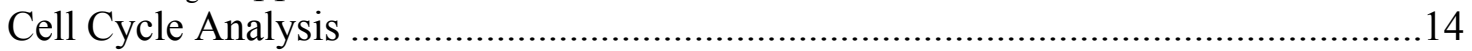

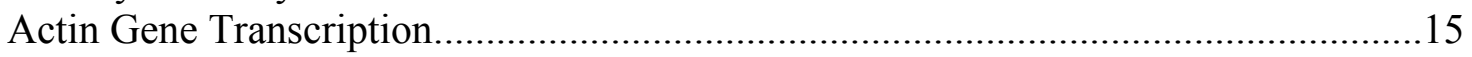

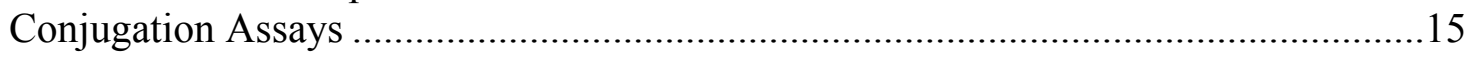

Migration Assays and CCL19 Treatment ........................................................ 15

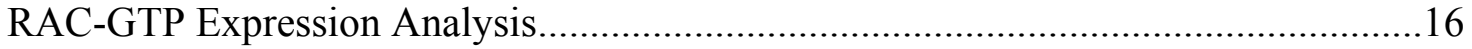

\section{CHAPTER 3. DRAK2 CONTRIBUTES TO TYPE 1 DIABETES BY} ALTERING REGULATORY T CELL DEVELOPMENT ........................................17

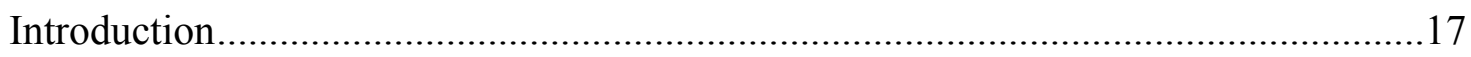

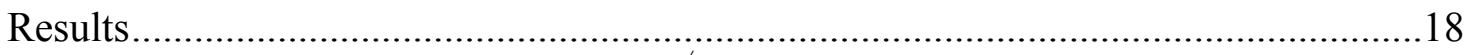

The resistance to T1D in NOD.Drak $2^{-/-}$mice transfers with the T cells and is independent of Drak2 expression in islet cells ......................................................18

The resistance to T1D in NOD.Drak2 ${ }^{-/}$mice requires Tregs .................................18

NOD.Drak2 $2^{-/}$Tregs function similar to NOD Tregs.............................................20

Drak2 ${ }^{-/}$mice exhibit an increase in the proportion of Foxp $3^{+} \mathrm{CD} 4^{+}$Tregs

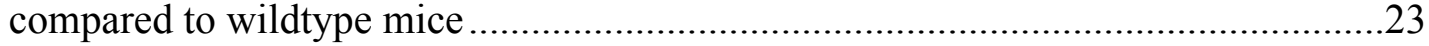

The induction of Tregs is not enhanced in the absence of Drak2 …........................25 
The proportion of precursor Tregs is comparable between wildtype and Drak2 $2^{-/-}$

thymocytes in NOD and C57BL/6 mice...........................................................25

NOD thymocytes are more sensitive to IL-2 signaling in the absence of Drak2 ......28

Discussion

\section{CHAPTER 4. DRAK2 DOES NOT REGULATE TGF-BETA SIGNALING}

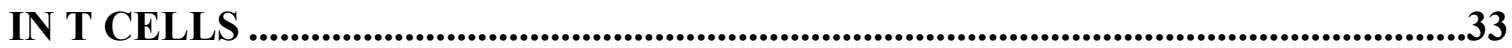

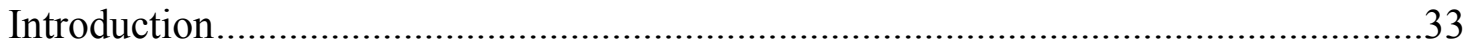

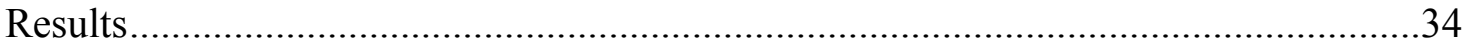

TGF- $\beta$ signaling via Smad proteins is not enhanced in Drak2 $2^{-/}$T cells compared

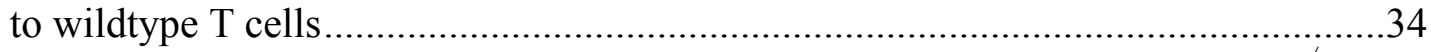
The effects of TGF- $\beta$ on T cells are comparable between wildtype and Drak2 $2^{-/-} \mathrm{T}$

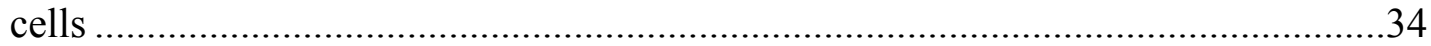

TGF- $\beta$-mediated T cell differentiation is not altered in the absence of Drak2 2.........37 Enhanced susceptibility to death of Drak2 ${ }^{-/} \mathrm{T}$ cells compared to wildtype T cells

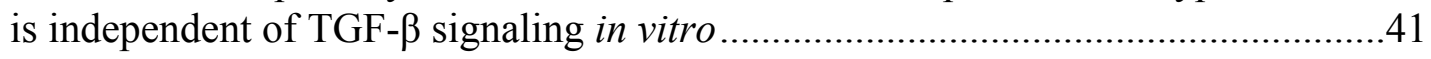

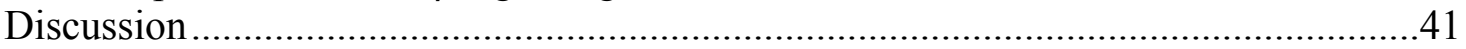

\section{CHAPTER 5. DRAK2 ALTERS ACTIN POLYMERIZATION AND ACTIN-} DEPENDENT T CELL FUNCTIONS ..............................................................44

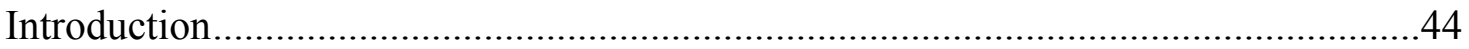

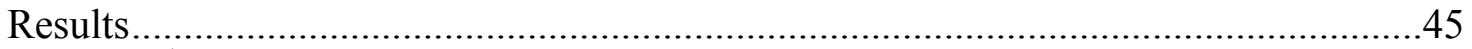

Drak2 $2^{-/}$CD4 T cells exhibit decreased accumulation upon stimulation in vitro ......45 $\mathrm{CD}^{+} \mathrm{T}$ cells display abnormal morphology and alterations during interphase in

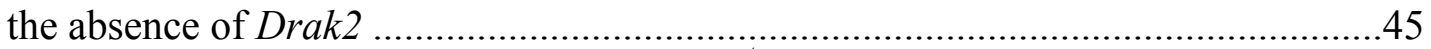

Actin polymerization is decreased in $\mathrm{Drak}^{-/-} \mathrm{CD} 4^{+} \mathrm{T}$ cells compared to

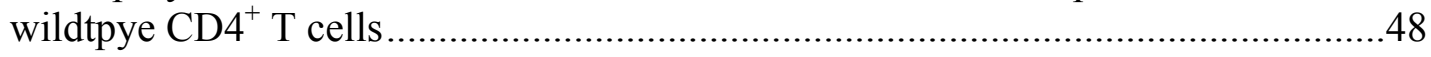

Actin-dependent $\mathrm{T}$ cell functions are impaired in the absence of Drak2 ..................50

Active Rac-GTP expression is decreased in Drak2 ${ }^{-/} \mathrm{T}$ cells upon stimulation..........52

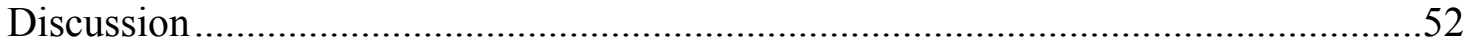

CHAPTER 6. DISCUSSION AND CONCLUSIONS ...........................................57

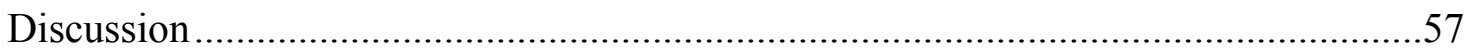

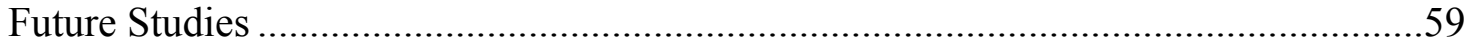

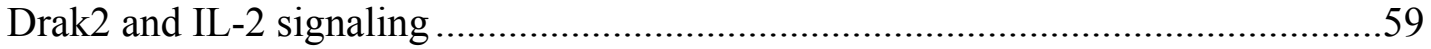

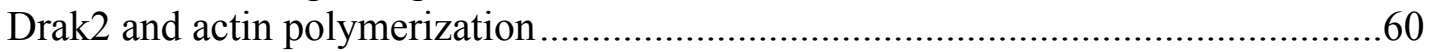

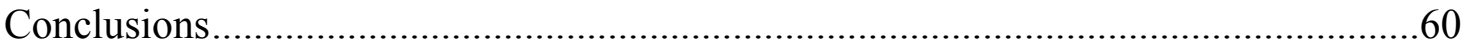

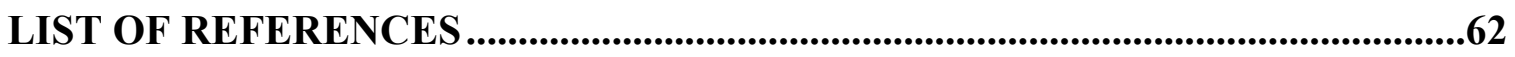

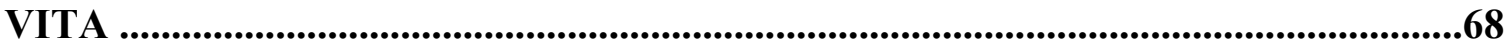




\section{LIST OF FIGURES}

Figure 3-1. The resistance to T1D in NOD.Drak ${ }^{-/}$mice transfers with the T cells and is independent of Drak2 expression in islet cells

Figure 3-2. The resistance to T1D in NOD.Drak2 ${ }^{-/}$mice requires Tregs .......................21

Figure 3-3. NOD.Drak2 ${ }^{-/}$Tregs function similar to NOD Tregs ..................................22

Figure 3-4. $\mathrm{Drak2}^{-/}$mice exhibit an increase in the proportion of Foxp $3^{+} \mathrm{CD} 4^{+}$Tregs compared to wildtype mice .......................................................................24

Figure 3-5. The induction of Tregs is not enhanced in the absence of Drak2 …............26

Figure 3-6. The proportion of precursor Tregs is comparable between wildtype and Drak2 ${ }^{--}$thymocytes in NOD and C57BL/6 mice

Figure 3-7. NOD thymocytes are more sensitive to IL-2 signaling in the absence of Drak2

Figure 3-8. Proposed model of Drak2 function in IL-2 signaling. .31

Figure 4-1. Smad2 translocation is not enhanced in Drak2 ${ }^{-/-} \mathrm{T}$ cells compared to wildtype T cells .....

Figure 4-2. Smad2 and Smad2/3 complex phosphorylation is not enhanced in $\operatorname{Drak}^{-/} \mathrm{T}$ cells compared to wildtype T cells.

Figure 4-3. TGF- $\beta$-mediated inhibition of naïve $\mathrm{T}$ cell proliferation is comparable between wildtype and $\mathrm{Drak}^{-/} \mathrm{T}$ cells

Figure 4-4. TGF- $\beta$-mediated responses to opposing cytokines are comparable between wildtype and $\mathrm{Drak2}^{-\alpha} \mathrm{T}$ cells

Figure 4-5. TGF- $\beta$-mediated regulatory $\mathrm{T}$ cell induction is not altered in the absence of Drak2

Figure 4-6. Enhanced susceptibility to death of $\operatorname{Drak}^{-/-} \mathrm{T}$ cells compared to wildtype T cells is independent of TGF- $\beta$ signaling in vitro

Figure 5-1. $\operatorname{Drak2}^{-/-} \mathrm{CD} 4 \mathrm{~T}$ cells exhibit decreased accumulation upon stimulation in vitro

Figure 5-2. CD4 $\mathrm{T}$ cells display abnormal morphology and alterations during interphase in the absence of Drak2

Figure 5-3. Actin polymerization is decreased in $\operatorname{Drak}^{-/} \mathrm{CD} 4 \mathrm{~T}$ cells compared to wildtpye CD4 T cells. 
Figure 5-4. Actin-dependent $\mathrm{T}$ cell functions are impaired in the absence of Drak2 .....51

Figure 5-5. Active Rac-GTP expression is decreased in Drak2 $2^{--} \mathrm{T}$ cells upon

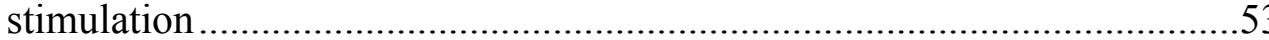

Figure 5-6. Proposed model of Drak2 function in actin polymerization .........................54 


\section{LIST OF ABBREVIATIONS}

\begin{tabular}{|c|c|}
\hline APC & Antigen-presenting cells \\
\hline CFSE & Carboxyfluorescein diacetate succinimidyl ester \\
\hline $\mathrm{CNS}$ & Central nervous system \\
\hline DNRII & Dominant-negative TGF- $\beta$ receptor II \\
\hline Drak2 & DAP kinase-related apoptosis-inducing protein kinase 2 \\
\hline EAE & Experimental autoimmune encephalomyelitis \\
\hline FACS & Fluorescence-activated cell sorting \\
\hline FFA & Free fatty acid \\
\hline MFI & Mean fluorescence intensity \\
\hline $\mathrm{MHC}$ & Major histocompatibility complex \\
\hline MS & Multiple sclerosis \\
\hline NLS & Nuclear localization signal \\
\hline NOD & Non-obese diabetic \\
\hline$S C I D$ & Severe combined immunodeficiency \\
\hline SDS-PAGE & Sodium dodecyl sulfate-polyacrylamide gel electrophoresis \\
\hline SNP & Single nucleotide polymorphism \\
\hline TCR & $\mathrm{T}$ cell receptor \\
\hline $\mathrm{T}_{\text {conv }}$ & Conventional $\mathrm{T}$ cells \\
\hline $\mathrm{T}_{\text {regs }}$ & Regulatory $\mathrm{T}$ cells \\
\hline T1D & Type 1 diabetes \\
\hline $\mathrm{T} 2 \mathrm{D}$ & Type 2 diabetes \\
\hline
\end{tabular}




\section{CHAPTER 1. INTRODUCTION}

\section{Drak2}

$\mathrm{T}$ cells play crucial roles in tumor surveillance and protection against invading pathogens. However, if not properly regulated, T cells can attack normal, healthy cells of the body. This unregulated response may lead to tissue and organ destruction and devastating autoimmune diseases such as type 1 diabetes (T1D) and multiple sclerosis (MS). The immune system utilizes several mechanisms to regulate T cells, reduce damage, and prevent autoimmunity. One important regulatory mechanism is preventing inappropriate T cell activation. Several signaling molecules, including Cbl and PTEN, can negatively regulate inappropriate $\mathrm{T}$ cell activation. Removing these molecules increases susceptibility to autoimmunity [1-3], highlighting the importance of regulating $\mathrm{T}$ cell activation.

DAP kinase-related apoptosis-inducing protein kinase 2 (Drak2) is also a negative regulator of T cell activation [4-6]. Drak2 was originally cloned due to its homology to the kinase domain of Death-associated protein kinase (DAPK) [7]. While the kinase domain of Drak2 is homologous with the other DAPK kinase family members (DAPK, DRP-1, ZIPK, and Drak1), its non-catalytic C-terminal region is structurally distinct [7]. These serine-threonine kinase proteins are characterized as pro-apoptotic proteins based on their ability to induce apoptosis upon overexpression in cell lines [8]. However, several studies highlighted additional roles for Drak2 beyond the scope of apoptosis, and in particular, its role in T cells and autoimmunity is of considerable interest as a potential target to treat autoimmune diseases.

\section{Expression}

Drak2 is expressed most abundantly in lymphoid organs, although expression was also detected in various tissues during embryogenesis, in some tumor types, and in pancreatic $\beta$-islet cells after stimulation [4,5,9-14]. Within the lymphoid compartment, Drak2 expression increases during $\mathrm{T}$ and $\mathrm{B}$ cell development, and remains abundant in mature T and B cells. On the other hand, Drak2 is expressed at extremely low levels in natural killer cells, and is not expressed in macrophages and dendritic cells.

Interestingly, the intracellular localization of Drak2 varies depending upon cell type and activation state. Drak2 was primarily restricted to the cytoplasm upon ectopic expression in ACL-15, HeLa, and WI-38 cells $[15,16]$. Alternatively, its overexpression in NRK, NIH 3T3, and Caco-2 cells caused Drak2 to localize to the nucleus. In T cells, Drak2 localizes to both the cytoplasm and the nucleus [4]. However, shortly after stimulation, Drak2 expression decreases in the nucleus, but is retained in the cytoplasm for 24 hours before total expression levels decrease due to reduced mRNA transcription, suggesting that $\mathrm{T}$ cell receptor (TCR) stimulation mediates Drak2 localization and expression. 


\section{Drak2 activation and protein interactions}

In addition to altering the localization and expression of Drak2, TCR stimulation also induces Drak2 phosphorylation [6]. The release of intracellular calcium stores with thapsigargin also activates Drak2. Three kinases have been implicated in Drak2 phosphorylation. First, Drak2 autophosphorylates itself, which is dependent on the presence of calcium [6]. Second, Drak2 was phosphorylated by $\mathrm{PKC}-\gamma$, a serine-threonine kinase that is activated by calcium [16]. Finally, Protein kinase D (PKD), a protein belonging to the same calcium/calmodulin-dependent superfamily of serine-threonine kinases as Drak2, phosphorylated Drak2 in an in vitro kinase assay [17]. PKD catalytic activity also promoted Drak2 autophosphorylation in 293T cells and Jurkat cells. In cells ectopically expressing Drak2, PKD and Drak2 interacted at the mitochondria membrane, and this interaction was enhanced upon thapsigargin treatment. Thus, Drak2 function and activation is associated with intracellular calcium release.

The kinase activity of Drak2 requires both the ATP-binding loop within its kinase domain and the $\mathrm{C}$-terminal region, which contains a functional nuclear localization signal (NLS) sequence [6]. In vitro kinase assays revealed that, in addition to phosphorylating itself, Drak2 phosphorylates myosin light chain as an exogenous substrate [7,9]. Drak2 also phosphorylated p70S6 kinase, which plays important roles in protein synthesis and cell cycle progression [14]. Drak2 overexpression in NIT-1 cells increased p70S6 kinase phosphorylation, while siRNA-mediated knockdown of Drak2 resulted in reduced p70S6 kinase phosphorylation.

In addition to its substrates, Drak2 also interacts with other proteins. When Drak2 was overexpressed in COS-7 cells, it interacted with the calcium-binding protein, calcineurin homologous protein (CHP). This interaction was calcium-dependent, and caused inhibition of Drak2 kinase activity $[9,18]$. Drak2 was also shown to interact with the transforming growth factor- $\beta$ (TGF- $\beta$ ) receptor I in several tumor cell lines. Drak2 inhibited TGF- $\beta$ signaling in these cells by blocking phosphorylation of the Smad $2 / 3$ complex [10]. These potential substrates and interacting proteins were identified mainly through in vitro kinase assays or overexpression in cell lines, therefore it is not known what Drak2 may phosphorylate in vivo at physiological levels of expression.

\section{Function}

Other members of the DAPK kinase family (DAPK, DRP-1, and ZIPK) have well-established roles as pro-apoptotic proteins [8]. However, the role of Drak2 in apoptosis-mediated cell death is less clear. Early studies utilizing NIH 3T3 cells demonstrated that ectopic expression of Drak2 induced apoptosis, which required Drak2 kinase activity [7,9]. However, enforced expression of Drak2 did not cause apoptosis in COS-7 cells [7]. Additional investigations suggest that the intracellular location of Drak2 determines whether it contributes to apoptosis [15]. Ectopic Drak2 expression in ACL15, HeLa, and WI-38 cells, where Drak2 was localized to the cytoplasm, did not enhance cell death. Alternatively, overexpression of Drak2 in NRK, NIH3T3, and Caco-2 cells led 
to Drak2 localization to the nucleus and induced apoptosis. Interestingly, UV irradiation of ACL-15 cells, which exhibit cytoplasmic Drak2 expression, resulted in nuclear translocation of Drak2 and subsequent apoptosis. Thus, Drak2 localization to the nucleus correlates with increased cell death in overexpression experiments.

In addition to cell lines, the potential apoptotic effects of Drak2 have been studied in pancreatic $\beta$-islet cells. Drak2 augmented free fatty acid (FFA)-mediated apoptosis in vitro in primary $\beta$-islet cells and NIT-1 insulinoma cells [13]. Furthermore, transgenic overexpression of Drak2 via the $\beta$-actin promoter increased apoptosis in islet cells following FFA stimulation [14]. Drak2 overexpression in these models mediated apoptosis via reduced induction of the anti-apoptotic family members Bcl-2, Bcl-xL, and Flip.

The role of Drak2 in T cell apoptosis has also been extensively studied. Transgenic expression of Drak2, via the $\beta$-actin promoter, increased apoptosis in T cells following anti-CD3 and anti-CD28 stimulation, but only in the presence of exogenous IL2 [12]. This increased apoptosis correlated with upregulation of pro-apoptotic proteins. However, ectopic expression of Drak2 in primary T cells did not increase apoptosis upon anti-CD3 and anti-CD28 stimulation even in the presence of IL-2 [6]. Furthermore, the absence of Drak2 did not cause a reduction in apoptosis in primary T cells upon in vitro stimulation with anti-CD3 and anti-CD28, or during an in vivo infection with lymphocytic choriomeningitis virus (LCMV) [4,5]. Moreover, thymocytes from Drak2 ${ }^{-1-}$ mice did not exhibit impaired apoptosis during negative selection or upon stimulation with multiple agents, including anti-CD3, anti-Fas, peptide-pulsed antigen-presenting cells, and $\gamma$-irradiation compared to wildtype thymocytes [4]. Collectively, these data indicate that Drak2 does not play a required pro-apoptotic role in primary $\mathrm{T}$ cells. It is possible that the role of Drak2 varies between cell types. In addition, overexpression of Drak2 in cell lines that do not normally express Drak2, and enhanced ectopic expression in primary cells may impact cell survival due to inappropriate expression levels of Drak2. Thus, overexpression experiments do not necessarily indicate how Drak2 functions during normal physiological processes. The fact that Drak2 $2^{--}$mice develop normally, and apoptosis of $\mathrm{T}$ cells from these mice is comparable to wildtype mice, suggests that Drak2 is not required for apoptosis.

Contrary to decreased cell death that would be expected in Drak2 $2^{-/-} \mathrm{T}$ cells if Drak2 was required for apoptosis, Drak2 $2^{-/}$T cells were actually more susceptible to apoptosis upon in vitro and in vivo stimulation. In vitro superantigen staphylococcal enterotoxin B (SEB) stimulation enhanced death of Drak2 ${ }^{-/-}$T cells compared to wildtype $\mathrm{T}$ cells [19]. This enhanced death was associated with reduced anti-apoptotic protein expression, and retroviral overexpression of the anti-apoptotic protein Bcl-xL rescued this survival defect. Reduced survival of Drak $2^{-/} \mathrm{T}$ cells also contributed to an impaired antibody response following immunization with NP16-CGG [20]. Drak2 ${ }^{-/}$mice exhibited reduced development of germinal centers $(\mathrm{GC})$, which was associated with decreased numbers of GC B cells, and lower levels of antibodies, compared to wildtype mice following immunization. Interestingly, induced expression of the anti-apoptotic protein $\mathrm{Bcl}-\mathrm{xL}$ in $\mathrm{T}$ cells rescued these B cell defects, suggesting that the impaired B cell 
response was due to decreased T cell survival in the absence of Drak2. Furthermore, in an allogeneic tumor model, Drak $2^{-/} \mathrm{T}$ cells exhibited increased cell death following allogeneic activation, which culminated in decreased allogeneic rejection [21]. Taken together, these data suggest that following stimulation, $\mathrm{T}$ cells are more susceptible to death in the absence of Drak2, and therefore Drak2 plays a critical role in promoting T cell survival rather than apoptosis.

While Drak2 was not critical to induce apoptosis of T cells, and therefore does not appear to function as a pro-apoptotic protein, several studies suggest that Drak2 functions as a negative regulator of TCR signaling. Peripheral Drak $2^{-/-}$T cells were hyperproliferative, exhibited enhanced cytokine production, and increased calcium flux in response to suboptimal TCR stimulation [4]. Likewise, Drak2 ${ }^{-/} \mathrm{CD} 4^{+}$thymocytes exhibited increased calcium flux compared to wildtype thymocytes in response to antiCD3 and anti-CD4 stimulation [5]. In addition, ectopic expression of Drak2 via the lck proximal promoter led to high levels of Drak2 expression in double positive thymocytes and diminished calcium flux [22]. Interestingly, Drak2 autophosphorylation requires calcium mobilization, and in the absence of Drak2, TCR-induced calcium flux is increased [6]. This suggests that Drak2 is activated in response to calcium, and then functions to negatively regulate calcium signaling. In addition, thapsigargin treatment enhanced Drak2 expression in splenic T and B cells, and Drak2 potentially interacts with proteins involved in calcium signaling (PKC- $\gamma, \mathrm{CHP}$, and PKD). Together, these studies demonstrate that Drak2 modulates calcium signaling, which may mediate its negative regulatory role during $\mathrm{T}$ cell activation. Thus, in the absence of Drak2, the TCR activation threshold is reduced, and Drak2 $2^{--}$T cells are hypersensitive to suboptimal stimulation.

\section{Drak2 and Autoimmunity}

Because Drak2 $2^{--}$mice have hypersensitive T cells, it was reasonable to hypothesize that these mice would be more susceptible to autoimmune diseases. Surprisingly, Drak $2^{-/}$mice do not develop spontaneous autoimmune disease. In fact, in an induced model of autoimmune disease, experimental autoimmune encephalomyelitis (EAE), Drak2 $2^{-/}$mice are paradoxically more resistant to disease [4,23]. Drak2 $2^{-/}$mice exhibited reduced incidence, severity, and numbers of infiltrating T cells in the CNS compared to wildtype mice. Furthermore, disease resistance was intrinsic to the T cells, and due, at least in part, to enhanced death of the autoreactive T cells. This is supported by the fact that enforced expression of Bcl-xL in T cells restored EAE susceptibility in Drak2 $^{-/}$mice, suggesting that Drak2 promotes survival of autoreactive T cells, which contributes to autoimmune disease in this model [19]. In addition, Drak2 $2^{-/-}$mice are resistant to disease in the Non-obese diabetic (NOD) mouse model of T1D. Similarly, this disease resistance is due to decreased accumulation of $\mathrm{T}$ cells in the pancreatic islets, possibly due to enhanced apoptosis of T cells in the absence of Drak2 [23]. These data indicate that Drak2 expression in T cells promotes the survival of autoreactive T cells and contributes to autoimmunity. In support of this, transgenic mice ectopically expressing Drak2 via the T cell specific $l c k$ promoter exhibited enhanced incidence of spontaneous 
autoimmunity compared to wildtype littermate controls [22]. Furthermore, the onset and mean clinical severity of EAE in Drak2 transgenic mice was enhanced compared to wildtype mice. This enhanced autoimmunity was due to activation of autoreactive $\mathrm{T}$ cells that either escaped thymic negative selection or exhibited lower activation thresholds, due to overexpression of Drak2. Together, these data indicate that Drak2 expression in T cells contributes to autoimmunity.

However, $\operatorname{Drak2}^{-/-}$mice were not resistant to disease in all models of autoimmunity [23]. Specifically, Drak2 $2^{-/-}$mice responded similar to wildtype mice in models of autoimmunity in which disease is mediated by autoantibodies or cells of the innate immune system, such as a collagen-induced model of arthritis, systemic lupus erythematosus (SLE), and passive cutaneous anaphalaxis. These data support the notion that Drak2 plays a role specifically in T cell-mediated autoimmune diseases.

While the role of Drak2 in the EAE model was intrinsic to the T cells, and due to increased susceptibility to apoptosis of autoreactive cells, other data suggest that Drak2 may contribute to T1D by affecting survival of pancreatic $\beta$ cells [14]. Treatment of islet cells with inflammatory cytokines led to the upregulation of Drak2 expression in these cells, which correlated with islet apoptosis. In addition, overexpression of Drak2 (driven by the $\beta$-actin promoter) in transplanted islets enhanced apoptosis and was accompanied by increased disease incidence in the streptozotocin-induced model of T1D. According to this view, NOD.Drak ${ }^{-/}$mice could be resistant to T1D due to the absence of Drak2 in $\beta$ islet cells, which would enhance islet survival during disease. However, ectopic expression of Drak2 in islet cells may not mimic physiological Drak2 expression and/or function. Therefore, identifying the cell type(s) in which Drak2 elicits its effects is important to study its mechanism of action. It remains unclear if the absence of Drak2 in T cells, $\beta$-islet cells, or a combination of both, mediates resistance to T1D. This dissertation will address and clarify this question.

\section{Drak2 and Infectious Diseases}

Given that Drak2 $^{-/-}$T cells are more susceptible to apoptosis upon stimulation and that this susceptibility contributes to resistance to autoimmune disease, this survival defect could also affect immunity to infectious pathogens. Surprisingly, Drak2 ${ }^{-/}$mice responded comparably to wildtype mice following a variety of infections. During lymphocytic choriomeningtitis virus (LCMV) infection, wildtype and $\mathrm{Drak}^{-/-}$mice had similar numbers of antigen-specific T cells and viral clearance was enhanced in the absence of Drak2 [4] and (unpublished data). Furthermore, Drak2 $2^{-/-} \mathrm{T}$ cells were able to infiltrate nonlymphoid organs following LCMV infection, although they were more susceptible to death in the brain during later stages of infection [4,23]. These data suggest that the absence of Drak2 does not impair the immune response to LCMV.

In addition, Drak2 $2^{--}$mice exhibited a greater survival rate than wildtype mice in response to West Nile Virus (WNV)-induced encephalitis (47\% vs. 16.7\%, respectively) [24]. Although viral loads and kinetics were similar in the blood and spleen, brain viral 
load was significantly reduced in $\mathrm{Drak}^{-/}$mice compared to wildtype mice. WNVinfected $\mathrm{T}$ cells may function to carry virus into the brain. Therefore, the reduction in viral load was attributed to reduced T cell infiltration in the CNS in response to WNV infection. Lastly, Drak2 ${ }^{-/-}$mice respond similar to wildtype mice during intra-cerebral and intraperitoneal infection with mouse hepatitis virus in terms of $\mathrm{T}$ cell activation, expansion, and cytokine production $[25,26]$. Surprisingly, memory T cell function was enhanced in the absence of Drak2. Thus, although $\operatorname{Drak}^{-/-} \mathrm{T}$ cells are more susceptible to death following stimulation, $\mathrm{Drak} 2^{-/-}$mice respond effectively to these viral pathogens, suggesting that Drak2 expression is not required to elicit productive immune responses against infectious agents.

Unpublished data from our lab also show that $\operatorname{Drak2}^{-/}$mice launch effective immune responses to various other pathogens. $\operatorname{~rak}^{-/}$mice exhibited similar clearance and increased numbers of antigen-specific cells in response to the bacterium, Listeria monocytogenes, compared to wildtype mice. In addition, following influenza virus infection, $\mathrm{Drak}^{-/-}$mice showed similar survival, viral clearance, and numbers of virusspecific T cells as wildtype mice. Furthermore, $\operatorname{Drak2}^{-/-}$mice exhibit no alterations in response to the protozoan Leishmania major, based on the number of Leishmaniaspecific T cells. Also, the number of IL-4 producing CD4 T cells responding to the parasite, Heligmosomoides polygyrus, was similar between wildtype and $\mathrm{Drak2}^{-/}$mice. In fact, there was less shedding of the parasite in the absence of Drak2. Therefore, not only do $\mathrm{Drak}^{-/-}$mice retain immune function in response to an array of pathogens, but they actually exhibit enhanced responses in many infection models.

\section{Drak2 and Tumorigenesis}

DAPK, the founding member of the DAPK family, functions as a tumor suppressor in several different types of cancer [27-29]. Therefore, studies explored whether Drak2 also suppresses tumorigenesis. A correlation between reduced Drak2 expression and elevated cyclooxygenase-2 (COX-2) expression was found in human colorectal tumors, leading to enhanced tumor growth, suggesting that Drak2 functions as a tumor suppressor [30]. Moreover, enhanced expression of Drak2 induced cell death in colon cancer cell lines, via COX-2 inhibition, highlighting an anti-tumor role for Drak2 via pro-apoptotic effects. In addition, in a human acute myeloid leukemia (AML) cell line, knockdown of the oncogene $M Y B$ led to induction of Drak2, which served as a proapoptotic protein to induce tumor cell death [11]. Furthermore, up-regulation of $M Y B$ and down-regulation of Drak2 was seen in AML patients, further suggesting a role for Drak2 in tumor suppression. Alternatively, opposing evidence suggests that Drak2 functions as an oncogene. Drak2 was preferentially expressed in skin samples from cutaneous T-cell Lymphoma (CTCL) patients. In addition, Drak2 was identified as an antigen that elicited antibody reactions in some of the CTCL patient sera but not in healthy patients, indicating a tumor-dependent antibody production and implicating Drak2 expression as a risk factor for this disease [31]. In addition, enhanced Drak2 expression in several tumor

cell lines led to a decrease in TGF- $\beta$ signaling, overriding the function of TGF- $\beta$ in tumor suppression [10]. These data suggest that Drak2 may function as a negative regulator of 
TGF- $\beta$ signaling and serve as an oncogene in basal-like and HER2-enriched human breast tumors and cell lines, where it is highly expressed. Furthermore, loss of Drak2 expression inhibited tumor growth in a xenograft model, implicating that Drak2 potentiates tumor development.

Due to opposing findings implicating Drak2 as either a tumor suppressor or an oncogene, the role of Drak2 in tumor surveillance and suppression was investigated in Drak $2^{-/-}$mice utilizing various in vivo tumor models [32]. Drak2 ${ }^{-/-}$mice did not exhibit altered onset, severity, or incidence of transplanted tumors, spontaneous tumors resulting from carcinogen treatment, tumors induced by the absence of the p53 tumor suppressor, or inflammation-induced tumors. These data suggest that Drak2 is neither a prerequisite tumor suppressor nor oncogene, and it is not required for immune-cell mediated tumor surveillance. Further, the role for Drak2 as an oncogene or tumor suppressor is dependent on the tumor type.

\section{Therapeutic Implications}

Effective treatments of autoimmune diseases require a balance between blocking the adverse effects of autoreactive T cells while preserving immune cell function. Drak $^{-/}$mice are resistant to T1D and MS, but retain the ability to respond effectively to infectious pathogens and tumors. Therefore, Drak2 inhibition represents a potential therapeutic approach to treat autoimmune disorders such as MS and T1D without increasing the risks of tumor development and increased pathogen susceptibility caused by broad immunosuppression.

Drak2 has also been implicated as a therapeutic target in West Nile Virus infection. During infection with WNV, pathogenesis in the CNS may be mediated by T cells that transport the virus to the brain [24]. Drak $2^{-/}$mice exhibited decreased T cell infiltration in the brain, which decreased viral load and increased survival. These findings suggest that Drak2 contributes to WNV disease pathogenesis, which could be reduced through Drak2 inhibition.

In addition to T1D, Drak2 has also been implicated in type 2 diabetes (T2D) [13]. While reduced insulin sensitivity is the main initial concern during T2D, islet cell apoptosis is a long-term mediator of disease. Upon overexpression of Drak2 via the $\beta$ actin promoter, transgenic islet cells exhibited increased apoptosis in response to free fatty acid treatment, a compound that is elevated in obesity and supports T2D development, suggesting a role for Drak2 in islets cells as a pro-apoptotic protein. Thus, further studies should investigate if enhanced Drak2 gene expression is a risk factor in pre-diabetic T2D patients, which could implicate Drak2 as a therapeutic target.

Furthermore, Drak2 may also contribute to allogeneic rejection [21]. Following transplantation of allogeneic tissue, $\mathrm{T}$ cells specific for alloantigens can become activated and promote allograft rejection. Long-term treatments using immunosuppressant drugs can increase toxicity and risk of pathogenic infections. In an allogeneic tumor transplant 
model, Drak $2^{-/-}$T cells did not reject the transplanted tumors, due to enhanced cell death of the T cells, highlighting that inhibition of Drak2 may elicit protective effects and enhance patient outcome following organ transplant.

Based on the aforementioned investigations, Drak2 is a compelling therapeutic target to inhibit for the treatment of T cell-mediated autoimmune diseases, to prevent graft rejection, and to inhibit growth of certain tumors in which it functions as an oncogene. An initial attempt to discover novel small-molecule inhibitors of Drak2 identified a compound that exhibited inhibition of Drak2. However, this compound also blocked other members of the DAPK family [33], rendering it a nonselective inhibitor. Subsequent studies revealed a more selective compound that served as a dual inhibitor for only Drak1 and Drak2, however inhibitory effects were not robust [34]. Therefore, more work is needed to develop selective and effective functional inhibitors of Drak2 to further explore its potential as a therapeutic target.

\section{Organization of the Dissertation}

Although several data indicate that Drak2 plays a role in autoimmune disease, the precise mechanisms by which it impacts autoimmunity are not clear. Understanding the function of Drak2 is of great importance, as it will provide insight into novel mechanisms that mediate $\mathrm{T}$ cell dysregulation to enhance susceptibility or resistance to autoimmune disease. This understanding will benefit future studies to develop novel therapeutic treatments for these diseases. The work in this dissertation was proposed to investigate the function of Drak2 and mechanisms by which it contributes to autoimmune disease and $\mathrm{T}$ cell function.

In chapter 3, we explored the mechanism by which Drak2 contributes to autoimmunity by first examining the cell type(s) in which Drak2 expression contributes to T1D. Although many lines of evidence indicate that Drak2 plays a critical role within the T cells, other data suggested that Drak2 expression in $\beta$-islet cells augments T1D $[14,23]$. Therefore, we investigated whether Drak2 expression in T cells, $\beta$-islet cells, or both cell types regulated disease in the NOD model of T1D. We determined that, similar to the EAE model, resistance to T1D was also due to the absence of Drak2 in the T cells. We next showed that in the absence of Drak2, IL-2 signaling was enhanced in thymocytes, which led to increased proportion of cells expressing phosphorylated Stat5 and enhanced Foxp3 induction. Furthermore, regulatory T cells (Tregs) were required for disease resistance and inhibition of autoreactive NOD.Drak2 ${ }^{-/-} \mathrm{T}$ cells.

Knowledge gained from the investigations completed in chapter 3, showing that Drak2 contributes to autoimmune disease via its function in T cells, coupled with a previous report suggesting that Drak2 is a negative regulator of TGF- $\beta$ signaling [10], led to the research in chapter 4 to investigate the role of Drak2 in TGF- $\beta$ signaling within $\mathrm{T}$ cells. The study indicating that Drak 2 negatively regulates TGF- $\beta$ signaling utilized a variety of cell lines and whole splenocytes, but did not test whether Drak2 inhibited TGF$\beta$ signaling specifically in T cells. It was reasonable to hypothesize that enhanced TGF- $\beta$ 
signaling in the absence of Drak2 mediated autoimmune disease resistance, because the TGF- $\beta$ pathway is critical for suppressing autoimmunity. Therefore, we performed several in vitro experiments to determine if Drak2 functions as a negative regulator of TGF- $\beta$ signaling in primary T cells. We conclude that Drak 2 does not negatively regulate TGF- $\beta$ signaling in $T$ cells, and thus does not contribute to autoimmunity via alterations in TGF- $\beta$ signaling.

The research described in chapter 5 investigated mechanisms by which Drak2 may alter $\mathrm{T}$ cell accumulation, as decreased $\mathrm{T}$ cell accumulation in the target organs during T1D and MS mediates disease resistance in the absence of Drak2. Although enhanced $\mathrm{T}$ cell apoptosis has been implicated, detailed proliferative studies had not been completed. To explore Drak2 function more directly, we established in vitro culture conditions that elicited decreased $\mathrm{T}$ cell accumulation in the absence of Drak2, similar to in vivo observations. We discovered defects in proliferation and decreased actin polymerization in $\mathrm{Drak}^{-/} \mathrm{T}$ cells compared to wildtype T cells. Efficient actin polymerization facilitates many $\mathrm{T}$ cell processes including activation, calcium signaling, and cell cycle progression. Each of these processes cooperate to elicit productive T cell survival and proliferation, both of which lead to $T$ cell accumulation. Our preliminary data and previously published investigations suggest many of these actin-mediated processes may be altered in Drak2 $2^{-/} \mathrm{T}$ cells compared to wildtype T cells. Therefore, we investigated actin polymerization in the absence of Drak2. In addition to a significant reduction in polymerized actin, we also found alterations in downstream actin-mediated $\mathrm{T}$ cell functions in the absence of $\operatorname{Drak} 2$, suggesting a novel role for Drak2 in directly or indirectly mediating actin dynamics. This dissertation sheds light on some of the debated questions regarding Drak2 and introduces novel insights and new roles for Drak2 in autoimmunity and $\mathrm{T}$ cell function. 


\title{
CHAPTER 2. MATERIALS AND METHODS
}

\begin{abstract}
Mice
$C 57 B L / 6 . D r a k 2^{-/}$mice were previously described and backcrossed 19 generations to $C 57 B L / 6$ [4]. OT-II mice were obtained from Kristin Hogquist [35] and TGF- $\beta$ DNRII mice were obtained from Hongbo Chi [36]. C57BL/6, CD451/1, OT-I and NOD.SCID mice were purchased from Jackson Laboratories. NOD.Drak2 ${ }^{-/}$and NOD.BDC2.5.Drak2 $2^{-/-}$mice were previously described [23]. NOD.Drak2 $2^{-/-}$mice were crossed to the $N O D$ background for greater than 11 generations. SNP analysis with Illumina Low Density Linkage Panels showed that greater than $99.3 \%$ of the SNPs analyzed in NOD.Drak2 ${ }^{-/}$mice, and $100 \%$ of the SNPs analyzed in Drak2.NOD.SCID mice were of $N O D$ origin (Charles River Laboratories). Mice were age and gender matched within each experiment and held under specific pathogen-free conditions at St. Jude Children's Research Hospital. Animal studies met the approval of the Animal Ethics Committee.
\end{abstract}

\section{Fluorescence-Activated Cell Sorting and Purification of Lymphoid Populations}

Mouse T cells were purified from spleen and/or lymph nodes and FACS sorting using antibodies specific for CD4, CD8, CD25, CD44, CD45RB, and CD62L (eBioscience). Naïve T cells $\left(\mathrm{CD} 4^{+}\right.$or $\mathrm{CD} 8^{+}$) were CD44, CD25 CD45RB ${ }^{\text {hi }}, \mathrm{CD} 25^{-}$ $\mathrm{CD} 44^{\mathrm{lo}}$, or $\mathrm{CD} 25^{-} \mathrm{CD} 44^{\mathrm{lo}} \mathrm{CD} 62 \mathrm{~L}^{\mathrm{hi}}$. Regulatory T cells were $\mathrm{CD} 4{ }^{+} \mathrm{CD} 25^{+} \mathrm{CD} 45 \mathrm{RB}^{\mathrm{lo}}$ [37,38]. Cell sorting was performed using the iCyt Reflection or SY3200 Cell Sorters (Sony Biotechnology).

\section{Magnetic Separation of T Cells}

Mouse T cells were purified from spleen and/or lymph nodes by negative selection with biotin-conjugated antibodies specific for B220, CD8 (for CD4 T cell enrichment only), CD11b, DX5, and MHC class II (eBioscience), followed by separation with streptavidin-conjugated magnetic beads (Miltenyi Biotech), and collection of the flow-through fraction of cells. T cell populations were greater than $95 \%$ pure.

\section{CFSE Labeling}

Following purification, cells were treated with 5,6-carboxyfluorescein succinimidyl ester (CFSE) (Molecular probes) as previously described [39], with modifications. Cells were washed twice with PBS and incubated with CFSE prepared at $0.4 \mu \mathrm{M}$ in pre-warmed PBS $(0.1 \% \mathrm{FCS})$, for 10 minutes at $37^{\circ} \mathrm{C}$. Cells were washed twice with RP10 advanced media (RPMI advanced media, 10\% FCS, 5nM Hepes, 50 $\mu \mathrm{g} / \mathrm{ml}$ Pen-Strep, 4mM L-glutamine, $50 \mathrm{uM}$ BME, $50 \mu \mathrm{g} / \mathrm{ml}$ gentamicin). 


\section{Flow Cytometric Analysis}

Single cell suspensions from in vitro cultures or organs were stained with antibodies specific for CD4, CD8, CD25, CD44, CD45RB, CD45.1, CD45.2, and/or CD62L (eBioscience and BioLegend). Cell death and viability was determined utilizing Annexin V (BD Biosciences) or Fixable Viability Dye (eBioscience), according to manufacturer's instructions. To detect Foxp ${ }^{+}$cells, suspensions were stained with antibodies specific for CD4, CD8, and CD25. Cells were then fixed and permeabilized with the Foxp3/Transcription Factor Staining Buffer Set according to manufacturer's instructions (eBioscience) and stained with anti-Foxp3 antibody (eBioscience). For Factin and G-actin analysis, cells were treated with viability dye and stained with antibodies specific for CD4. Cells were fixed and permeabilized with the Foxp3/Transcription Factor Staining Buffer and stained with Alex Flour 488-conjugated phalloidin (Life Technologies) for F-actin and/or Alexa-Fluor 594-conjugated DNase I (Invitrogen: Molecular Probes) for G-actin. For analysis of phosphorylated Smad2/3, cells were stained with antibodies specific for CD4 and CD8, fixed with 1X BD Phosflow Lyse/Fix Buffer and permeabilized with BD Phosflow Perm Buffer III according to manufacturer's instructions (BD Biosciences), then stained with anti-pSmad2/3 antibody (BD Biosciences). To detect Helios ${ }^{+}$cells and expression of phosphorylated Stat5 (pStat5), cells were immediately fixed with BD Phosflow Fix Buffer I for 10 minutes in a $37^{\circ} \mathrm{C}$ water bath and surface stained with anti-CD25 (Clone 7D4; eBiosciences). Cell suspensions were permeabilized with BD Phosflow Perm Buffer III, according to manufacturer's instructions (BD Biosciences), then stained with antibodies specific for CD4, CD8, Helios (eBiosciences) and pStat5 (Cell Signaling). Cells were collected on a FACSCalibur or LSRFortessa (BD Biosciences). Analysis was performed with FlowJo software (TreeStar, Inc.).

\section{Anti- CD3 and Soluble Anti-CD28 Stimulation}

Tissue culture-treated plates were incubated for one hour with $30 \mu \mathrm{g} / \mathrm{ml}$ goat antihamster IgG (Vector Laboratories) in PBS, then washed and incubated one hour with $1 \mu \mathrm{g} / \mathrm{ml}$ anti-CD3 (eBioscience). Plates were washed before addition of cells and $1 \mu \mathrm{g} / \mathrm{ml}$ anti-CD28 (eBioscience) [4]. Alternatively, tissue culture-treated chambered coverglass slides were incubated with $0.01 \%$ solution of Poly-L-Lysine (Sigma-Aldrich), then washed and allowed to dry. Chambers were coated twice prior to treatment with hamster IgG and anti-CD3 as described above. Chamber slides were washed before the addition of cells and $1 \mu \mathrm{g} / \mathrm{ml}$ anti-CD28.

\section{Stimulations of $O T-I$ Cells}

Naïve (CD8 $\left.{ }^{+} \mathrm{CD} 25^{-} \mathrm{CD} 44^{\mathrm{lo}} \mathrm{CD} 62 \mathrm{~L}^{\mathrm{hi}}\right) \mathrm{T}$ cells were sorted from spleen and lymph nodes of OT-I and OT-I.Drak2 $2^{-/}$mice using the iCyt Reflection or Sy3200 Cell sorters. Naïve T cells were labeled with CFSE and stimulated in vitro with $100 \mathrm{pM} \mathrm{OVA}_{257}$ peptide-pulsed, CD45. $1^{+}$splenocytes that were irradiated at 3000 rads. Cells were 
cultured in media only or media with TGF- $\beta$ for two days, harvested, then analyzed by flow cytometry.

Alternatively, $2 \times 10^{6}$ FACS-sorted, naïve $\left(\mathrm{CD} 8^{+} \mathrm{CD} 25^{-} \mathrm{CD} 44^{\mathrm{lo}} \mathrm{CD} 62 \mathrm{~L}^{\text {hi }}\right)$ OT-I and OT-I.Drak2 $2^{-/} \mathrm{T}$ cells were stimulated for two days with $4.5 \times 10^{6} \mathrm{CD} 45.1^{+}$, irradiated splenocytes pulsed with $200 \mathrm{nM} \mathrm{OVA}_{257}$ peptide at $37^{\circ} \mathrm{C}$. The cells were harvested, washed, and replated with naïve splenocytes in the presence of $5 \mathrm{ng} / \mathrm{ml}$ TGF- $\beta$ (R\&D Systems) with or without $20 \mathrm{ng} / \mathrm{ml}$ recombinant mouse IL-2 (BD Biosciences), IL-7 (Invitrogen Life Technologies), or IL-15 (R\&D Systems). Two days later, fresh media and cytokines were added, and two days later, cells were harvested. Cells were stained with antibodies specific for CD8, CD45.1, and CD45.2, followed by Annexin V, and analyzed by flow cytometry.

\section{Stimulation of $O T-I I$ Cells}

Single cell suspensions were prepared and sorted for naïve $\left(\mathrm{CD} 4^{+} \mathrm{CD} 25^{-} \mathrm{CD} 44^{\text {lo }}\right) \mathrm{T}$ cells from spleen and lymph nodes of OT-II and OT-II.Drak2 ${ }^{-/}$mice. Naive CD4 ${ }^{+} \mathrm{T}^{-}$cells were CFSE labeled and stimulated in vitro for three days with $10 \mu \mathrm{M} \mathrm{OVA}_{323}$ peptidepulsed, irradiated splenocytes in the presence or absence of 10 -fold TGF- $\beta$ titrations. Cells were harvested, stained with viability dye and antibodies specific for CD4 and Foxp3, and analyzed for viability and proliferation by flow cytometry.

\section{$T_{\text {reg }}$ Induction}

In vitro Treg inductions were performed in two alternative ways. For the first analysis, single cell suspensions were prepared and sorted for naïve (CD4 ${ }^{+} \mathrm{CD} 25^{-} \mathrm{CD} 44^{\mathrm{lo}}$ ) $\mathrm{T}$ cells from spleen and lymph nodes of wildtype and Drak $2^{--}$mice. Naïve CD4 ${ }^{+} \mathrm{T}$ cells were stimulated with $1 \mu \mathrm{g} / \mathrm{ml}$ plate-bound anti-CD3 and $1 \mu \mathrm{g} / \mathrm{ml}$ soluble anti-CD28 for 72 hours with $20 \mathrm{ng} / \mathrm{ml}$ IL-2 and increasing amounts of TGF- $\beta$. For the second in vitro induction experiment, naïve OT-II and OT-II.Drak2 ${ }^{-/}\left(\mathrm{CD} 4^{+} \mathrm{CD} 25^{-} \mathrm{CD} 44^{\mathrm{lo}}\right) \mathrm{T}$ cells were purified and stimulated with irradiated splenocytes (loaded with $10 \mathrm{uM} \mathrm{OVA} 323$ peptide) for 72 hours with increasing amounts of TGF- $\beta$ (R\&D Systems and Cell Signaling). Cells were harvested and analyzed for Foxp3 expression by flow cytometry.

For in vivo Treg induction, naïve OT-II (CD45.1/CD45.2) and OT-II.Drak2-(CD45.2/CD45.2) $\mathrm{T}$ cells were sorted and combined at 1:1 ratio. Two million total $\mathrm{T}$ cells were transferred intravenously into wildtype (CD45.1/CD45.1) host mice. The following day, host mice were given water or water containing $2 \%$ ovalbumin ad libitum. Appropriate water treatments were replaced on day 2.5 and all mice were given water without ovalbumin on day 5 . Organs were harvested five days after administration of ovalbumin and analyzed by flow cytometry for Foxp3 expression. 


\section{Microscopy}

For observation of anti-Smad2 expression using fluorescent microscopy, single cell suspensions were prepared and negatively selected by magnetic separation for $\mathrm{CD} 4^{+}$ $\mathrm{T}$ cells from lymph nodes of wildtype and Drak $2^{-/}$mice. $\mathrm{CD} 4{ }^{+} \mathrm{T}$ cells were stimulated for 24 hours with $1 \mu \mathrm{g} / \mathrm{ml}$ anti-CD3 (coated onto poly L-lysine-treated coverglass slides) and $1 \mu \mathrm{g} / \mathrm{ml}$ soluble anti-CD28. TGF- $\beta$ was added to some samples for the final 20 minutes. Cells were fixed with $4 \%$ methanol-free formaldehyde, permeabilized in $0.1 \%$ Triton-X in PBS, washed with PBS, and blocked with 1\% BSA, followed by an overnight incubation with a primary rabbit antibody specific for Smad2 (Cell Signaling). Cells were stained with a secondary Alexa Fluor 647-conjugated goat anti-rabbit antibody, Alexa Fluor 488-conjugated phalloidin, and DAPI (Invitrogen Life Technologies). Images were collected utilizing a Nikon C1Si laser scanning confocal microscope.

To conduct live cell imaging and mitotic analysis, single cell suspensions were prepared and negatively selected for $\mathrm{CD}^{+} \mathrm{T}$ cells from lymph nodes of wildtype and $\operatorname{Drak}^{-/}$mice and stimulated with $1 \mu \mathrm{g} / \mathrm{ml}$ anti-CD3 (coated onto poly L-lysine-treated coverglass slides) and $1 \mu \mathrm{g} / \mathrm{ml}$ soluble anti-CD28. For live cell imaging, CD $4^{+} \mathrm{T}$ cells were stimulated for a total of 36 hours, and images were collected in 6 minute increments beginning at 18 hours post-stimulation and ending at 36 hours. For mitotic analysis, cells were stimulated for 48 hours and fixed with a mixture containing 3 parts methanol and 1 part acetic acid. Finally, cells were washed, permeabilized, stained with DAPI, and images were collected.

\section{Western Blot Analysis}

Single cell suspensions were prepared from spleen and lymph nodes of wildtype and Drak2 $2^{-/}$mice. Whole splenocytes and FACS-sorted naïve (CD25 CD44 ${ }^{\mathrm{lo}}$ ) CD $4^{+}$and $\mathrm{CD}^{+} \mathrm{T}$ cells were stimulated for two hours with plate-bound anti-CD3 and anti-CD28. Media with or without $2 \mathrm{ng} / \mathrm{ml}$ TGF- $\beta$ was added to cells for one additional hour. Cells were harvested and frozen at $-80^{\circ} \mathrm{C}$. Frozen cell pellets were lysed $(50 \mathrm{mM}$ Tris, $150 \mathrm{mM}$ $\mathrm{NaCl}, 1 \%$ Triton $\mathrm{X}-100,0.5 \%$ sodium deoxycholate, $2 \mathrm{mM}$ EDTA, $10 \%$ glycerol with phosphatase and protease inhibitors (Calbiochem)). Protein concentration was determined using a BCA Protein Assay (Thermo Scientific). Equal amounts of protein were denatured in sample buffer (10\% SDS, 20\% Glycerol, 0.2M Tris $\mathrm{HCl}, 0.05 \%$ Bromophenol Blue), separated by SDS-PAGE, and transferred to PVDF membranes for immunoblot analysis of anti-Smad2, anti-pSmad2, and anti-HSP90 (Cell Signaling) expression.

\section{T Cell Adoptive Transfer}

Single cell suspensions were prepared and FACS sorted for naïve (CD25$\left.\mathrm{CD} 44^{\mathrm{lo}} \mathrm{CD} 62 \mathrm{~L}^{\mathrm{hi}}\right) \mathrm{T}$ cells from spleen and lymph nodes of female mice and injected

intravenously via the tail vein into female recipient mice. Mice received $1.5-3.5 \times 10^{6} \mathrm{~T}$ 
cells. For adoptive transfer experiments utilizing T cells from NOD or NOD.Drak $2^{-/}$mice expressing the islet antigen-specific BDC2.5 T cell receptor (TCR) transgene, 7,500

naïve $\left(\mathrm{CD} 4^{+} \mathrm{CD} 25^{-} \mathrm{CD} 44^{\mathrm{lo}} \mathrm{CD} 62 \mathrm{~L}^{\mathrm{hi}}\right) \mathrm{T}$ cells were transferred in the presence or absence of $1 \times 10^{5}\left(\mathrm{CD}^{+} \mathrm{CD} 25^{+} \mathrm{CD} 45 \mathrm{Rb}^{10}\right)$ NOD Tregs to recipient mice. Ten days following the injection, a sample of blood was analyzed to verify efficient transfer. Blood glucose was monitored weekly by testing a drop of venous tail blood with an OneTouch Ultra or Bayer Contour ${ }^{\circledR}$ blood glucose meter. Mice were considered diabetic after two consecutive readings of $290 \mathrm{mg} / \mathrm{dL}$ or greater.

\section{In Vitro $\mathbf{T}_{\text {reg }}$ Suppression}

Single cell suspensions from spleen and lymph nodes of NOD and NOD.Drak2 $2^{-1-}$ mice were prepared and FACS-sorted for naïve $\left(\mathrm{CD} 4^{+} \mathrm{CD} 25^{-} \mathrm{CD} 44^{\mathrm{lo}} \mathrm{CD} 62 \mathrm{~L}^{\text {hi }}\right) \mathrm{T}$ cells. Cells were labeled with CFSE. Next, 50,000 labeled cells were stimulated with 15,000 or 50,000 anti-CD3/CD28-coated T-Activator Dynabeads per well (0.3:1 or 1:1 beads/effector T cell ratios, respectively; Life Technologies). Naive T cells were stimulated alone or with various ratios of NOD or NOD.Drak $2^{-/-}$Tregs $\left(\mathrm{CD} 4^{+} \mathrm{CD} 25^{+} \mathrm{CD} 45 \mathrm{RB}^{10}\right)$ for 72 hours. Cell viability was analyzed using fixable viability dye, and effector $T$ cell proliferation was determined by measuring CFSE dilution of viable cells.

\section{In Vivo $\mathbf{T}_{\text {reg }}$ Suppression}

Single cell suspensions prepared from spleen and lymph nodes of NOD mice (Thy1.1/Thy1.2) were FACS-sorted for naïve $\left(\mathrm{CD} 4^{+} \mathrm{CD} 25^{-} \mathrm{CD} 44^{10}\right) \mathrm{T}$ cells, CFSElabeled, and transferred intravenously into NOD.SCID mice (Thy1.2/Thy1.2) with or without NOD or NOD.Drak2 $2^{-/}$Tregs $\left(\mathrm{CD}^{+} \mathrm{CD} 25^{+} \mathrm{CD} 45 \mathrm{Rb}^{10}\right)$ (Thy1.1/Thy1.1) at a ratio of 4:1. Lymph nodes were harvested seven days after injection and analyzed for effector $\mathrm{T}$ cell proliferation to determine Treg suppression.

\section{Cell Cycle Analysis}

Single cell suspensions from the lymph nodes and spleen of wildtpye and $\mathrm{Drak2}^{-1-}$ mice were FACS-sorted for naïve $\left(\mathrm{CD} 4^{+} \mathrm{CD} 25^{-} \mathrm{CD} 44^{\mathrm{lo}}\right) \mathrm{T}$ cells, then stimulated for 24 hours with $1 \mu \mathrm{g} / \mathrm{ml}$ plate-bound anti-CD3 and $1 \mu \mathrm{g} / \mathrm{ml}$ soluble anti-CD28. Cells were harvested, washed once with PBS, then resuspended in propidium iodide solution $(0.05$ $\mathrm{mg} / \mathrm{ml}$ propidium iodide, $0.1 \%$ sodium citrate, $0.1 \%$ Triton X-100). Samples were treated with $10 \mu \mathrm{l}$ of $0.2 \mathrm{mg} / \mathrm{ml}$ RNase (DNase-free) for 30 minutes at room temperature. Samples were filtered, then analyzed by flow cytometry. 


\section{Actin Gene Transcription}

Single cell suspensions were prepared from the lymph nodes and spleen of wildtype and $\mathrm{Drak}^{-/-}$mice and sorted for naive $\left(\mathrm{CD} 4^{+} \mathrm{CD} 25^{-} \mathrm{CD} 44^{\mathrm{lo}}\right) \mathrm{T}$ cells. Naïve $\mathrm{CD}^{+} \mathrm{T}$ cells were stimulated with $1 \mu \mathrm{g} / \mathrm{ml}$ plate-bound anti-CD3 and $1 \mu \mathrm{g} / \mathrm{ml}$ soluble anti-CD28. Forty hours post-stimulation, RNA was extracted from cells with an RNeasy Mini Kit (Qiagen) and quantified using a NanoDrop 8000 Spectrophotometer (Thermo Scientific). Complementary DNA was synthesized from 500 ng RNA with TaqMan Reverse Transcription reagents (Applied Biosystems). The cDNA was analyzed by SYBR Green dye (Thermo Scientific) with primers for $\beta$-actin (Actb), and $\gamma$-actin (Actg1) using an Applied Biosystems 7500 Fast Real-Time PCR System. The amount of $A c t b$ and Actgl transcripts was quantified by the relative standard curve method (User Bulletin 2; Applied Biosystems) and was normalized to GAPDH expression.

\section{Conjugation Assays}

Cell conjugation assays were performed as previously described [40,41], with modifications. Single cell suspensions from the spleen and lymph nodes of OT-I and OTI.Drak2 $2^{-/}$mice were FACS-sorted for naïve $\left(\mathrm{CD}^{+} \mathrm{CD} 44^{\mathrm{lo}}\right) \mathrm{T}$ cells. In addition, single cell suspensions from the spleen of wildtype mice were prepared and pulsed with various concentrations of $\mathrm{OVA}_{257}$ peptide for $30 \mathrm{~min}$ at $37^{\circ} \mathrm{C}$, then CFSE-labeled. Naïve $\mathrm{CD} 8^{+} \mathrm{T}$ cells and $\mathrm{OVA}_{257}$-loaded splenocytes were co-cultured at a 1:1 ratio, pelleted in a roundbottom plate, and incubated for 10 minutes at $37^{\circ} \mathrm{C}$. Cells were vortexed on a plate shaker for 20 s, then fixed immediately with $1 \%$ paraformaldehyde. Finally, cells were stained with antibodies specific for B220 and CD8, and analyzed by flow cytometry. Antigenpresenting cells (APCs) were characterized as $\mathrm{B}_{2} 20^{+} \mathrm{CFSE}^{+}$cells. Conjugates were electronically gated on APCs that were $\mathrm{B} 220^{+} \mathrm{CD} 8^{+}$.

\section{Migration Assays and CCL19 Treatment}

Transwell migration assays were performed as previously described [40,42], with modifications. Single cell suspensions from the lymph nodes of wildtype and Drak2 ${ }^{-1-}$ mice were negatively selected for $\mathrm{CD}^{+}$and $\mathrm{CD} 8^{+} \mathrm{T}$ cells using Miltenyi magnetic beads. $\mathrm{T}$ Cells were stimulated with $1 \mu \mathrm{g} / \mathrm{ml}$ anti-CD3 and $1 \mu \mathrm{g} / \mathrm{ml}$ anti-CD28 for 2 hours. Cells were counted and equal numbers were added to a 96-well permeable support insert that was placed within receiver plate wells (Sigma-Aldrich, CLS3388), which contained either media only or $250 \mathrm{ng} / \mathrm{ml}$ CCL19 chemokine (Sigma-Aldrich). Migrated cells were recovered from the lower chamber and counted using a hemacytometer. The percentage of migrated $T$ cells was determined by dividing the number of migrated cells by the number of input cells.

Alternatively, for CCL19-mediated actin polymerization analysis, CD4 ${ }^{+}$and $\mathrm{CD}^{+} \mathrm{T}$ cells were negatively selected from the lymph nodes of wildtype and Drak $^{-/-}$ mice and rested in culture media at $37^{\circ} \mathrm{C}$ for 20 minutes. Cells were treated with media 
only or media with $250 \mathrm{ng} / \mathrm{ml} \mathrm{CCL19}$ for various time points between 0 and 30 minutes, then fixed immediately with BD Phosflow Fix Buffer I for 10 minutes in a $37^{\circ} \mathrm{C}$ water bath. Cells were washed and stained with anti-CD4 and anti-CD8 antibodies prior to treatment with 1X Permeabilization Buffer (eBioscience), according to manufacturer's instructions. Finally, samples were stained with phalloidin and MFI expression was analyzed by flow cytometry.

\section{RAC-GTP Expression Analysis}

$\mathrm{CD}^{+}$and $\mathrm{CD}^{+} \mathrm{T}$ cells were negatively selected from the lymph nodes of wildtype and $\mathrm{Drak2}^{-/}$mice. Cells were resuspended in HBSS (containing $\mathrm{Ca}^{2+}+0.5 \%$ FCS) and incubated on ice for 30 minutes with $2 \mu \mathrm{g}$ of biotin-conjugated anti-CD3 and $1.5 \mu \mathrm{g}$ biotin-conjugated anti-CD28 (eBioscience) per $10 \times 10^{6}$ cells. Cells were stimulated by crosslinking biotin with $0.7 \mu \mathrm{g}$ of prewarmed streptavidin per $10 \times 10^{6}$ cells and incubated in $37^{\circ} \mathrm{C}$ water bath. Stimulation was stopped by adding ice cold PBS and transferring cells to ice. Cells were washed, stained with antibodies specific for anti-CD4 and anti-CD8, then fixed and permeabilized with the Foxp3/Transcription Factor Staining Buffer Set according to manufacturer's instructions (eBioscience). Cells were stained with a primary mouse monoclonal antibody specific for active Rac-GTP (NewEast Biosciences), followed by a secondary anti-mouse PE-conjugated antibody. Cells were analyzed by flow cytometry. Rac-GTP expression for each genotype is normalized to each group's Rac-GTP MFI at "0 minutes post-stimulation" (i.e. unstimulated cells). 


\section{CHAPTER 3. DRAK2 CONTRIBUTES TO TYPE 1 DIABETES BY ALTERING REGULATORY T CELL DEVELOPMENT}

\section{Introduction}

Type 1 diabetes (T1D) occurs when T cells and other cells of the immune system attack and destroy the insulin-producing, islet $\beta$-cells in the pancreas. Mice deficient in Drak2 are resistant to T1D when bred to the Non-obese diabetic (NOD) background [23]. NOD mice spontaneously develop diabetes, and disease etiology is similar to T1D in humans, including the involvement of autoreactive $\mathrm{T}$ cells, autoantibodies, and similar genetic risk factors [43]. Interestingly, despite the diminished autoimmunity, Drak2 ${ }^{-/}$ mice effectively eliminate infectious pathogens and retain the ability to combat tumors similar to wildtype mice [23-26,32]. Thus, Drak2 is an ideal protein to target in order to treat autoimmune disorders without compromising immunity to pathogens and tumors. However, it is not clear exactly how Drak2 signaling contributes to autoimmunity.

Drak2 is expressed highest in B cells and T cells [4,5,7]. In addition, Drak2 is also expressed in multiple tissues during development and in pancreatic $\beta$-cells after stimulation with free fatty acid (FFA) or cytokines [12-14]. We previously demonstrated that the resistance to T1D in NOD.Drak2 ${ }^{-/}$mice occurs because the Drak2 $^{-/-}$T cells do not accumulate in the pancreas to the same extent as wildtype NOD T cells [23]. T cell transfer experiments demonstrated that the defect in $\mathrm{T}$ cell accumulation was partly due to enhanced sensitivity to death in the absence of $\operatorname{Drak2}$, which contributed to decreased $\mathrm{T}$ cell accrual in the pancreas and the pancreatic draining lymph nodes. Similarly, Ramos et al. found that $\mathrm{Drak2}^{-/-} \mathrm{T}$ cells were more susceptible to death following superantigen stimulation, and that overexpression of $B c l-x(L)$, an anti-apoptotic protein, in T cells rendered $\mathrm{Drak2}^{-\alpha}$ mice susceptible to EAE [19]. These data suggest that Drak2 promotes the survival of autoreactive T cells, which contributes to autoimmune disease. However, it was not determined if the resistance to T1D in NOD.Drak2 $2^{-/}$mice was due solely to an increased susceptibility to death in the T cells, or if T cells were the central mediators of disease resistance in the NOD model. On the other hand, transgenic expression of Drak2 in pancreatic $\beta$-cells rendered these cells more sensitive to apoptosis following in vitro stimulation [13]. Furthermore, mice that overexpressed Drak2 in the islet cells were more susceptible to diabetes in a streptozotocin-induced model [14]. These data suggest that Drak2 induces $\beta$-cell apoptosis, and that NOD.Drak $2^{--}$mice may be resistant to T1D because the $\beta$-cells are less susceptible to apoptosis in the absence of Drak2.

Therefore, we investigated whether the absence of Drak 2 in the T cells, $\beta$-cells, or both cell types contributed to the resistance to T1D. We found that the resistance to T1D was due to Drak2-deficiency in the T cells, and that the absence of Drak2 in the pancreatic $\beta$-cells did not alter the incidence of T1D. Additionally, we show that the enhanced susceptibility to death of autoreactive NOD.Drak2 ${ }^{-\alpha} \mathrm{T}$ cells was not the sole mediator of disease resistance, but that regulatory $\mathrm{T}$ cells (Tregs) were also required to prevent autoimmunity in NOD.Drak $2^{-/-}$mice. Interestingly, NOD.Drak2 $2^{-/}$mice had a higher proportion of Tregs than $N O D$ mice, which was due to enhanced IL-2 signaling 
that increased the transition of Treg precursors into mature Tregs. These data provide novel insight into the etiology of T1D by showing that Drak2 not only contributes to autoimmune disease by enhancing survival of autoreactive $T$ cells, but also reduces the proportion of Tregs through negative regulation of IL-2 signaling in thymocytes.

\section{Results}

\section{The resistance to $\mathrm{T} 1 \mathrm{D}$ in $N O D . D r a k 2^{-/}$mice transfers with the $\mathrm{T}$ cells and is independent of Drak2 expression in islet cells}

To test whether the absence of Drak2 in the $\beta$-cells or in the T cells contributes to T1D resistance in NOD.Drak2 $2^{-/}$mice, we performed T cell transfer experiments in which Drak2 was absent in the T cells, but not the $\beta$-cells. T cells were purified from NOD or NOD.Drak $2^{-/-}$mice and transferred into NOD.SCID host mice. NOD.SCID mice lack functional T cells, but have normal expression of Drak2 in the islets. If the absence of Drak2 in the islets is required for disease resistance, then NOD.SCID mice receiving NOD.Drak2 ${ }^{-/}$T cells should develop T1D. Conversely, if the absence of Drak2 in the T cells contributes to disease resistance, then NOD.SCID mice receiving NOD.Drak ${ }^{-/-} \mathrm{T}$ cells will not develop T1D. We found that NOD.SCID mice that received NOD.Drak2 $2^{-/} \mathrm{T}$ cells did not develop T1D, while all of the mice that received NOD T cells developed T1D by 24 weeks after T cell transfer (Figure 3-1A). This suggests that the absence of Drak2 in the T cells is important for resistance to T1D.

To further explore whether Drak2 expression in the islets contributes to T1D disease resistance, we performed an additional cell transfer experiment in which Drak2 was expressed in the transferred T cells, but not in the $\beta$-islet cells. Naïve T cells were sorted from NOD mice and transferred into either NOD.SCID or Drak2 $2^{--}$.NOD.SCID host mice. If the absence of Drak2 in $\beta$-islet cells contributes to disease resistance, then we would expect Drak2 ${ }^{-/}$.NOD.SCID host mice to be less susceptible to disease than NOD.SCID host mice. We found that NOD.SCID and Drak2 ${ }^{--}$.NOD.SCID host mice that received NOD T cells developed T1D with a similar incidence and frequency (Figure 3-1B). These data suggest that there is no protective effect for mice that lack Drak2 expression in the islets, and that expression of Drak2 in the T cells, rather than islet cells, plays a pivotal role in disease susceptibility.

\section{The resistance to T1D in NOD.Drak2 $2^{-/}$mice requires Tregs}

The resistance to T1D in NOD.Drak2 $2^{-/-}$mice was due to the absence of Drak2 in the T cells. Although we previously showed that there was decreased accumulation and enhanced death in $\mathrm{Drak}^{-/-} \mathrm{T}$ cells [23], we did not examine if this was the only factor contributing to autoimmune disease resistance. Therefore, we next tested whether Tregs 
A

- NODT cells $\longrightarrow$ NOD.SCID host

$\diamond$ NOD.Drak2'-T cells $\longrightarrow$ NOD.SCID host

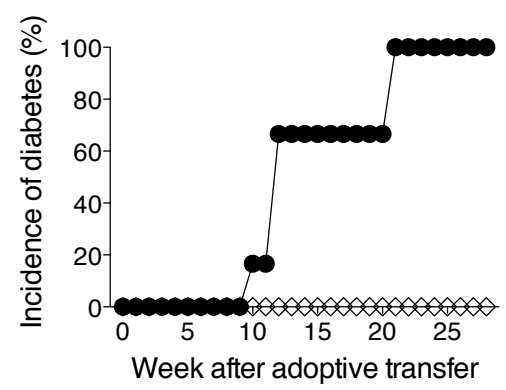

B

- NODT cells $\longrightarrow$ NOD.SCID host

$\diamond$ NODT cells $\longrightarrow$ Drak2.NOD.SCID host

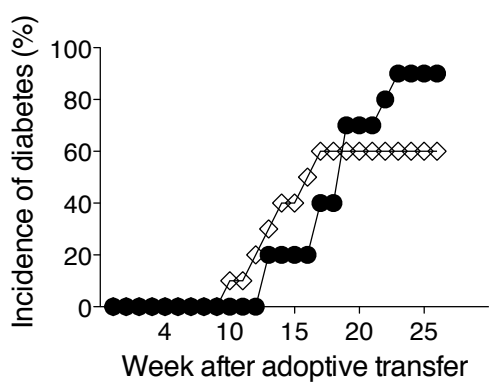

Figure 3-1. The resistance to T1D in NOD.Drak $2^{-/-}$mice transfers with the T cells and is independent of Drak2 expression in islet cells.

(A) T cells were purified from lymph nodes and spleen of female NOD or NOD.Drak $2^{-/-}$ mice and transferred into NOD.SCID host mice. Mice were monitored weekly for diabetes by testing glucose levels in the blood. Incidence of diabetes for six mice receiving NOD or NOD.Drak2 ${ }^{-/} \mathrm{T}$ cells is plotted. Data were analyzed with a Log-rank (Mantel-Cox) test, $P=0.0005$, and are representative of two independent experiments. (B) Naive T cells from NOD mice were transferred into NOD.SCID or Drak2 $2^{-/}$ .NOD.SCID mice. The host mice were monitored weekly for diabetes. Diabetes incidence for ten mice per group is plotted. Data represent two combined experiments and were analyzed with a Log-rank (Mantel-Cox) test, $P=0.7907$ 
were required for the resistance to T1D in NOD.Drak ${ }^{-/-}$mice, or whether the resistance was due solely to enhanced death of $\operatorname{Drak}^{-/-}$effector T cells. We sorted conventional T $\left(\mathrm{T}_{\text {conv }}\right.$ ) cells from NOD or NOD.Drak $2^{-/-}$mice and transferred them into NOD.SCID mice in the absence of Tregs. As the transfer of effector T cells without Tregs into lymphopenic NOD.SCID hosts can induce colitis and other autoimmune symptoms prior to diabetes onset, we recorded the incidence of mice that developed T1D, colitis, or dermatitis. In the absence of Tregs, NOD.Drak $2^{-/}$effector T cells induced autoimmunity to the same extent as $N O D$ effector T cells, suggesting that Tregs are required for the resistance to autoimmunity in $\operatorname{Drak}^{-/-}$mice (Figure 3-2A). To examine the incidence specifically of T1D in the absence of Tregs, we transferred a small number of NOD.BDC2.5 TCR transgenic T cells, which are specific for an islet autoantigen. NOD.BDC2.5 and Drak2 ${ }^{--}$.NOD.BDC2.5 $\mathrm{T}_{\text {conv }}$ cells were sorted and transferred into NOD.SCID mice. We found that in the absence of Tregs, both NOD.BDC2.5 and Drak2 $2^{-1}$ .NOD.BDC2.5 $\mathrm{T}_{\text {conv }}$ cells induced T1D, although there was a delay in T1D onset in mice receiving Drak ${ }^{-/}$. NOD.BDC2.5 $\mathrm{T}_{\text {conv }}$ cells (Figure 3-2B). These data suggest that Tregs are required for the resistance to T1D in NOD.Drak2 $2^{-/-}$mice, but that enhanced susceptibility to death of the Drak $2^{-/}$effector T cells also contributes to the resistance to $\mathrm{T} 1 \mathrm{D}$, as disease onset was delayed in the group receiving Drak2 $2^{-/} . N O D . B D C 2.5 \mathrm{~T}_{\text {conv }}$ cells.

To test whether the addition of Tregs to the Drak2 $2^{-/}$.NOD.BDC2.5 $\mathrm{T}_{\text {conv }}$ cells could restore the resistance to T1D, we transferred NOD.BDC2.5 or Drak2 $2^{-/-}$ .NOD.BDC2.5 $\mathrm{T}_{\text {conv }}$ cells with NOD $\mathrm{T}_{\text {regs }}$ into NOD.SCID host mice. The addition of Tregs along with Drak2 ${ }^{-/} . N O D . B D C 2.5 \mathrm{~T}_{\text {conv }}$ cells rescued T1D disease resistance completely, whereas the addition of Tregs to NOD.BDC2.5 $\mathrm{T}_{\text {conv }}$ cells did not prevent T1D (Figure 3-2C). These data further suggest that in NOD.Drak2 ${ }^{-/-}$mice, complete resistance to T1D requires Tregs in cooperation with enhanced T effector cell death.

\section{NOD.Drak2 ${ }^{-/}$Tregs function similar to NOD Tregs}

Given that Tregs were required to elicit resistance to T1D in NOD.Drak2 $2^{-/-}$mice, we examined whether the function of Tregs was augmented in the absence of Drak2. $N O D$ effector T cells were stimulated and cultured alone or with increasing ratios of NOD or NOD.Drak2 $2^{-/-}$Tregs. We found that NOD and NOD.Drak2 $2^{-/-}$Tregs suppressed in vitro $\mathrm{T}$ effector cell proliferation to a similar extent (Figure 3-3A). To confirm this finding in vivo, we transferred naïve, NOD T cells into NOD.SCID mice and examined the ability of NOD or NOD.Drak2 ${ }^{-/-}$Tregs to inhibit homeostatic proliferation of the $N O D$ effector T cells. The percent and number of live, divided $N O D$ effector $\mathrm{T}$ cells decreased in the presence of both NOD and NOD.Drak2 ${ }^{-/}$Tregs (Figure 3-3B).

Importantly, there was not a significant difference in the ability of $N O D$ and NOD.Drak2 $2^{-/}$Tregs to suppress effector T cell proliferation. These data suggest that NOD and NOD.Drak ${ }^{-/}$Tregs function similarly, and therefore Drak2 does not affect the suppressive function of Tregs. 
A

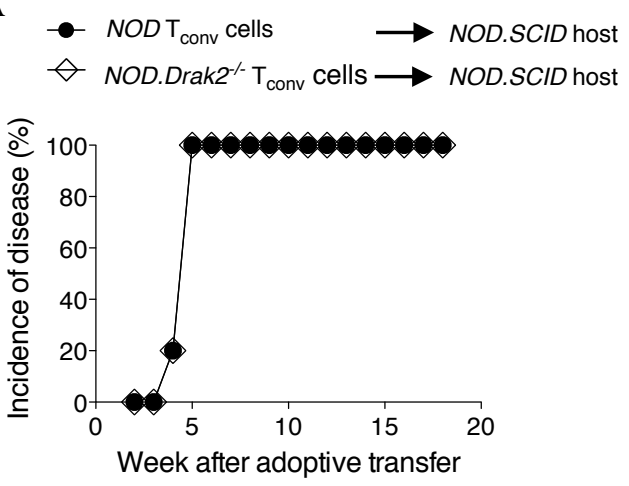

B
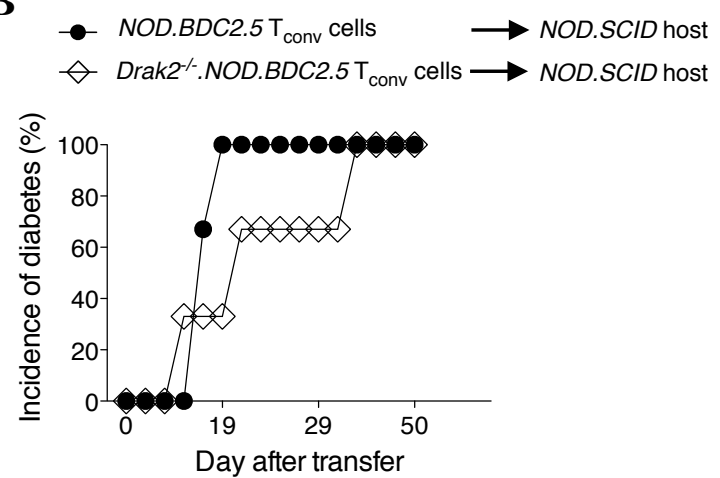

C

- NOD.BDC2.5 $\mathrm{T}_{\text {conv }}$ cells $\quad \longrightarrow$ NOD.SCID host

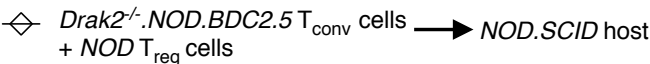

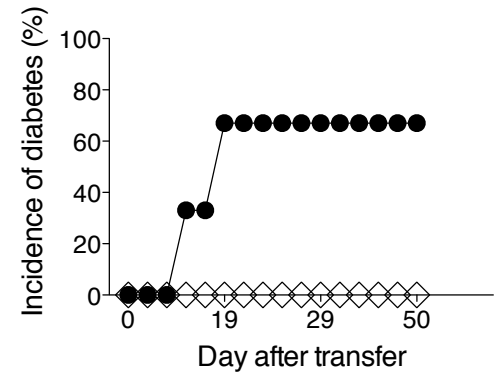

Figure 3-2. The resistance to T1D in NOD.Drak2 $2^{-/-}$mice requires Tregs.

(A) Three million purified CD25 ${ }^{-}$D $45 \mathrm{RB}^{\text {hi }}$ conventional $\mathrm{T}$ ( $\mathrm{T}_{\text {conv }}$ ) cells from NOD or NOD.Drak $2^{--}$mice were transferred into NOD.SCID mice in the absence of Tregs. Host mice were monitored weekly for diabetes, dermatitis, or colitis. The incidence of any one of these symptoms in five mice that received NOD or NOD.Drak $2^{-/-} \mathrm{T}$ cells is plotted. Data were analyzed with a Log-rank (Mantel-Cox) test, $P=1.00$, and are representative of three independent experiments. (B) Naive NOD.BDC2.5 or Drak2 ${ }^{-/}$. NOD.BDC2.5 $\mathrm{T}_{\text {conv }}$ cells were transferred into NOD.SCID mice in the absence of regulatory $\mathrm{T}$ cells. The host mice were monitored for diabetes. Diabetes incidence in 3-4 mice per group is shown. Data were analyzed with a Log-rank (Mantel-Cox) test, $P=0.2412$, and are representative of two experiments. (C) NOD Tregs were transferred with naive NOD.BDC2.5 or Drak2 $2^{-/}$.NOD.BDC2.5 $\mathrm{T}_{\text {conv }}$ cells into NOD.SCID mice. The incidence of diabetes in 3-4 mice per group is shown. Data were analyzed with a Log-rank (MantelCox) test, $P=0.0736$, and are representative of one experiment. 
A

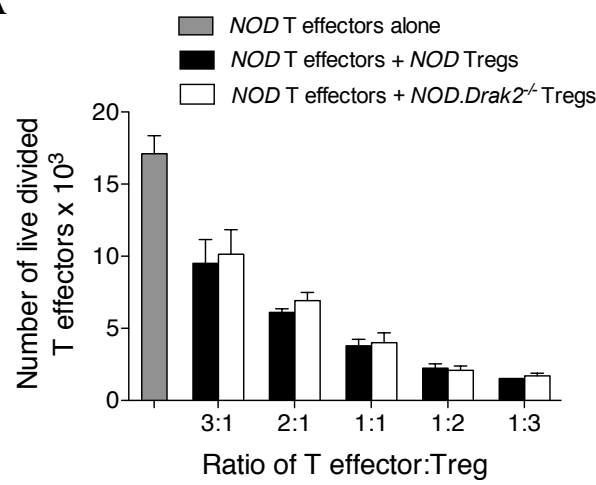

B

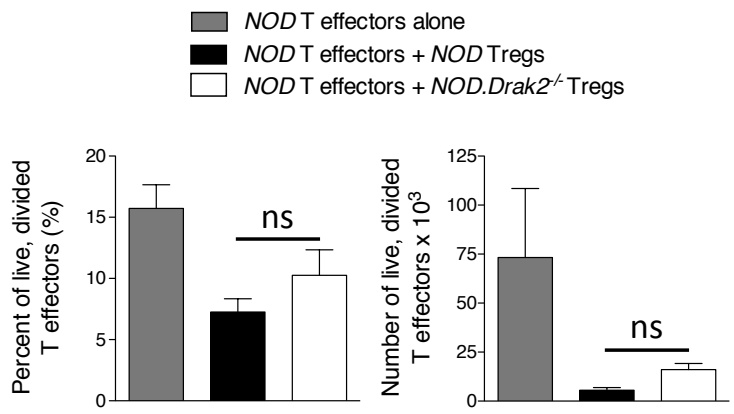

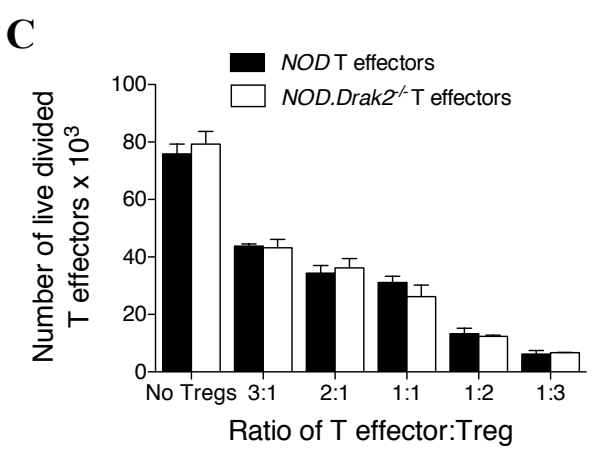

Figure 3-3. NOD.Drak2 ${ }^{-/}$Tregs function similar to NOD Tregs.

(A) Naïve $N O D$ T cells were purified, CFSE labeled, and stimulated with anti-CD3/antiCD28 coated beads in vitro either alone or mixed at various ratios with NOD or NOD.Drak2 $2^{-/}$Tregs. The number of live, divided T effectors is shown. Samples were plated in triplicate and error bars represent standard deviation. There was no significant difference between samples that included NOD or NOD.Drak2 ${ }^{-/}$Tregs as determined by two-way ANOVA analysis with Bonferroni post-tests. Data are representative of 6 experiments. (B) Naive NOD T cells were transferred into NOD.SCID host mice alone or mixed at a 4:1 ratio with either NOD or NOD.Drak ${ }^{-1-}$ Tregs. The percent and number of live, divided T effectors, 7 days after injection, are shown for 4 mice per group, and error bars represent SEM. Data were analyzed using the Mann-Whitney test and there was no significant difference between mice that received NOD or NOD.Drak2 ${ }^{-/}$Tregs. Data are representative of three independent experiments. (C) Naive NOD or NOD.Drak2 ${ }^{-/} \mathrm{T}$ cells were purified, CFSE labeled, and stimulated with anti-CD3/anti-CD28 coated beads in vitro either alone or mixed at various ratios with NOD Tregs. The number of live, divided T effectors is shown. Samples were plated in triplicate and error bars represent standard deviation. There was no significant difference between samples in response to NOD Tregs as determined by two-way ANOVA analysis with Bonferroni post-tests. Data are representative of four experiments. 
Since the addition of Tregs enhanced disease resistance when transferred with Drak2 $2^{-1} . N O D . B D C 2.5 \mathrm{~T}_{\text {conv }}$ cells, to a greater extent than NOD.BDC2.5 $\mathrm{T}_{\text {conv }}$ cells (Figure 3-2C), we tested whether $\mathrm{T}_{\text {conv }}$ cells were more susceptible to $\mathrm{T}_{\text {reg-mediated }}$ suppression in the absence of Drak2. NOD and NOD.Drak2 $2^{-1} \mathrm{~T}$ cells were stimulated and cultured in vitro alone or with increasing ratios of NOD Tregs. We found that $N O D$ and NOD.Drak2 ${ }^{-/} \mathrm{T}$ effectors were suppressed similarly in response to NOD Tregs in vitro. These data suggest that $\mathrm{T}$ effectors are not more susceptible to Treg suppression in the absence of Drak2.

\section{Drak2 $^{--}$mice exhibit an increase in the proportion of $\mathrm{Foxp3}^{+} \mathrm{CD}^{+}$Tregs compared to wildtype mice}

Since the $\mathrm{T}$ cell transfer experiments indicate that Drak 2 mediates autoimmunity within $\mathrm{T}$ cells, and that Tregs are required, we investigated whether there were differences in the proportion of Tregs in NOD.Drak $2^{--}$mice compared to NOD mice. We previously examined Foxp3 expression in a very small group of 10-12 week old NOD mice. While we did observe a trend towards an increase in $\mathrm{Foxp}^{+} \mathrm{CD}^{+}$cells in NOD.Drak $2^{-/}$mice compared to NOD mice, this difference was not statistically significant [23]. Therefore, we further explored the Treg populations in a larger cohort of mice. Analysis of the thymus, spleen, peripheral lymph nodes, pancreatic lymph nodes (LN), and pancreas from 13-week-old NOD and NOD.Drak2 $2^{-/-}$mice showed that the proportion of $\mathrm{CD}^{+}$cells in the lymphoid organs that were Foxp $3^{+}$Tregs was significantly increased in NOD.Drak2 ${ }^{-/}$mice compared to NOD mice (Figure 3-4A).

The increased proportion of Tregs in the NOD.Drak $2^{-/}$mice could be due to enhanced induction of Tregs in the periphery as a result of inflammation caused by $\mathrm{T}$ cells infiltrating the pancreas. Therefore, we analyzed lymphoid organs from four week old mice, which is prior to the onset of insulitis. Similar to the 13 week old mice, we found that the proportion of $\mathrm{CD}^{+} \mathrm{T}$ cells that were Foxp $3^{+}$was significantly increased in four week old NOD.Drak2 $2^{-/}$mice compared to NOD mice (Figure 3-4B), suggesting that the difference in the proportion of Tregs is not due to insulitis or diabetes in the NOD mice.

We previously analyzed the number and proportion of Tregs in $C 57 B L / 6$ mice during the course of EAE and did not see an increase in Tregs in Drak2 ${ }^{-/-}$mice compared to wildtype mice. We did observe that prior to induction of EAE, there were more Tregs in the $\operatorname{Drak}^{-/}$mice compared to wildtype mice, however we did not analyze enough mice to ascertain whether the difference was significant [23]. Therefore, we also examined the lymphoid organs of $C 57 B L / 6$ mice to determine whether the absence of Drak2 altered the proportion of Tregs in this strain. We found that, similar to NOD mice, there was a significant increase in the proportion of $\mathrm{CD}^{+} \mathrm{T}$ cells that expressed Foxp3 in the absence of Drak2 in the thymus and spleen of $C 57 B L / 6$ mice (Figure 3-4C). These data suggest that Drak2 may play a role in Treg development or in the induction of Tregs prior to autoimmunity, and that this function of Drak2 is not restricted to the NOD 
A

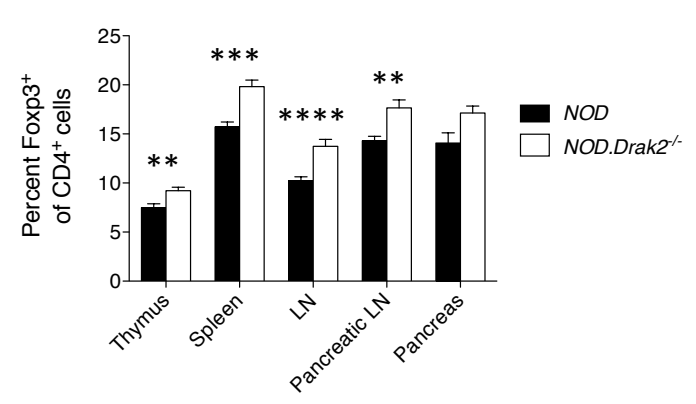

B

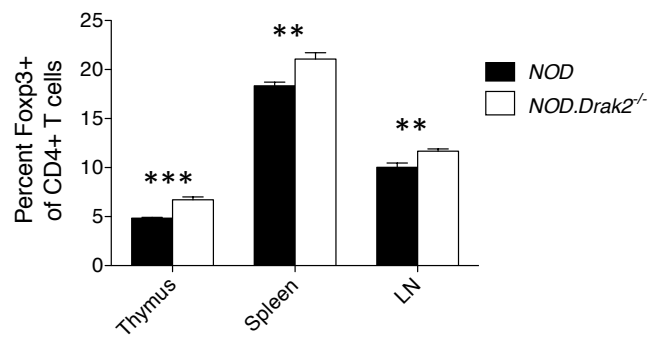

C

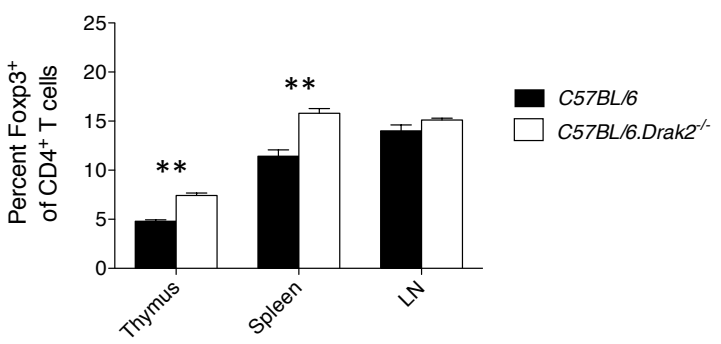

Figure 3-4. Drak2 ${ }^{-/}$mice exhibit an increase in the proportion of $\mathrm{Foxp3}^{+} \mathrm{CD4}^{+}$ Tregs compared to wildtype mice.

Cells were harvested from the various organs at (A) 13 weeks of age and (B) 4 weeks of age, and (C) 4-6 weeks of age, and stained with antibodies specific for Foxp3 and CD4. The percent of Foxp $3^{+}$cells of electronically gated, viable $\mathrm{CD} 4^{+}$cells is shown for each organ. (A) Data represent two combined experiments with 13-15 mice per group. (B) Data are representative of three experiments with at least 7 mice per group. (C) Data are representative of three experiments with at least 5 mice per group. All data were analyzed using Mann-Whitney U test (two-tailed) and error bars represent SEM. ${ }^{*} P \leq 0.05$, $* * P \leq$ $0.01, * * * P \leq 0.001, * * * * P \leq 0.0001$. 
background. Furthermore, as we observed the increased Treg proportion prior to disease onset, the early impact of Drak2 on the proportion of Tregs may have long-term effects on autoimmune disease outcome.

\section{The induction of Tregs is not enhanced in the absence of Drak2}

The increase in Tregs in the NOD.Drak2 $2^{-/}$mice could be due to an enhanced development of Tregs in the thymus or due to an increased induction of Tregs in the periphery. Thus, we investigated whether Drak2 affects the induction of Tregs utilizing both in vitro and in vivo methods. Naïve OT-II and OT-II.Drak2 $2^{--} \mathrm{CD}^{+}{ }^{+}$cells were activated in vitro with $\mathrm{OVA}_{323}$-pulsed splenocytes in the presence or absence of TGF- $\beta$. We did not observe an enhanced induction of Tregs in the OT-II.Drak ${ }^{-/} \mathrm{CD}^{+} \mathrm{T}$ cells compared to $O T-I I \mathrm{CD}^{+} \mathrm{T}$ cells, indicating that the induction of Tregs was not enhanced in the absence of Drak2 (Figure 3-5A). To determine if Treg induction was enhanced in vivo, we transferred naive OT-II and OT-II.Drak $2^{-/}$conventional T cells, mixed at a 1:1 ratio, into congenically marked host mice. The host mice were then given water with or without $2 \%$ Ovalbumin, which elicits proliferation of transferred OT-II cells, as well as induction of Foxp $3^{+} \mathrm{CD}^{+}$Tregs. Similar to the in vitro induction experiment, the percent and number of induced Foxp $3^{+} \mathrm{CD} 4^{+}$Tregs in the spleen and lymph nodes was comparable between OT-II and OT-II.Drak $2^{-/}$cells (Figure 3-5B). While there was a slight, yet significant decrease in the percent of induced Foxp $3^{+} \mathrm{CD} 4^{+}$Tregs in $O T$ II.Drak $2^{-/} \mathrm{CD}^{+} \mathrm{T}$ cells compared to OT-II $\mathrm{CD}^{+} \mathrm{T}$ cells in the mesenteric lymph nodes, similar numbers were observed. These data indicate that the induction of Tregs was not enhanced in the absence of Drak2. Together these data suggest that the increased proportion of Tregs in NOD.Drak $2^{-/}$mice is not due to enhanced induction in the periphery, but rather may be the result of augmented development of Tregs in the thymus.

\section{The proportion of precursor Tregs is comparable between wildtype and $\mathrm{Drak}^{-/-}$ thymocytes in $N O D$ and $C 57 B L / 6$ mice}

Given that the absence of Drak2 did not enhance the induction of Tregs, we explored whether the absence of Drak2 altered Treg development in the thymus. The development of thymic Tregs occurs in a two-step process in which TCR engagement and $\mathrm{CD} 28$ co-stimulation induces the development of $\mathrm{CD} 4^{+} \mathrm{CD} 25^{+} \mathrm{Foxp} 3^{-}$precursor Tregs. Then, IL-2 signals mediate the transition from precursor Tregs into mature $\mathrm{CD}^{+} \mathrm{CD} 25^{+} \mathrm{Foxp}^{+}$Tregs $[44,45]$. To determine if there was an increase in precursor Tregs in the absence of Drak2, we analyzed NOD and NOD.Drak2 $2^{--} \mathrm{CD}^{+} \mathrm{CD}^{-}$ thymocytes for the proportion of precursor and mature Tregs. The proportion of mature Tregs was significantly increased in 1 week old and 5 week old NOD.Drak $2^{-/-}$mice compared to NOD mice, similar to our previous experiments (Figure 3-4). However, the proportion of precursor Tregs was similar in both groups (Figure 3-6A and 3-6B). Likewise, 4-6 week old $C 57 B L / 6 . D r a k 2^{-/}$mice displayed an increase in the proportion of mature Tregs, but not Treg precursors compared to $C 57 B L / 6$ mice. These data suggest that the first stage of Treg development is not affected by Drak2, but that the transition 
A

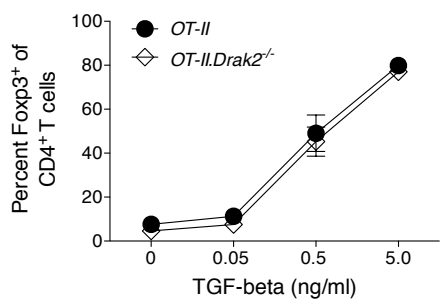

B

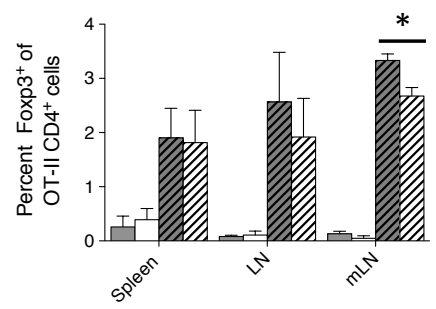

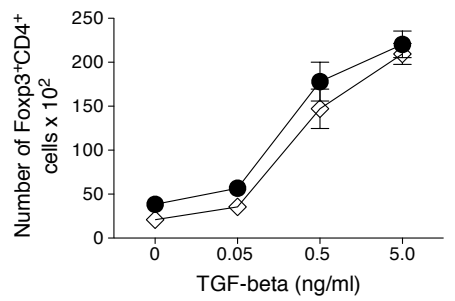

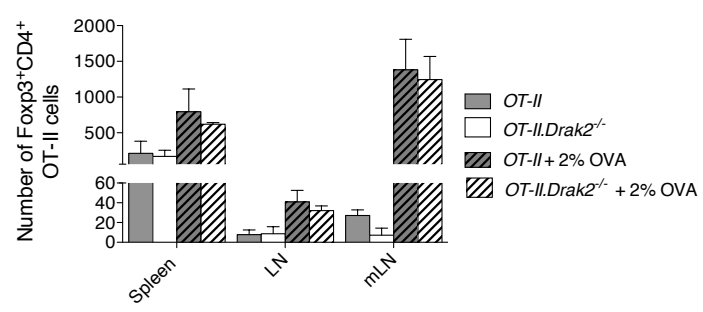

Figure 3-5. The induction of Tregs is not enhanced in the absence of Drak2.

(A) $\mathrm{CD} 4{ }^{+} \mathrm{CD} 25^{-} \mathrm{CD} 44^{\text {lo }}$ naïve $\mathrm{T}$ cells were purified from the spleen and lymph nodes of $O T-I I$ and $O T$-II.Drak $2^{-/-}$mice and stimulated with irradiated, $\mathrm{OVA}_{323}$ peptide-pulsed splenocytes in the presence or absence of 10-fold TGF- $\beta$ titrations. Three days later, cells were harvested, stained with antibodies specific for CD4 and Foxp3, and analyzed by flow cytometry. The percent and number of Foxp $3^{+}$cells of electronically gated, viable $\mathrm{CD}^{+}$cells are shown. Cells were tested in quadruplicate and error bars indicate standard deviation. There was no significant difference between samples in response to TGF- $\beta$ mediated Foxp3 induction as determined by two-way ANOVA analysis with Bonferroni post-tests. Data are representative of five separate experiments. (B) $\mathrm{CD} 4{ }^{+} \mathrm{CD} 25^{-} \mathrm{CD} 44^{\text {lo }}$ naïve $O T-I I$ and $O T-I I . D r a k 2^{-/} \mathrm{T}$ cells were mixed at a 1:1 ratio and intravenously injected into congenically marked wildtype host mice. Host mice received either water containing $2 \%$ ovalbumin or water alone for 5 days. Spleen, peripheral lymph nodes $(\mathrm{LN})$, and mesenteric lymph nodes $(\mathrm{mLN})$ were harvested on day 6. Cells from 3 mice per group were analyzed by flow cytometry for Foxp3 expression of electronically gated, viable $O T-I I \mathrm{CD}^{+}{ }^{\mathrm{T}}$ cells. Data were analyzed using an unpaired t-test, ${ }^{*} P=0.0287$, and are representative of three independent experiments. 


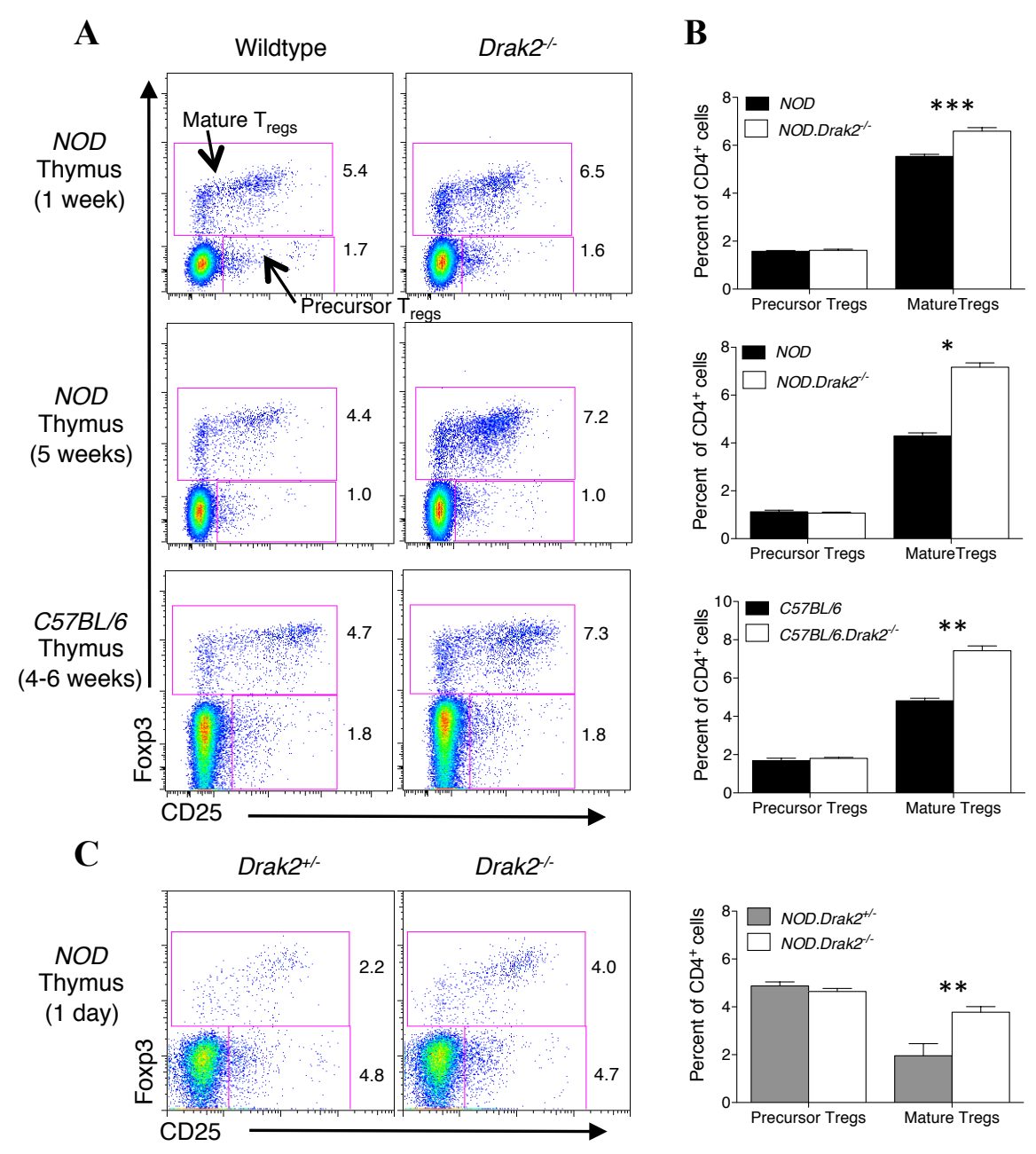

Figure 3-6. The proportion of precursor Tregs is comparable between wildtype and Drak $^{-/-}$thymocytes in $N O D$ and $C 57 B L / 6$ mice.

Cells were harvested from the thymus of NOD, NOD.Drak2 $2^{-/}, C 57 B L / 6$, and $C 57 B L / 6 . D r a k 2^{-/-}$mice of various ages and stained with antibodies specific for CD4, CD8, CD25, and Foxp3. (A) Representative flow cytometry plots of electronically gated, viable $\mathrm{CD}^{+} \mathrm{CD}^{-}$thymocytes are shown. (B) The percent of CD25 ${ }^{+} \mathrm{Foxp} 3^{-}$precursor Tregs or Foxp $3^{+}$mature Tregs of electronically gated CD4 single positive (SP) cells is shown for at least 4 mice per group. Data are representative of at least three independent experiments and were analyzed using Mann-Whitney test (two-tailed). Error bars represent SEM. (C) Cells were harvested from the thymus of 1 day old NOD.Drak2 ${ }^{+/-}$ and NOD.Drak2 $2^{-/}$mice and stained with antibodies specific for CD4, CD8, CD25, and Foxp3. Representative flow cytometry plots of electronically gated CD4 ${ }^{+} \mathrm{CD} 8^{-}$

thymocytes are shown. Bar graphs show percent of CD25 $5^{+}$Foxp3 $^{-}$precursors and Foxp3 ${ }^{+}$ mature Tregs of electronically gated, viable CD4 SP cells from at least 3 mice per group and are representative of two independent experiments. Data were analyzed using an unpaired t-test and error bars represent SEM. $* P \leq 0.05, * * P \leq 0.01, * * * P \leq 0.001$. 
from precursor Treg to mature Treg may be enhanced in the absence of Drak2. To further confirm that Drak2 affects Treg development, rather than induction, we examined precursor and mature Treg populations in 1 day old NOD.Drak2 $2^{+/}$and NOD.Drak2 $2^{--}$ neonates. Similar to comparisons between older NOD and NOD.Drak ${ }^{-/-}$mice, we found that during this very early stage of $\mathrm{T}$ cell development, there were comparable proportions of precursor Tregs, but enhanced frequencies of mature Tregs in the absence of Drak2 (Figure 3-6C). These data further suggest that Drak2 plays a role in early Foxp3 induction and the development of Tregs.

\section{NOD thymocytes are more sensitive to IL-2 signaling in the absence of Drak2}

As the transition from precursor Treg to mature Treg is mediated by IL-2, we examined if IL-2 signaling was enhanced in NOD.Drak $2^{-/-}$thymocytes. NOD.Drak $2^{+/-}$ and NOD.Drak $2^{-/-}$thymocytes from 1 day old mice were cultured in vitro with IL-2 and analyzed for phosphorylation of Stat5, a transcription factor that is critical for IL-2mediated Foxp3 induction and Treg development [46]. Interestingly, a greater proportion of NOD.Drak $2^{-/} \mathrm{CD} 4^{+} \mathrm{CD} 25^{+}$thymocytes expressed phosphorylated Stat5 in response to IL-2 compared to NOD.Drak2 $2^{+/}$thymocytes (Figure 3-7A and 3-7B). Because $\mathrm{CD} 4^{+} \mathrm{CD} 25^{+}$thymocytes include both precursor and mature Tregs, we investigated whether these two populations exhibited comparable responses to IL-2 in the absence of Drak2. To distinguish between these populations, we used expression of the transcription factor, Helios, to identify mature thymic Tregs because the reagents used to stain for pStat5 were incompatible with Foxp3 staining. Interestingly, we found that in response to IL-2, the proportion of $\mathrm{pStat} 5^{+}$precursor Tregs was significantly enhanced in the absence of Drak2, while the proportion of NOD and NOD.Drak2 ${ }^{-/}$mature Tregs that phosphorylated Stat5 was similar (Figure 3-7C). These data suggest that, in the absence of Drak2, enhanced IL-2 signaling via Stat5 in precursor Tregs increases the transition of these cells into mature Tregs. To examine whether the enhanced IL-2 signaling in the NOD.Drak $2^{-/}$thymocytes was due to differences in the expression level of CD25, a component of the high affinity IL-2 receptor complex, we compared the mean fluorescence intensity (MFI) of CD25 on CD25 CD4 SP thymocytes, precursor Tregs, and mature Tregs from NOD.Drak2 ${ }^{+/-}$and NOD.Drak2 $2^{-/}$mice. The expression of CD25 was not increased on these subsets in NOD.Drak2 $2^{-/}$mice compared to NOD.Drak $2^{+/-}$ mice, indicating that the enhanced IL-2 signaling is not due to increased CD25 expression in the absence of Drak2 (Figure 3-7D).

To determine if enhanced IL-2 signaling leads to the enhanced proportion of Foxp3-expressing cells in the absence of Drak2, we cultured NOD.Drak2 ${ }^{+/}$and NOD.Drak $2^{-/}$thymocytes from 1 day old mice with increasing amounts of IL-2 for 24 hours. Interestingly, we found that a greater the proportion of NOD.Drak2 $2^{-/-}$CD4 SP cells upregulated Foxp3 in response to IL-2 compared to NOD CD4 SP cells (Figure 3-7E). Together these data show that in the absence of Drak2, IL-2 signaling is enhanced in precursor Tregs, which induces increased phosphorylation of Stat5 and Foxp3 expression. Thus, more precursor Tregs transition into mature Tregs during development in the 

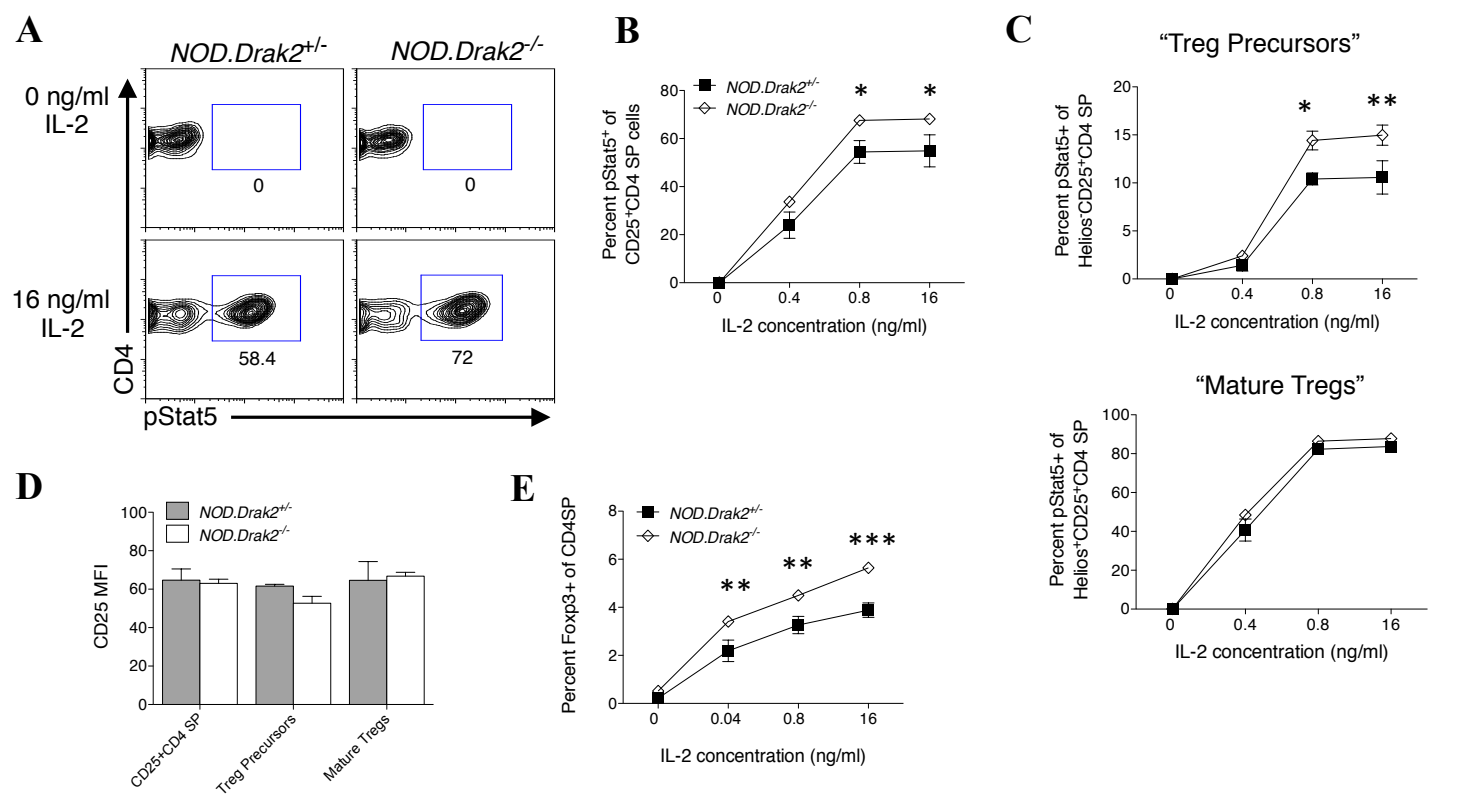

Figure 3-7. NOD thymocytes are more sensitive to IL-2 signaling in the absence of Drak2.

(A) Thymocytes were harvested from 1 day old NOD.Drak2 $2^{+/-}$and NOD.Drak $2^{-/}$mice and incubated for 20 minutes with media alone $(0 \mathrm{ng} / \mathrm{ml} \mathrm{IL-2})$ or with $16 \mathrm{ng} / \mathrm{ml}$ recombinant mouse IL-2. Representative flow cytometry plots of electronically gated, viable $\mathrm{CD} 4^{+} \mathrm{CD} 8^{-} \mathrm{CD} 25^{+}$thymocytes are shown. Numbers indicate percent of $\mathrm{CD} 4^{+} \mathrm{CD} 8^{-}$ CD25 $5^{+}$cells that express phosphorylated Stat5 (pStat5) (B-C) Thymocytes from 1 day old NOD.Drak $2^{+/-}$and NOD.Drak2 $2^{-/-}$mice were incubated for 20 minutes with media alone or with increasing concentrations of IL-2. Cells were harvested and stained with antibodies specific for CD4, CD8, CD25, and Helios and analyzed by flow cytometry. (B) The percent of $\mathrm{pStat} 5^{+}$cells of electronically gated, viable $\mathrm{CD} 4{ }^{+} \mathrm{CD} 8^{-} \mathrm{CD} 25^{+}$ thymocytes is shown. (C) The percent of pStat $5^{+}$of Helios ${ }^{-}$(Precursor Tregs) and Helios ${ }^{+}$ (Mature Tregs) of electronically gated, viable $\mathrm{CD} 4^{+} \mathrm{CD} 8^{-} \mathrm{CD} 25^{+}$thymocytes is shown. Data were analyzed using two-way ANOVA with Bonferroni post-tests and error bars represent SEM. (D) Thymocytes were stained with anti-CD4, anti-CD8, anti-CD25, and anti-Foxp3 and analyzed by flow cytometry. The mean fluorescence intensity of CD25 expression is shown for $\mathrm{CD} 25^{+} \mathrm{CD} 4^{+} \mathrm{CD} 8^{-}$cells, $\mathrm{CD}^{+} \mathrm{CD}^{-} \mathrm{CD} 25^{+} \mathrm{Foxp} 3^{-}$(Precursor Tregs) and $\mathrm{CD}^{+} \mathrm{CD}^{-}{ }^{-} \mathrm{Foxp}^{+}$(Mature Tregs). Data were analyzed using an unpaired ttest and are representative of 2 independent experiments with at least 3 mice per group. (E) Thymocytes were incubated for 24 hours with media alone or with increasing concentrations of IL-2. Cells were harvested and stained with antibodies specific for CD4, CD8, CD25, and Foxp3, along with fixable viability dye. The percent Foxp $3^{+}$cells of electronically gated, viable $\mathrm{CD} 4^{+} \mathrm{CD} 8^{-}$cells is shown for at least 3 mice per group. Data were analyzed using two-way ANOVA with Bonferroni post-tests and error bars represent SEM. $* P \leq 0.05, * * P \leq 0.01, * * * P \leq 0.001$. 
thymus, in the absence of Drak2. This enhanced proportion of Tregs contributes to the resistance to T1D in the NOD.Drak2 $2^{-/}$mice.

\section{Discussion}

Drak2 plays a critical role in the induction of autoimmunity, but does not impact immunity to infectious pathogens and tumors. Therefore, Drak2 is an ideal protein to target to treat diseases such as T1D and MS without causing generalized immune suppression. Further insight into the immunological functions by which Drak2 impacts autoimmunity is important in order to understand the multiple checkpoints that work together to prevent autoimmune disease. We and others previously demonstrated that the resistance to autoimmunity in $\mathrm{Drak}^{-/}$mice was partly due to increased susceptibility to death in T cells following activation $[19,23]$. This increased $\mathrm{T}$ cell death resulted in fewer autoreactive $T$ cells and less accumulation in the target organ. The data presented here show that this increased susceptibility to death of Drak $2^{-/}$T cells was not sufficient to prevent autoimmune disease, and that the presence of Tregs was also required for NOD.Drak2 $2^{-/}$mice to be resistant to T1D. Further, we show that in the absence of Drak2, there was an increase in the proportion of Tregs due to increased IL-2 signaling via Stat5 in thymic precursor Tregs. Although the increase in the proportion of Tregs in the absence of Drak2 was small, this increase was consistently significant in mice of various ages and of two independent background strains. Given that Tregs were required for the resistance to T1D in the NOD.Drak $2^{-/}$mice, these data suggest that a small increase in the proportion of Tregs, along with an increased sensitivity to death of the effector T cells together prevent T1D.

Our data indicate that Drak2 reduces the development of Tregs in the thymus by negatively regulating IL-2 signaling in CD4 SP cells. This was evident by the fact that there was an increased proportion of Tregs in NOD.Drak $2^{-/}$mice as early as one day of age, and that more of the NOD.Drak2 $2^{-/}$thymocytes phosphorylated Stat5 in response to IL-2 compared to NOD thymocytes. This is similar to $\operatorname{Traf}^{--}$thymocytes that display an increased transition from precursor to mature Treg due to enhanced IL-2 signaling [47]. Traf3 reduces IL-2 signaling by recruiting the tyrosine phosphatase, TCPTP, to the IL-2 receptor complex, in turn, reducing activation of Jak1, Jak3, and Stat5. The finding that more cells phosphorylate Stat5 in the absence of Drak2 suggests that Drak2 blocks IL-2 signaling upstream of Stat5 activation (Figure 3-8). Similar to Traf3, Drak2 may also act as a scaffold to recruit negative regulators of IL-2 signaling such as SOCS1, SOCS3, or SHP-1 to the receptor complex, or may play a role in the induction of one of these negative regulators. In addition, Drak2 may block recruitment of Jak1 or Jak3 to the IL-2 receptor complex. The exact mechanism by which Drak2 reduces pStat5-mediated Foxp3 induction following IL-2 signaling must be further explored. Interestingly, enhanced IL-2 signaling also renders mature T cells more susceptible to apoptosis [48], and we previously demonstrated that Drak $2^{-/-} \mathrm{T}$ cells produced more IL-2 than wildtype T cells after stimulation [4]. Thus, an intriguing possibility is that the enhanced susceptibility to apoptosis of mature, autoreactive $\operatorname{Drak}^{--}$T cells may also be due to increased IL-2 signaling, a concept that also requires further study. 


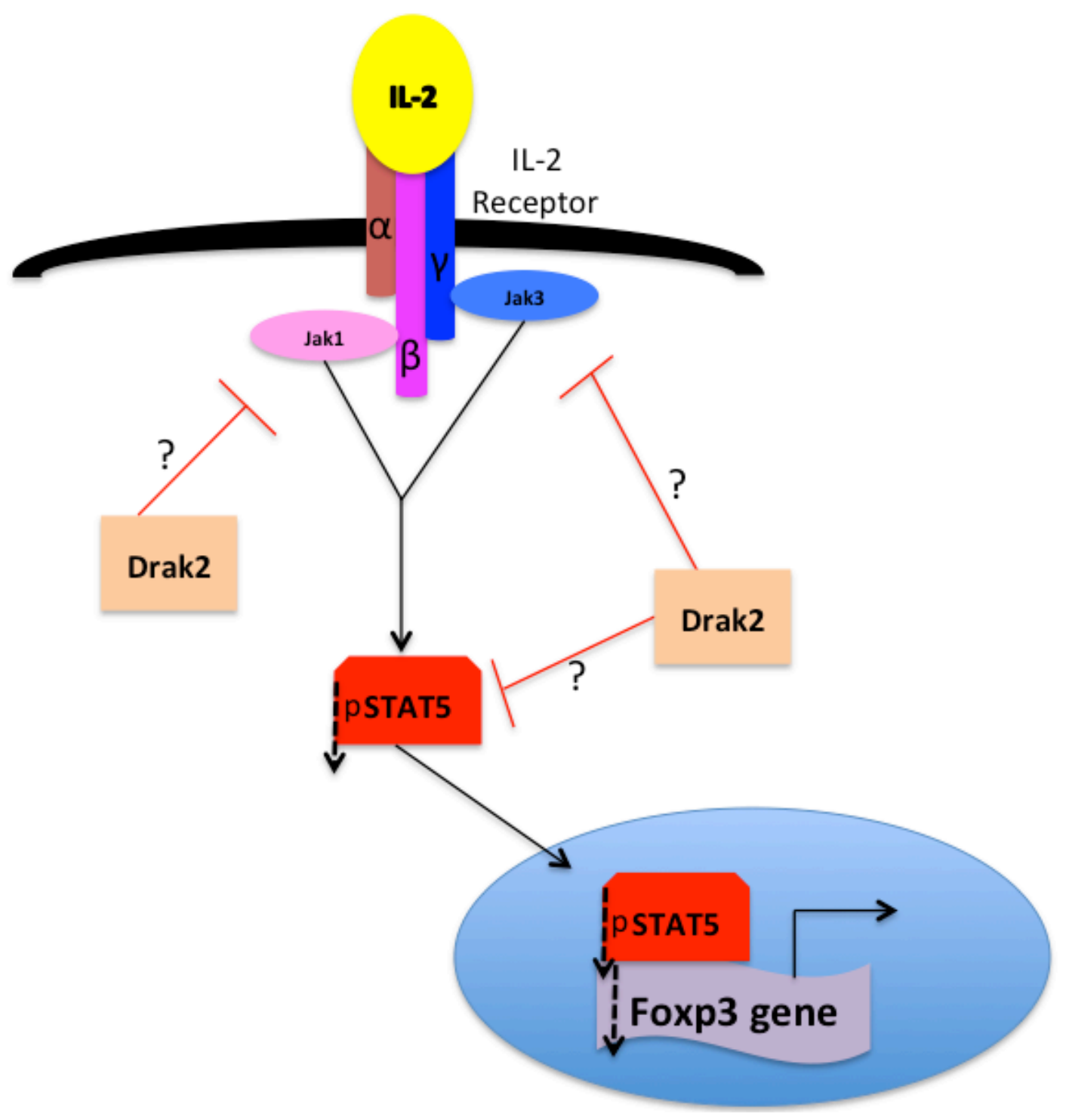

Figure 3-8. Proposed model of Drak2 function in IL-2 signaling.

Drak2 is a negative regulator of IL-2 signaling upstream of Stat5 during Treg development in the thymus. Negative regulatory effects lead to decreased Stat5 phosphorylation and decreased Foxp3 gene transcription. As a result, fewer regulatory Tregs develop, which contributes to enhanced autoimmunity. 
Others reported that Drak2 is expressed in pancreatic $\beta$-cells following stimulation with cytokines or FFA, and this may contribute to the resistance to T1D in NOD.Drak2 $2^{-/}$mice [13]. However, our data show that transfer of NOD T cells into mice that lack Drak2 in the $\beta$-cells still results in T1D, suggesting that the absence of Drak2 in the $\beta$-cells does not render mice more resistant to T1D. Furthermore, transfer of NOD T cells, but not NOD.Drak2 ${ }^{-/} \mathrm{T}$ cells, into NOD.SCID mice caused T1D, again suggesting that the resistance to T1D was due to the absence of Drak2 in the T cells, rather than the $\beta$-cells. While Drak2 overexpression increased $\beta$-cells death in vitro and increased the susceptibility of mice to streptozotocin-induced diabetes, the expression of Drak 2 in the $\beta$-cells was not important for resistance to T1D in NOD mice.

Based on our data, and that of others, Drak2 is a promising target to treat autoimmune diseases. Studies showed that exogenous IL-2 treatment offers protection against T1D in NOD mice primarily by maintaining Tregs [49]. In addition, reduced IL-2 production and consequent Treg dysfunction was reported in T1D patients [50]. Thus, it is an intriguing possibility that therapeutic inhibition of Drak2 may enhance IL-2 signaling and benefit downstream functional effects of IL-2 in the treatment of T1D. Inhibition of Drak2 in patients initially after diagnosis may also prevent further $\beta$-cell destruction by not only decreasing the number of autoreactive $T$ cells via enhanced susceptibility to death, but it may also boost the proportion of protective Tregs through increased IL- 2 signaling. In this way, the $\beta$-cells would be preserved, which would maintain insulin production. In T1D patients already suffering from significant $\beta$-cell destruction, Drak2 inhibition could be used along with therapies that enhance the generation of $\beta$-cells, to prevent $T$ cell destruction of these newly generated cells. While much progress has been made in inducing the development of $\beta$-cells, if the T cells that destroy the $\beta$-cells are not inhibited, these therapies will not have long-term success.

Together the data presented here offer important insight into the role of Drak2 in T1D. First, the absence of Drak2 in the T cells, and not the $\beta$-cells contributes to the resistance to T1D. Therefore, the molecular mechanisms in which Drak2 functions should be further explored in T cells rather than $\beta$-cells. In addition, enhanced IL-2 signaling via Stat5 increases Foxp3 expression and development of Tregs, which contributes to the resistance to T1D in the NOD.Drak $2^{-/}$mice. Thus, Drak2 impacts autoimmunity by decreasing the proportion of Tregs, along with enhancing the survival of autoreactive T cells. 


\section{CHAPTER 4. DRAK2 DOES NOT REGULATE TGF-BETA SIGNALING IN T CELLS*}

\section{Introduction}

Drak2 has been shown to interact with several proteins in in vitro recombinant assays and in cell lines. These proteins include myosin light chain [7], protein kinase $\mathrm{C}-\gamma$ [16], protein kinase D, p70S6 [14], CHP [9], and transforming growth factor- $\beta$ receptor I (TGF- $\beta$ RI) [10]. However, most of these interactions were based on overexpression experiments in cell lines and have not been confirmed in $\mathrm{T}$ cells. Therefore, it is not clear which of these interactions may affect autoimmune disease.

As TGF- $\beta$ is a critical suppressor of autoimmunity, the interaction of Drak2 and the TGF- $\beta$ RI is an intriguing possibility to explain how Drak2 contributes to autoimmunity. TGF- $\beta$ is a pleiotropic cytokine that elicits numerous effects on various cell types [51]. In T cells specifically, TGF- $\beta$ inhibits proliferation of naïve T cells, induces development of regulatory $\mathrm{T}$ cells, and enhances apoptosis of activated T cells. A recent study proposed that Drak2 functions as a negative regulator of TGF- $\beta$ signaling by inhibiting the phosphorylation and recruitment of Smad2 and Smad3 to the TGF- $\beta$ RI in cell lines [10]. Thus, the absence of Drak2 in T cells may render these cells more susceptible to TGF- $\beta$ signaling, which could prevent autoimmunity. However, it has not been tested if Drak2 functions as a negative regulator of TGF- $\beta$ in T cells, and consequently, whether Drak2 $2^{-/-}$T cells are more sensitive to TGF- $\beta$ signaling.

Therefore, we investigated whether Drak2 functions as a negative regulator of TGF- $\beta$ signaling in T cells, and further if the enhanced susceptibility to apoptosis in Drak $2^{-/-}$T cells was due to augmented TGF- $\beta$ signaling. We found that TGF- $\beta$ signaling via Smad 2 and Smad3 was not enhanced in the absence of Drak2 in T cells, and that Drak $^{-/-} \mathrm{T}$ cells did not exhibit enhanced responses to TGF- $\beta$ signaling during in vitro assays. These data suggest that Drak2 does not function as an inhibitor of TGF- $\beta$ signaling in T cells. Moreover, in the absence of TGF- $\beta$ signaling, Drak2 $2^{-/-} \mathrm{T}$ cells remained more susceptible to apoptosis, suggesting that the increase in cell death observed in vitro, was not due to enhanced TGF- $\beta$-mediated signals. These data provide insight into the role of Drak2 in autoimmune diseases by showing that Drak2 does not suppress TGF- $\beta$ signaling in T cells, and therefore may contribute to autoimmune disease via other molecular pathways.

*Reprinted with permission. Harris TL, McGargill MA. Drak2 Does Not Regulate TGF- $\beta$ Signaling in T Cells. PLoS ONE. 2015;10(5):e0123650 [52]. 


\section{Results}

\section{TGF- $\beta$ signaling via Smad proteins is not enhanced in Drak2 $2^{-/}$T cells compared to wildtype $T$ cells}

Given that recent experiments in cell lines suggested that Drak2 negatively regulates TGF- $\beta$ signaling [10], and enhanced TGF- $\beta$ signaling in T cells could contribute to the resistance to autoimmune disease, we tested whether Drak2 functions as a negative regulator of TGF- $\beta$ signaling in T cells. TGF- $\beta$ receptor engagement results in the phosphorylation of the Smad2/Smad3 signaling complex, which then translocates from the cytoplasm into the nucleus to facilitate transcription of TGF- $\beta$ target genes. To determine if Smad2 translocation into the nucleus was increased in the absence of Drak2, we activated $\mathrm{CD}^{+}$T cells with anti-CD3 and anti-CD28 antibodies for 24 hours, and then utilized confocal fluorescent microscopy to analyze Smad2 localization following addition of TGF- $\beta$. As expected, Smad 2 translocation into the nucleus was not observed in stimulated T cells without exogenous TGF- $\beta$ (Figure 4-1). The addition of TGF- $\beta$ during the final 20 minutes of culture elicited Smad2 translocation into the nuclear region of both wildtype and Drak2 $2^{-/} \mathrm{T}$ cells (Figure 4-1). Importantly, there were no differences in Smad 2 translocation between wildtype and $\operatorname{Drak}^{-/-} \mathrm{T}$ cells in response to exogenous TGF- $\beta$.

We also examined phosphorylation of Smad2 by western blot in lysates from purified $\mathrm{CD}^{+}{ }^{\mathrm{T}}$ cells, $\mathrm{CD} 8^{+} \mathrm{T}$ cells, or whole splenocytes. In all cell types, $\mathrm{Smad} 2$ was phosphorylated in response to TGF- $\beta$ treatment; however, the extent of phosphorylation was not increased in Drak2 $2^{-/}$cells compared to wildtype cells (Figure 4-2A). Finally, to determine if Drak $2^{-/}$cells are hypersensitive to lower concentrations of TGF- $\beta$, we analyzed the phosphorylation of the $\mathrm{Smad} 2 / \mathrm{Smad} 3$ complex by flow cytometry in response to decreasing amounts of TGF- $\beta$. Again, even at the lower doses of TGF- $\beta$, the phosphorylation of Smad2/3 was similar in wildtype and Drak $2^{-/}$cells (Figure 4-2B). Together, these data show that Drak $2^{-/-}$T cells do not exhibit enhanced TGF- $\beta$ signaling via Smad2 or Smad2/3 complex phosphorylation compared to wildtype T cells, suggesting that Drak2 does not function as a negative regulator of TGF- $\beta$ signaling in primary $\mathrm{T}$ cells activated in vitro.

\section{The effects of TGF- $\beta$ on $\mathrm{T}$ cells are comparable between wildtype and Drak2 ${ }^{-/-} \mathrm{T}$ cells}

Many of the downstream mechanisms utilized by TGF- $\beta$ to regulate T cells remain unclear. Although we did not observe enhanced TGF- $\beta$ signaling in Drak2 ${ }^{-/} \mathrm{T}$ cells via Smad proteins, it was possible that Drak2 regulated the pathway through alternative mechanisms. Therefore, we explored the effects of TGF- $\beta$ on several T cell functions in vitro. TGF- $\beta$ suppresses T cell receptor-induced proliferation of naïve T cells in vitro [53]. Thus, we examined if naïve Drak $2^{-/-} \mathrm{T}$ cells were more sensitive to TGF- $\beta$ - 


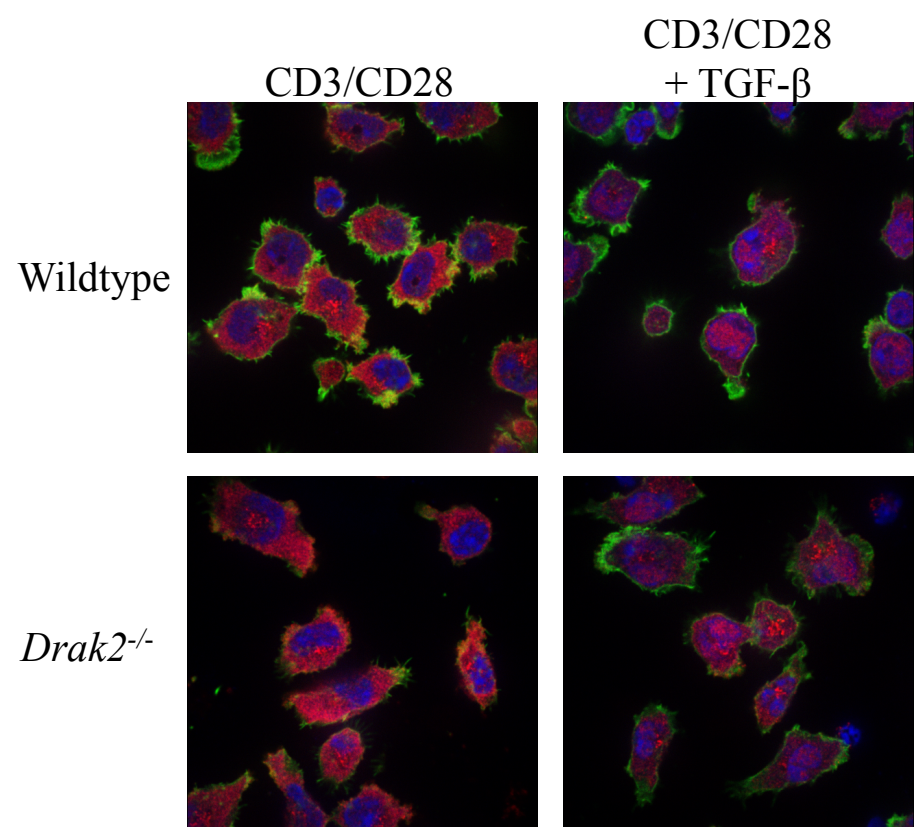

Figure 4-1. Smad2 translocation is not enhanced in Drak2 $2^{-/-} \mathrm{T}$ cells compared to wildtype $T$ cells.

Wildtype and Drak2 ${ }^{-/} \mathrm{CD}^{+} \mathrm{T}$ cells were purified with magnetic beads and stimulated on anti-CD3-coated coverglass slides along with soluble anti-CD28 for 24 hours. Half of the cells were treated with TGF- $\beta$ for the final 20 minutes of culture. Cells were fixed, permeabilized, and stained with DAPI (blue), phalloidin (green), and anti-Smad2 (red). Images were collected via confocal microscopy. Cells from 2 mice per group were pooled. Data are representative of two independent experiments. 

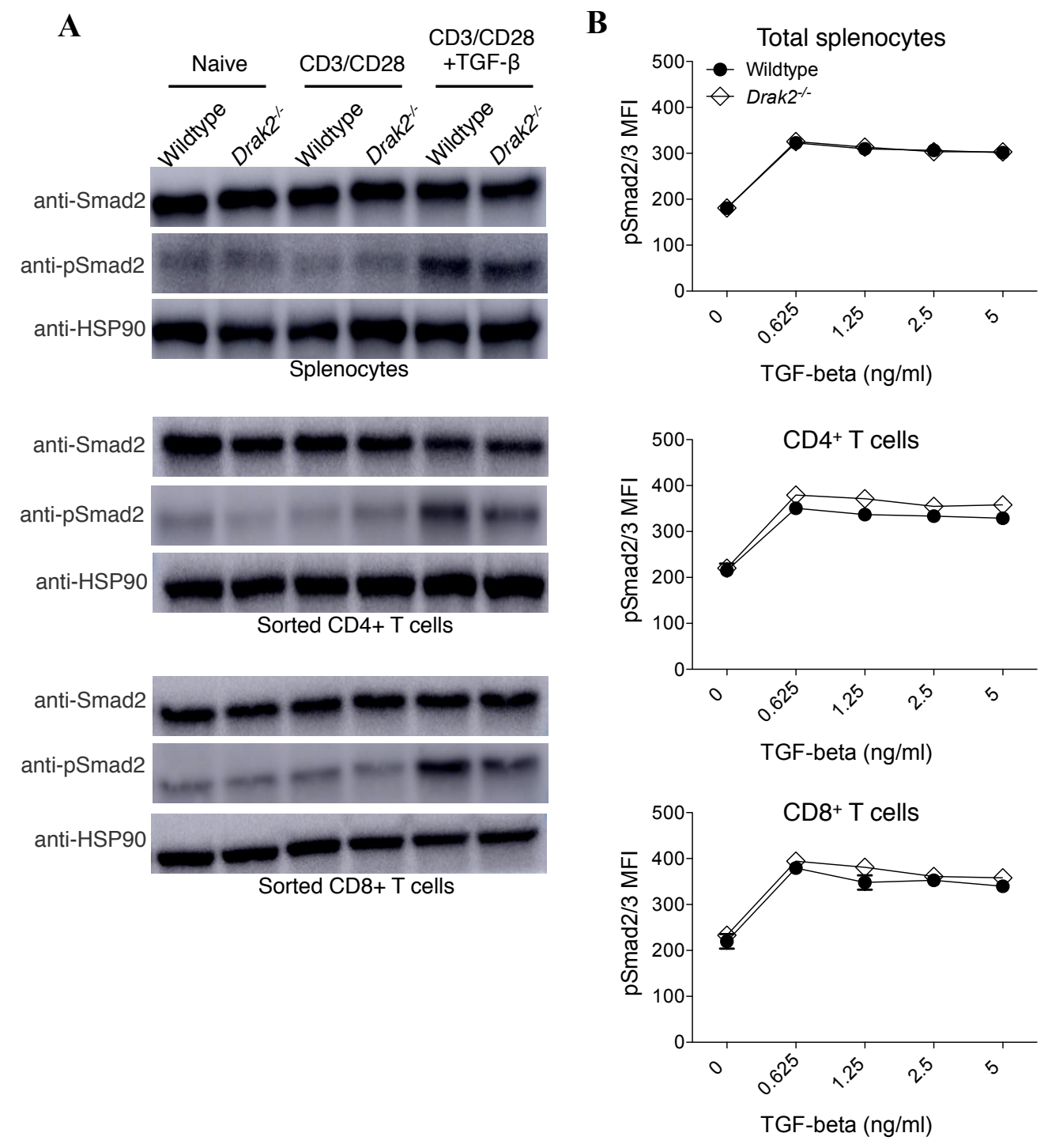

Figure 4-2. Smad2 and Smad2/3 complex phosphorylation is not enhanced in Drak $2^{-/-} \mathrm{T}$ cells compared to wildtype $\mathrm{T}$ cells.

(A) Wildtype and Drak $^{-/}$splenocytes, and FACS sorted naïve $\mathrm{CD} 4^{+}$and $\mathrm{CD} 8^{+} \mathrm{T}$ cells were stimulated for 2 hours with anti-CD3 and anti-CD28, with or without $2 \mathrm{ng} / \mathrm{ml} \mathrm{TGF-}$ $\beta$ for one additional hour. Cells were lysed and analyzed by western blot with antibodies specific for Smad2, phosphorylated Smad2, and HSP90 as a loading control. Cells were pooled from 9 wildtype and $8 \mathrm{Drak}^{-/}$mice. Data are representative of two independent experiments. (B) Wildtype and Drak $2^{-/}$splenocytes were stimulated for 2 hours with anti-CD3 and anti-CD28 with or without increasing concentrations of TGF- $\beta$ for one additional hour. The cells were harvested, stained with antibodies specific for CD4, CD8, and $\mathrm{pSmad} 2 / 3$, and analyzed by flow cytometry. The average mean fluorescence intensity (MFI) of pSmad2/3 expression is shown for 3 mice per group. There was no significant difference in the response of the wildtype and $\operatorname{Drak}^{-/}$cells according to the MannWhitney $U$-test. Data are representative of 3 independent experiments. 
mediated inhibition of proliferation than naive wildtype T cells. Naïve OT-II and OT-II.Drak2 ${ }^{--} \mathrm{CD}^{+} \mathrm{T}$ cells were stimulated with $\mathrm{OVA}_{323}$-pulsed splenocytes in the presence or absence of TGF- $\beta$, and analyzed for proliferation. The number of live, divided $\mathrm{CD}^{+} \mathrm{T}$ cells decreased in response to TGF- $\beta$ (Figure 4-3A). However, the effect of TGF- $\beta$ inhibition was comparable between OT-II and OT-II.Drak ${ }^{-/-}$T cells. We also tested the effect of TGF- $\beta$ on proliferation of naïve $\mathrm{CD}^{+} \mathrm{T}$ cells, by stimulating OT-I and OT-I.Drak $2^{-/} \mathrm{T}$ cells with $\mathrm{OVA}_{257}$-pulsed splenocytes in the presence of TGF- $\beta$. Similar to $\mathrm{CD}^{+} \mathrm{T}$ cells, the number of live, divided $\mathrm{CD} 8^{+} \mathrm{T}$ cells decreased in response to TGF$\beta$, and the amount of suppression was similar between OT-I and OT-I.Drak $2^{-/} \mathrm{T}$ cells (Figure 4-3B), again suggesting that neither TGF- $\beta$ signaling nor its downstream effects were enhanced in the absence of Drak2.

TGF- $\beta$ can abrogate survival signals provided by IL-15, but not those elicited by IL-2 and IL-7 in expanding CD8 ${ }^{+}$T cells [54]. To determine if TGF- $\beta$ function in response to opposing cytokines is altered in the absence of Drak2, we explored the antagonistic effects of TGF- $\beta$ on cell recovery and survival of activated CD ${ }^{+}$cells. OT-I and $O T-I . D r a k 2^{-/}$cells were stimulated with $\mathrm{OVA}_{257}$-pulsed splenocytes for two days. Cells were then washed and cultured with exogenous IL-2, IL-7, or IL-15 with or without TGF- $\beta$ for an additional four days. The addition of TGF- $\beta$ decreased the number of live $\mathrm{CD} 8^{+} \mathrm{T}$ cells compared to culture in media alone (Figure 4-4A). Adding IL-2, IL-7, and IL-15 enhanced the recovery of live $\mathrm{CD} 8^{+} \mathrm{T}$ cells compared to culture in media alone. The addition of TGF- $\beta$ masked the increased recovery in response to IL-15, but not IL-2 and IL-7. Decreased cell recovery in response to TGF- $\beta$ compared to culture in media alone correlated with an increase in the proportion of Annexin $\mathrm{V}^{+}$apoptotic cells

(Figure 4-4B). The addition of TGF- $\beta$ abrogated the survival effects of IL-15, but did not alter the anti-apoptotic effects of IL-2 and IL-7. However, the ability of TGF- $\beta$ to oppose the effects of IL-15, but not IL-2 and IL-7 was comparable between OT-I and OTI.Drak $2^{-/} \mathrm{T}$ cells, suggesting that these TGF- $\beta$-mediated effects are not enhanced in the absence of Drak2. These data further indicate that TGF- $\beta$ signaling and function is not increased in $\mathrm{Drak}^{-/} \mathrm{T}$ cells compared to wildtype T cells following in vitro stimulation.

\section{TGF- $\beta$-mediated T cell differentiation is not altered in the absence of Drak2}

Another function of TGF- $\beta$ is the induction of peripheral regulatory T cells [55]. As regulatory $\mathrm{T}$ cells are critical to prevent autoimmune diseases, we explored if there were alterations in TGF- $\beta$-mediated differentiation of induced regulatory T cells. Naïve wildtype and $\mathrm{Drak2}^{-/} \mathrm{CD}^{+} \mathrm{T}$ cells were purified and stimulated in vitro with anti-CD3, anti-CD28, and IL-2, with increasing amounts of TGF- $\beta$ (Figure 4-5). The addition of TGF- $\beta$ increased Foxp 3 expression, indicative of regulatory T cell induction. However, we did not observe an enhanced induction in the percent (Figure 4-5A) or number (Figure 4-5B) of Foxp $3^{+} \mathrm{CD}^{+}$cells in the absence of Drak2. These data also suggest that TGF- $\beta$ functions similarly in wildtype and Drak2 $^{-/} \mathrm{T}$ cells that were activated in vitro. Therefore, Drak 2 may not act as a negative regulator of TGF- $\beta$ signaling in T cells. 
A

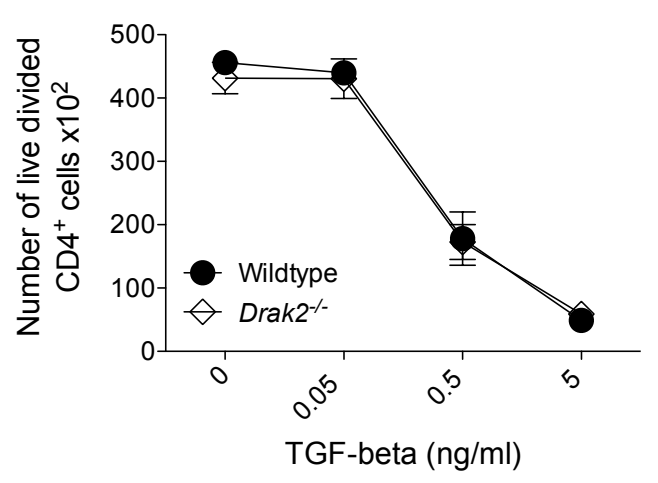

B

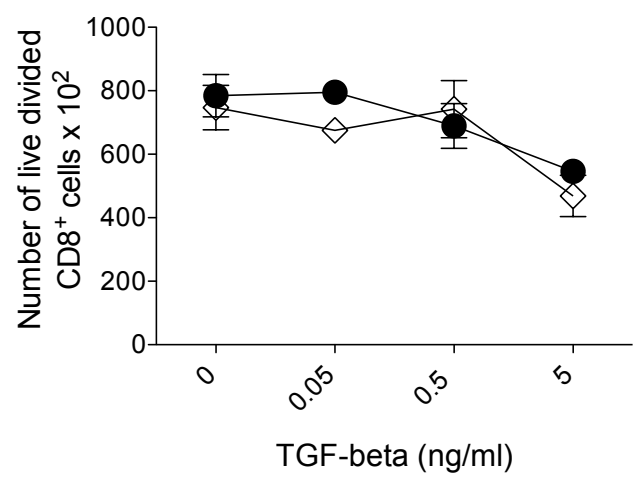

Figure 4-3. TGF- $\beta$-mediated inhibition of naïve $T$ cell proliferation is comparable between wildtype and $\mathrm{Drak}^{-/-} \mathrm{T}$ cells.

(A) Naïve OT-II and OT-II.Drak $2^{-/} \mathrm{CD} 4^{+} \mathrm{T}$ cells were FACS-sorted and stimulated with irradiated splenocytes loaded with $10 \mu \mathrm{M} \mathrm{OVA}_{323}$ peptide in the presence or absence of 10 -fold TGF- $\beta$ titrations for three days. The number of live, divided Foxp $3^{-} \mathrm{CD} 4^{+}$cells are shown for each titration. Cells were obtained from one OT-II or OT-II.Drak2-/mouse and tested in quadruplicate. Data are representative of five separate experiments. (B) Naïve $O T-I$ and $O T-I . D r a k 2^{--} \mathrm{CD} 8^{+} \mathrm{T}$ cells were sorted and stimulated with splenocytes loaded with $100 \mathrm{pM} \mathrm{OVA} 257$ peptide in the presence or absence of 10 -fold TGF- $\beta$ titrations. Two days later, cells were harvested and analyzed by flow cytometry. The number of live, divided $\mathrm{CD} 8^{+}$cells are shown for each titration. Cells were obtained from one OT-I or OT-I.Drak2 $2^{-/}$mouse and tested in quadruplicate. Data are representative of three separate experiments. There was no significant difference in the response of the wildtype and $\operatorname{Drak}^{-/}$cells according to the Mann-Whitney $U$-test. 
A

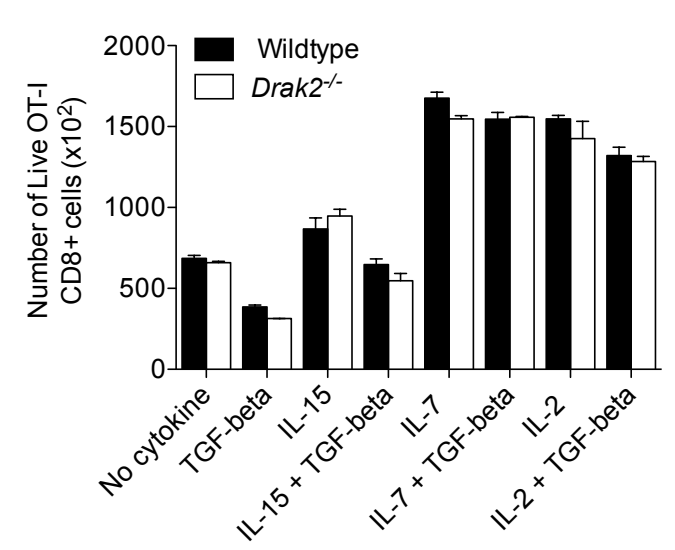

B

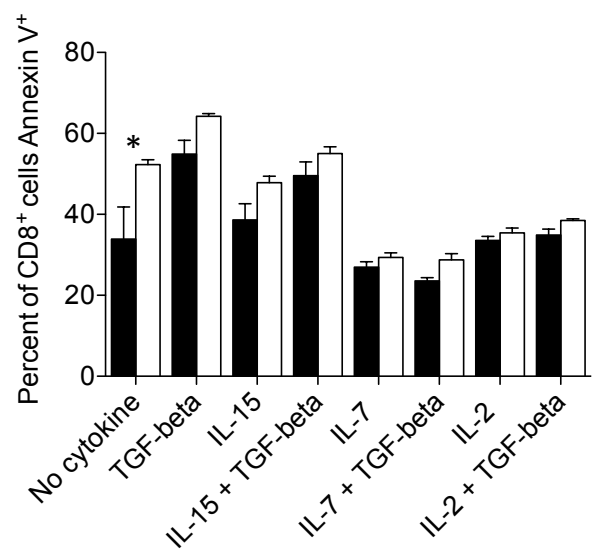

Figure 4-4. TGF- $\beta$-mediated responses to opposing cytokines are comparable between wildtype and $\operatorname{Drak} 2^{-/-} \mathrm{T}$ cells.

Naïve $O T-I$ and $O T-I . D r a k 2^{-/-} \mathrm{CD}^{+} \mathrm{T}$ cells were FACS-sorted and stimulated with $100 \mathrm{nM} \mathrm{OVA}_{257}-$ pulsed splenocytes for 2 days. Cells were harvested and replated at equal numbers with or without various cytokine combinations. Cytokines were replenished 2 days later. Cells were harvested and analyzed by flow cytometry on day 6. (A) The number of live, $\mathrm{CD}^{+}$cells and (B) percent Annexin $\mathrm{V}^{+}$of $\mathrm{CD}^{+}$cells are shown for each cytokine condition. Cells were obtained from one OT-I or OT-I.Drak $2^{-/}$mouse and tested in quadruplicate. Data are representative of two independent experiments. ${ }^{*} P<0.05$ (Mann-Whitney $U$-test). 
A

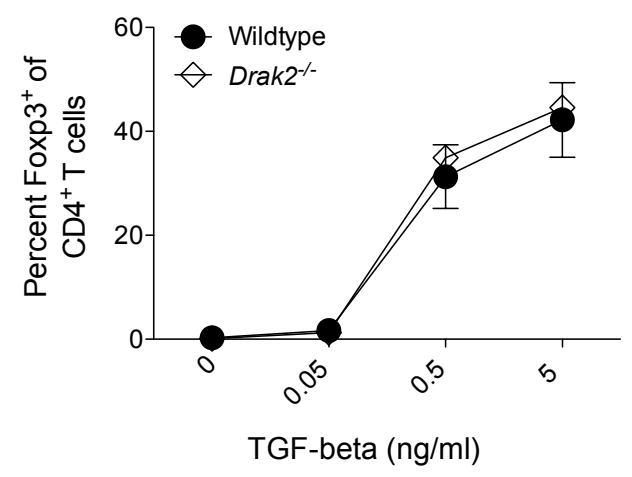

B

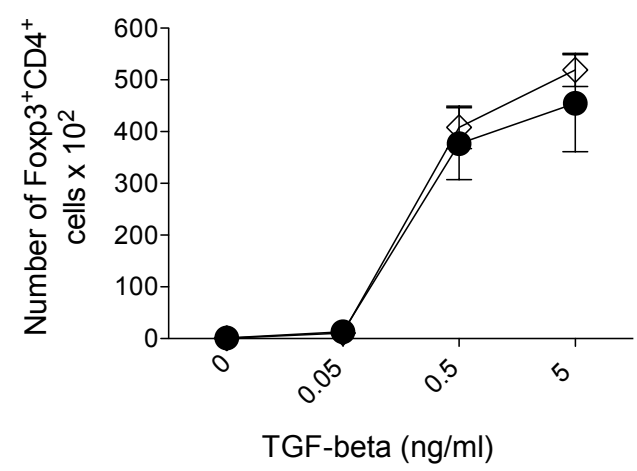

Figure 4-5. TGF- $\beta$-mediated regulatory $T$ cell induction is not altered in the absence of Drak2.

Naïve wildtype and Drak2 ${ }^{-/} \mathrm{CD}^{+} \mathrm{T}$ cells were purified and stimulated with $1 \mu \mathrm{g} / \mathrm{ml}$ antiCD3 and $1 \mu \mathrm{g} / \mathrm{ml}$ anti-CD28 with $20 \mathrm{ng} / \mathrm{ml} \mathrm{IL-2}$ alone or plus 10 -fold TGF- $\beta$ titrations for 3 days. The (A) percent and (B) number of Foxp $3^{+}$cells of electronically gated CD4 ${ }^{+}$ cells is shown. There was no significant difference in the response of the wildtype and Drak2 $2^{-/}$cells according to the Mann-Whitney $U$-test. 


\section{Enhanced susceptibility to death of $\operatorname{Drak}^{-/-} \mathrm{T}$ cells compared to wildtype $\mathrm{T}$ cells is independent of TGF- $\beta$ signaling in vitro}

We previously showed that $\operatorname{Drak}^{-/-} \mathrm{T}$ cells exhibit enhanced susceptibility to death in vivo, which promotes resistance to T1D and MS [23]. In addition, we found that following in vitro stimulation with anti-CD3 and anti-CD28, a greater proportion of Drak2 $2^{-/} \mathrm{T}$ cells were apoptotic compared to wildtype T cells (Figure 4-6A and 4-6B, left portion of graph). Although we did not observe differences in TGF- $\beta$ signaling in the absence of Drak2, there may be alternative TGF- $\beta$-mediated effects on T cell survival. Thus, we sought to determine if the survival defect in Drak2 $2^{-/} \mathrm{T}$ cells compared to wildtype T cells was due to enhanced TGF- $\beta$ signaling. To test this, we compared $\mathrm{T}$ cell survival between wildtype and Drak2 $2^{--}$T cells that exhibit impaired TGF- $\beta$ signaling due to expression of a dominant-negative TGF- $\beta$ receptor II (DNRII) transgene. The DNRII transgene is a kinase-dead mutant that blocks signaling through the endogenous TGF- $\beta$ receptor by competing for TGF- $\beta$ binding [17]. Naïve CD4 ${ }^{+}$and $\mathrm{CD} 8^{+}$T cells were sorted from wildtype, Drak $2^{-/}$, DNRII, and DNRII.Drak2 ${ }^{-/}$mice. The purified T cells were stimulated in vitro with anti-CD3 and anti-CD28. We found that even with the severe reduction in TGF- $\beta$ signaling, there was an increase in the proportion of nonviable DNRII.Drak2 $2^{--} \mathrm{CD}^{+}$(Figure 4-6A) and $\mathrm{CD}^{+}$(Figure 4-6B) $\mathrm{T}$ cells compared to DNRII $\mathrm{CD}^{+}$and $\mathrm{CD}^{+} \mathrm{T}$ cells. These data show that the enhanced death in the Drak2 ${ }^{-/} \mathrm{T}$ cells following in vitro stimulation is not due to increased TGF- $\beta$ signaling, and suggest that alternative signaling pathways play a role.

\section{Discussion}

TGF- $\beta$ is a multifunctional cytokine that controls many aspects of T cell behavior and elicits protective effects in several autoimmune diseases [51]. It has been suggested that Drak2 functions as a negative regulator of TGF- $\beta$ signaling [10]. As TGF- $\beta$ can inhibit proliferation, survival, and differentiation of T cells, enhanced TGF- $\beta$ signaling in Drak $2^{-/-} \mathrm{T}$ cells could contribute to the resistance to autoimmune disease in the Drak2 $2^{-/}$ mice via one or more of these mechanisms. However, our data suggest that in primary $\mathrm{T}$ cells stimulated in vitro, Drak2 does not function as a negative regulator of this pathway. Smad2/3 signaling after TGF- $\beta$ stimulation was not enhanced in Drak2 ${ }^{-/-}$T cells compared to wildtype T cells. Importantly, the impact of TGF- $\beta$ on T cell behavior was not enhanced in the absence of Drak2 as evidenced by equal inhibition of naïve $\mathrm{T}$ cell proliferation, comparable effects on activated $\mathrm{CD} 8^{+} \mathrm{T}$ cell accumulation and survival, and similar induction of regulatory T cells in wildtype and Drak ${ }^{-/-} \mathrm{T}$ cells.

The previous studies that suggested Drak2 negatively regulates TGF- $\beta$ signaling were performed in tumor cell lines [10]. It is possible that Drak2 inhibits TGF- $\beta$ in certain tumor cells, but not in primary T cells. Mutations that lead to tumorigenesis could facilitate a role for Drak2 regulation in TGF- $\beta$ signaling. Thus, as reported in certain tumors, Drak 2 may function to negatively regulate TGF- $\beta$ signaling and promote tumorigenesis [10]. However, this is contrary to other reports that describe Drak2 as a 
$\mathbf{A}$

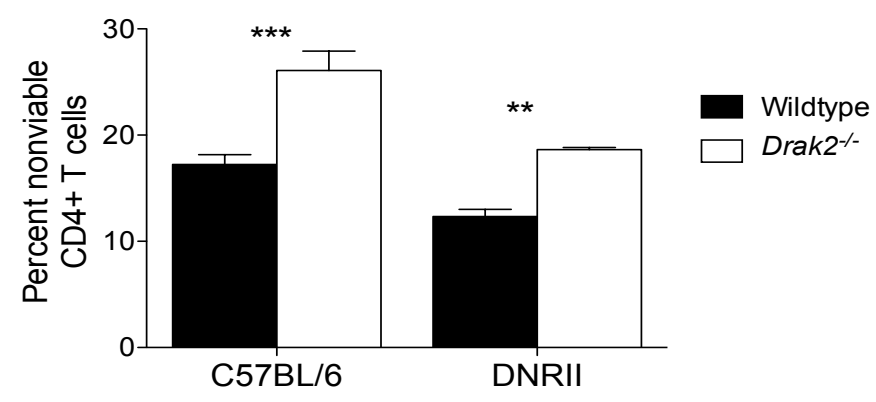

B

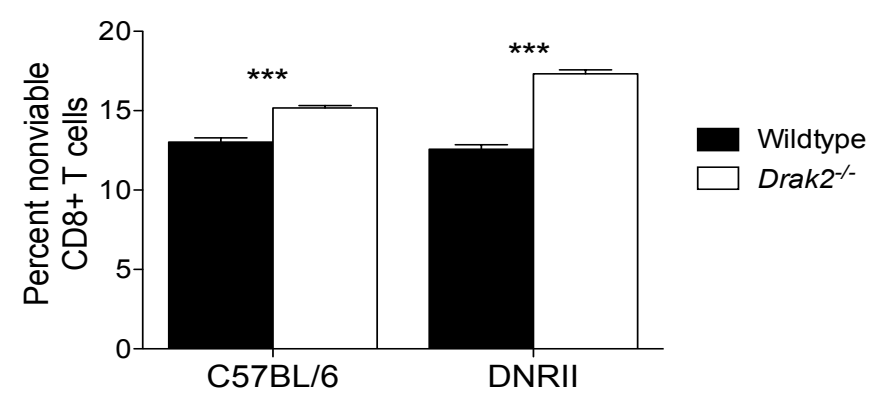

Figure 4-6. Enhanced susceptibility to death of $\operatorname{Drak2}^{-/} \mathrm{T}$ cells compared to wildtype $T$ cells is independent of TGF- $\beta$ signaling in vitro.

Naïve (CD25 CD44 ${ }^{\mathrm{lo}}$ ) T cells were purified from wildtype, Drak2 $2^{-/}$, DNRII, and DNRII. Drak2 $2^{-/}$mice and stimulated with anti-CD3 and anti-CD28 for 2-3 days. The percent of nonviable (A) $\mathrm{CD}^{+}$or (B) $\mathrm{CD} 8^{+} \mathrm{T}$ cells is shown. Cells were obtained from one mouse per group and tested in quadruplicate. Data are representative of four separate experiments. $* * P<0.01, * * * P<0.001$ (Mann-Whitney $U$-test). 
tumor suppressor $[11,15,30]$. Therefore, the role of Drak2 in different types of tumors is also controversial and needs to be studied further. Interestingly, we have shown that Drak $2^{-/}$mice respond similarly to wildtype mice in various in vivo tumor models, again suggesting that the role of Drak2 in cell lines may not mimic its role under physiological conditions [32].

Another possible explanation for the discrepancy between our results in primary $\mathrm{T}$ cells and the previous data in tumor cell lines is that during development, the $\operatorname{Drak}^{-/-} \mathrm{T}$ cells may have compensated for the loss of Drak 2 through modifications of alternate pathways involved in TGF- $\beta$ regulation. For example, increased levels of Smad7, a negative regulator of TGF- $\beta$ signaling [56], could mask alterations in TGF- $\beta$ signaling in the absence of Drak2. Therefore, Drak2 ${ }^{-/}$T cells may exhibit altered signaling pathways that function differently compared to physiological conditions in wildtype $\mathrm{T}$ cells, which warrants further investigation. Furthermore, it is important to investigate the molecular mechanisms of Drak2 in primary T cells, as these are the cells relevant to the induction or resistance to autoimmunity. The importance of Drak2 specifically in T cells during autoimmunity was highlighted in our previous studies, which demonstrated that the resistance to disease in the mouse model of MS was due to Drak2-deficiency in T cells [23]. In addition, we found that the resistance to T1D was also due to the absence of Drak2 in T cells (Chapter 3).

Together, our data presented here indicate that TGF- $\beta$ signaling is not enhanced in $\operatorname{Drak2}^{-\alpha} \mathrm{T}$ cells following in vitro stimulation. Consequently, Drak2 does not function as a negative regulator of TGF- $\beta$ signaling in T cells, which are critical for the induction of autoimmunity. Therefore, further investigation of the potential molecular mechanisms by which Drak2 functions during autoimmune disease is required to gain insight into the etiology of these diseases. 


\section{CHAPTER 5. DRAK2 ALTERS ACTIN POLYMERIZATION AND ACTIN- DEPENDENT T CELL FUNCTIONS}

\section{Introduction}

$\operatorname{Drak2}^{-/-}$mice are resistant to autoimmune diseases in models of T1D and MS due to decreased accumulation of infiltrating T cells in the pancreas and CNS, respectively. Decreased accumulation was, at least in part, due to enhanced susceptibility to death of Drak2 ${ }^{-/-}$T cells $[4,19,23]$. Studies in the T1D model showed that while antigen-specific NOD.Drak $2^{-/} \mathrm{T}$ cells proliferated in the draining, pancreatic lymph nodes, accumulation of these cells decreased as the cells divided. While there was an overall increase in the proportion of apoptotic cells in the absence of Drak2, the exact mechanism for enhanced death has not been determined, and it is not clear if other factors, such as defective proliferation, also mediate decreased accumulation.

Actin is a globular protein that is highly conserved in most eukaryotic cells, where it serves many important functions [57]. Specifically, the actin cytoskeleton plays pivotal roles in $\mathrm{T}$ cell activation, division, adhesion, and migration, which ultimately facilitate effective immune responses. T cells lacking key cytoskeletal regulatory proteins demonstrate that these deficiencies lead to impaired $\mathrm{T}$ cell functions involving F-actin reorganization, proliferation and other defects [58], highlighting the importance of efficient actin dynamics in $\mathrm{T}$ cell biology. Given that proper actin polymerization is required for productive $\mathrm{T}$ cell proliferation and survival, it is possible that altered actin polymerization plays a role in the accumulation defect of Drak2 $^{-/-} \mathrm{T}$ cells.

Therefore, we investigated whether defects in proliferation and actin dynamics contributed to the decreased T cell accumulation observed in the absence of Drak2. We found that upon in vitro stimulation, Drak2 ${ }^{-/}$CD4 T cells exhibit a progressive decrease in cell number per division, and decreased overall cell survival. Live cell imaging revealed altered cell division of Drak2 $2^{-/} \mathrm{T}$ cells, which was associated with abnormal morphology and defects in cell cycle progression. Drak $2^{-/-} \mathrm{T}$ cells also displayed reduced actin filament polymerization, migration, and conjugate formation with antigen presenting cells (APC). In addition, the activation of an important actin-regulatory protein, Rac, was reduced in the absence of Drak2. This finding suggests that Drak2 mediates actin dynamics either upstream or in collaboration with Rac-GTP in the actin polymerization pathway. Taken together, these data provide evidence that Drak2 plays a novel role in mediating cytoskeletal rearrangements via direct or indirect mechanisms, which may affect optimal $\mathrm{T}$ cell survival, proliferation, and other $\mathrm{T}$ cell functions to ultimately impact autoimmune diseases such as T1D and MS. 


\section{Results}

\section{Drak2 $^{-/-}$CD4 T cells exhibit decreased accumulation upon stimulation in vitro}

To test whether decreased accumulation of Drak2 $2^{--} \mathrm{CD} 4^{+} \mathrm{T}$ cells was due to decreased survival, defective proliferation, or a combination of both, we tested whether in vitro $\mathrm{T}$ cell stimulation would recapitulate the survival defect previously observed in Drak2 $^{-/}$T cells in vivo $[19,21,23]$. We sorted naïve CD4 ${ }^{+} \mathrm{T}$ cells from the spleen and peripheral lymph nodes of wildtype and $D r a k 2^{-/}$mice. Purified T cells were labeled with the fluorescent dye, CFSE, to track cell division, and stimulated with anti-CD3 and antiCD28 for 24 and 48 hours. Cells were harvested and stained with a viability dye. While the numbers of viable wildtype and Drak2 $2^{--} \mathrm{CD} 4^{+} \mathrm{T}$ cells were similar at 24 hours following activation, there were significantly fewer viable $D r a k 2^{-/} \mathrm{T}$ cells by 48 hours (Figure 5-1A). Furthermore, a greater proportion of Drak2 $2^{--} \mathrm{CD} 4^{+} \mathrm{T}$ cells were not viable compared to wildtype $\mathrm{CD} 4^{+} \mathrm{T}$ cells, 24 and 48 hours after stimulation (Figure 5-1B). The enhanced cell death in the Drak2 ${ }^{-/} \mathrm{CD}^{+} \mathrm{T}$ cells at 24 hours after stimulation likely contributed to the decreased number of viable Drak $2^{-/-} \mathrm{CD} 4^{+} \mathrm{T}$ cells observed at 48 hours compared to wildtpye $\mathrm{CD} 4^{+} \mathrm{T}$ cells. As the $\mathrm{CD} 4^{+} \mathrm{T}$ cells have not begun to divide at 24 hours after stimulation, yet show increased apoptosis at this time, alterations occurring prior to cell division potentially mediate cell survival fates and subsequent accumulation. A detailed analysis of the number of cells in each division 72 hours after stimulation showed that the number of Drak $2^{-/-} \mathrm{T}$ cells per division decreased significantly as cells proliferated compared to wildtype T cells (Figure 5-1C and 5-1D). These results show that the defect in Drak2 $2^{-/-}$T cell survival observed in vivo is also evident in vitro. Therefore, we will utilize this culture system to study the molecular mechanisms by which Drak2 affects T cell accumulation and function. While we also found similar trends for Drak2 ${ }^{-/} \mathrm{CD}^{+} \mathrm{T}$ cell survival defects compared to wildtype $\mathrm{CD}^{+} \mathrm{T}$ cells (data not shown), Drak2 $2^{--} \mathrm{CD} 4^{+} \mathrm{T}$ cells displayed a more prominent and consistent survival defect than Drak2 $2^{-/} \mathrm{CD} 8^{+} \mathrm{T}$ cells, therefore we will focus our investigations primarily on $\mathrm{CD}^{+} \mathrm{T}$ cells.

\section{$\mathrm{CD}^{+} \mathrm{T}$ cells display abnormal morphology and alterations during interphase in the absence of Drak2}

To investigate the dynamics of proliferation, we utilized live cell imaging. We purified wildtype and Drak $2^{--} \mathrm{CD}^{+} \mathrm{T}$ cells and stimulated them with anti-CD3 and antiCD28 in chambered coverglass slides. Images were collected every 6 minutes from 18-36 hours after stimulation. Time-lapse imaging revealed a higher proportion of activated Drak2 $2^{-/} \mathrm{T}$ cells that had blasted, but not completed cell division by 36 hours in culture, compared to wildtype T cells (data not shown). In addition, Drak2 ${ }^{-/-} \mathrm{T}$ cells exhibited an irregular cell morphology, which correlated with the prolonged inability to divide (Figure 5-2A). Notably, not all Drak ${ }^{-/-} \mathrm{T}$ cells exhibited abnormal morphology. A portion of $D r a k 2^{-/}$T cells divided comparably to wildtype T cells, explaining why there is only a partial block in T cell proliferation and accumulation in the absence of Drak2. 
A

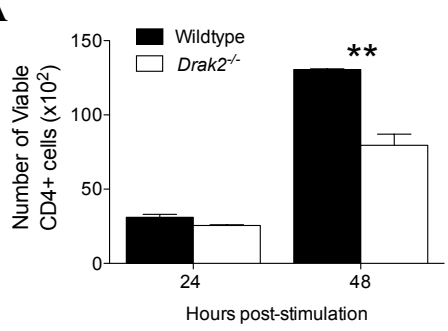

C

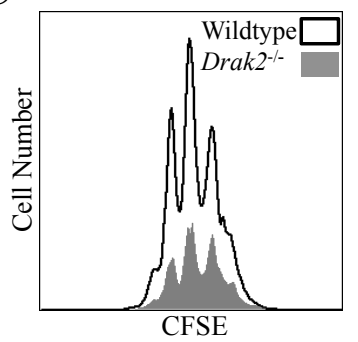

B

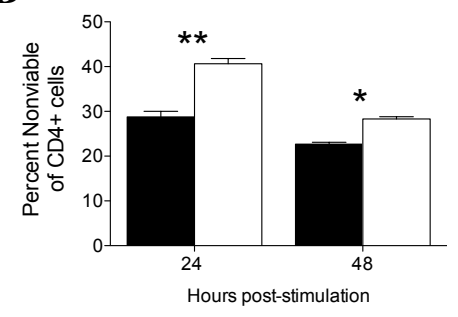

D

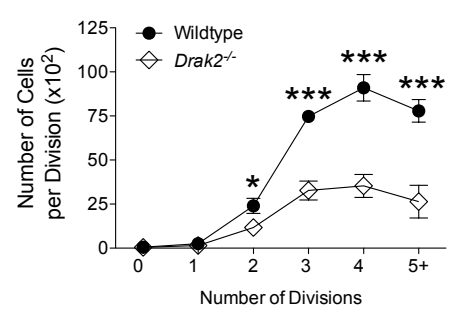

Figure 5-1. Drak2 $2^{-/}$CD4 T cells exhibit decreased accumulation upon stimulation in vitro.

$\mathrm{CD}^{+} \mathrm{T}$ cells were purified from the lymph nodes of wildtype and Drak2 $2^{-/-}$mice using negative selection with Miltenyi magnetic beads. The cells were stimulated in vitro with plate-bound anti-CD3 and soluble anti-CD28 for 24, 48, and 72 hours. After 24 and 48 hours, cells were harvested and stained with antibodies specific for anti-CD4 and viability dye. (A) The number of viable $\mathrm{CD}^{+}$cells and (B) the percent of nonviable $\mathrm{CD}^{+}$cells is shown for each time point, as analyzed by flow cytometry. (C) and (D) $\mathrm{CD}^{+} \mathrm{T}$ cells were stained with CFSE, harvested at 72 hours post-stimulation, stained with anti-CD4, then analyzed by flow cytometry. (C) The CFSE levels on electronically gated viable $\mathrm{CD} 4{ }^{+}$cells are shown. (D) The number of viable $\mathrm{CD} 4{ }^{+}$cells per division, based on CFSE histogram analysis, is shown. Samples represent two pooled mice per group and were tested in triplicate. Data were analyzed by two-way ANOVA with Bonferroni post-tests and error bars represent standard deviation. Data are representative of greater than three independent experiments. $* P \leq 0.05, * * P \leq 0.01, * * * P \leq 0.001$. 
A
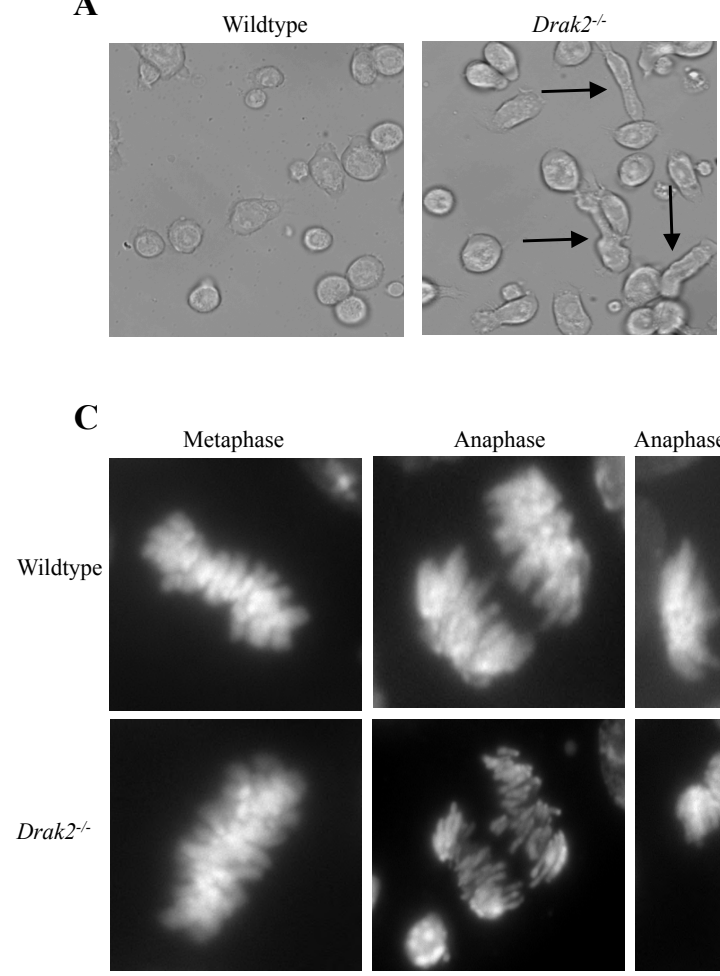

B

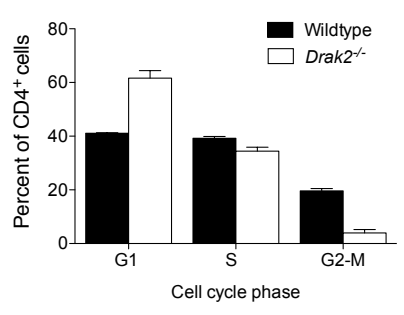

Figure 5-2. CD4 T cells display abnormal morphology and alterations during interphase in the absence of Drak2.

(A) $\mathrm{CD} 4^{+} \mathrm{T}$ cells were negatively selected from the lymph nodes of wildtype and Drak2 $2^{--}$mice, then stimulated with anti-CD3 and anti-CD28 in chambered coverglass slides for 36 hours. Live cell images were collected every 6 minutes from 18-36 hours following stimulation. The images shown were captured approximately 32 hours after stimulation. Black arrows indicate $\operatorname{Drak2}^{-/-} \mathrm{CD}^{+}$T cells exhibiting abnormal morphology. Cells were pooled from two mice per group. Data are representative of two independent experiments. (B) Naïve wildtype and Drak2 $2^{-/-} \mathrm{CD} 4^{+} \mathrm{T}$ cells were FACS sorted and stimulated with anti-CD3 and anti-CD28 for 24 hours. Cells were harvested, fixed, stained with propidium iodide, and analyzed by flow cytometry. The percent of $\mathrm{CD} 4{ }^{+}$cells per cell cycle phase is shown. Cells were pooled from two mice per group. Samples were tested in duplicate and error bars represent standard deviation. Data are representative of two separate experiments. (C) and (D) Wildtype and Drak2 ${ }^{-/} \mathrm{CD} 4{ }^{+} \mathrm{T}$ cells were negatively selected and stimulated for 48 hours with anti-CD3 and anti-CD28 in chambered coverglass slides. Cells were fixed, permeabilized, stained with DAPI, and images were collected. (C) The representative images show chromosomal dynamics during the phases of mitosis. (D) The number of cells per 50 mitotic cells in each phase is shown. Cells were pooled from two mice per group. Data represent one experiment. 
The elongated morphology and prolonged division time observed in the absence of Drak2, suggested that there may be defects in completing the cell cycle. Therefore, we investigated cell cycle progression utilizing propidium iodide (PI) staining, a DNA intercalating agent. Naïve $\mathrm{CD}^{+} \mathrm{T}$ cells were sorted from the lymph nodes and spleen of wildtype and Drak2 ${ }^{-/}$mice, then stimulated in vitro for 24 hours with anti-CD3 and antiCD28. There was a greater proportion of Drak2 $2^{--} \mathrm{CD}^{+} \mathrm{T}$ cells in the G1 phase at 24 hours and a significantly decreased proportion in the G2-M phase, compared to wildtype cells (Figure 5-2B). These data suggest that there is a defect or delay in G1-S phase transition in the absence of Drak2. Therefore, this interruption in G1-S phase transition during interphase of the cell cycle, may contribute to the decreased accumulation observed in Drak $2^{-/}$T cells following stimulation.

To determine if the Drak2 ${ }^{-/} \mathrm{CD} 4^{+} \mathrm{T}$ cells that progressed beyond the G1 to S phase proceeded through mitosis normally, we stimulated wildtype and Drak2 $2^{-/} \mathrm{CD} 4^{+} \mathrm{T}$ cells for 48 hours in chambered coverglass slides. Cells were then stained with DAPI, a fluorescent stain that binds DNA, to identify the mitotic phases and to track chromosomal segregation. Wildtype and Drak2 $2^{-/}$T cells exhibited similar dynamics in terms of chromosomal segregation during mitosis (Figure 5-2C). Furthermore, the number of cells per 50 mitotic cells, in each phase of mitosis, at 48 hours after stimulation was similar for wildtype and Drak2 $2^{-/}$T cells (Figure 5-2D). These data suggest that there are no obvious defects in microtubule function in regards to chromosomal segregation and that mitosis is not altered in the absence of Drak2. Furthermore, these findings imply that $\mathrm{Drak}^{-/}$cells that exit interphase and enter mitosis successfully complete cell cycle and proliferate. Conversely, the subset of Drak2 $2^{-/}$T cells that demonstrate defects in G1 to $\mathrm{S}$ phase transition during interphase, preceding mitosis, exhibit abnormal morphology and alterations in cell division, which may halt proliferation of these cells. Interestingly, these proliferative defects may render cells more susceptible to apoptosis, which could account for both decreased survival and reduced accumulation in the absence of Drak2.

\section{Actin polymerization is decreased in $\mathrm{Drak2}^{-/} \mathrm{CD4}^{+} \mathrm{T}$ cells compared to wildtpye $\mathrm{CD4}^{+} \mathrm{T}$ cells}

Abnormal morphology and altered proliferation in the absence of Drak2 suggests Drak2 may play a role in actin cytoskeletal processes. Therefore, we next measured actin filament polymerization following T cell activation. We purified wildtype and Drak ${ }^{-/}$ CD4 T cells and stimulated them with anti-CD3 and anti-CD28 for 48 hours in vitro. The mean fluorescence intensity of phalloidin, a bicyclic peptide that selectively binds polymerized actin (F-actin), was measured in viable CD4 T cells. There was no significant difference in basal F-actin expression between wildtype and Drak2 ${ }^{-/} \mathrm{T}$ cells prior to stimulation. However, 48 hours after stimulation, there was significantly lower Factin expression in the absence of Drak2 (Figure 5-3A and 5-3B). This trend was also seen at 72 hours (data not shown). These data suggest that Drak2 impacts actin polymerization, as the expression of F-actin is significantly reduced in its absence. 
A

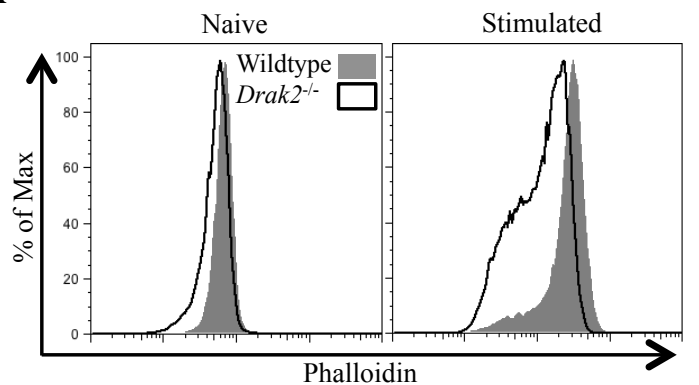

B

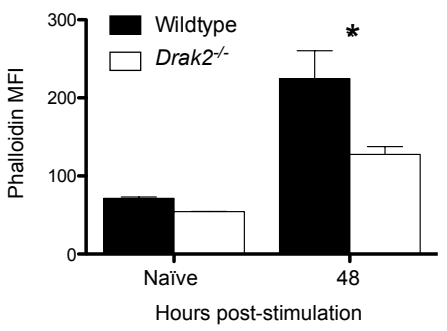

C

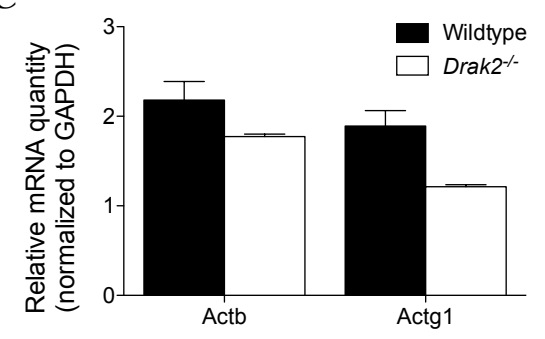

D

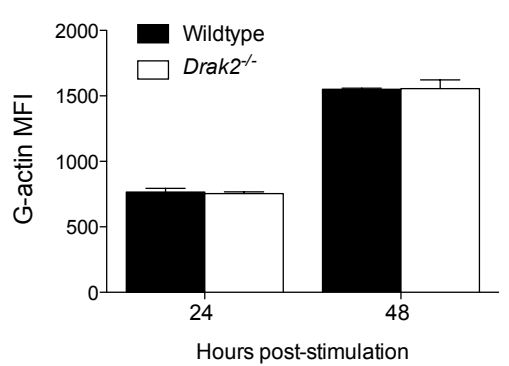

Figure 5-3. Actin polymerization is decreased in Drak2 ${ }^{-/} \mathrm{CD} 4 \mathrm{~T}$ cells compared to wildtpye CD4 T cells.

$\mathrm{CD}^{+} \mathrm{T}$ cells were negatively selected from lymph nodes of wildtype and $\mathrm{Drak}^{-/}$mice. Cells were either left unstimulated or stimulated for 48 hours with plate-bound anti-CD3 and soluble anti-CD28. Cells were harvested and stained with a viability dye and antiCD4, then fixed, permeabilized, stained with phalloidin, and analyzed by flow cytometry. (A) Representative histograms of phalloidin mean fluorescence intensity (MFI) on electronically gated viable $\mathrm{CD}^{+}{ }^{\mathrm{T}}$ cells. (B) Bar graphs representing MFI expression is shown. Samples represent two pooled mice per group and were tested in triplicate. Data were analyzed by two-way ANOVA with Bonferroni post-tests and error bars represent standard deviation. Data are representative of greater than three independent experiments. ${ }^{*} P \leq 0.05,{ }^{*} * P \leq 0.01,{ }^{*} * P \leq 0.001$. (C) Naïve wildtype and Drak2 ${ }^{-/} \mathrm{CD} 4^{+} \mathrm{T}$ cells were FACS sorted and stimulated with anti-CD3 and anti-CD28. RNA was extracted from $\mathrm{CD} 4{ }^{+} \mathrm{T}$ cells at 40 hours post-stimulation. The relative amount of $\beta$-actin $(A c t b)$ and $\gamma$ actin (Actg1) mRNA, normalized to $G A P D H$, was measured utilizing qPCR analysis. Three mice per group were tested. Data were analyzed using Mann-Whitney U test (twotailed) and error bars represent SEM. Data represent two experiments. (D) Naïve (CD25 $\left.\mathrm{CD} 44^{\mathrm{lo}} \mathrm{CD} 62 \mathrm{~L}^{\mathrm{hi}}\right) \mathrm{CD} 4+\mathrm{T}$ cells were harvested from the spleen and lymph nodes of wildtype and Drak2 $2^{--}$mice. Naïve CD $4^{+} \mathrm{T}$ cells were stimulated for 24 and 48 hours with anti-CD3 and anti-CD28, harvested, then stained with viability dye and antibodies specific for CD4. Cells were fixed, permeabilized, and stained with DNase I to selectively identify G-actin. G-actin MFI was determined by flow cytometry at the specified time points. Samples were tested in duplicate or triplicate. Error bars represent standard deviation and data are representative of two separate experiments. 
To examine whether the decrease in polymerized actin in Drak2 $^{-/-} \mathrm{CD}^{+} \mathrm{T}$ cells was due to decreased gene expression and availability of actin subunits, we first measured mRNA expression of $\beta$-actin $(A c t b)$ and $\gamma$ - actin $(A c t g 1)$ in $\mathrm{CD}^{+} \mathrm{T}$ cells stimulated with anti-CD3 and anti-CD28 for 40 hours. There were no significant differences in levels of $\beta$ - or $\gamma$-actin mRNA between wildtype and Drak2 $2^{-/} \mathrm{CD}^{+} \mathrm{T}$ cells (Figure 5-3C). These data imply that alterations in actin polymerization are not due to reduced expression of the genes required for actin protein expression. Next, we determined if the expression of globular actin (G-actin) protein monomers, the building blocks for F-actin, was altered in the absence of Drak2. We sorted naïve CD4 ${ }^{+} \mathrm{T}$ cells from the spleen and lymph nodes of wildtype and $\mathrm{Drak}^{-/-}$mice. Cells were stimulated with anti-CD3 and anti-CD28 for 40 hours in vitro, and G-actin monomer expression was measured with fluorescently labeled DNase I, which selectively binds G-actin. G-actin expression was similar between wildtype and Drak2 ${ }^{-/}$CD4 T cells (Figure 5-3D). Similar results for actin polymerization studies were also observed in $\mathrm{CD} 8^{+} \mathrm{T}$ cells (data not shown). These data suggest that alterations in polymerized actin are likely due to impairments within the actin polymerization pathway, rather than decreased mRNA or protein expression and monomer availability in the absence of Drak2.

\section{Actin-dependent $\mathbf{T}$ cell functions are impaired in the absence of Drak2}

To explore actin-dependent T cell functions, we investigated T cell:APC conjugation, which is a pivotal step in the initiation of immunological synapse formation and $\mathrm{T}$ cell activation. The establishment of actin-dependent protrusions in $\mathrm{T}$ cells is required for this initial interaction [59]. We sorted naïve $\mathrm{CD}^{+} \mathrm{T}$ cells from $O T-I$ and $O T$ I.Drak $2^{-/}$mice and cultured them in vitro with splenocytes pulsed with increasing amounts of $\mathrm{OVA}_{257}$ peptide, the cognate antigen for OT-I T cells. After 10 minutes, the number of T cells forming conjugates with the antigen-pulsed APCs was measured by flow cytometry. Significantly fewer conjugates formed between APCs and OT-I.Drak $2^{-/-}$ $\mathrm{CD} 8^{+} \mathrm{T}$ cells compared to $O T-I \mathrm{CD} 8^{+} \mathrm{T}$ cells (Figure 5-4A). These data suggest that Drak2 plays an important role in mediating T cell:APC conjugation, which is likely due to a direct or indirect role in actin polymerization.

Cell migration also requires intact actin dynamics. Therefore, we investigated whether there were defects in T cell migration in the absence of Drak2. Purified wildtype and Drak2 $2^{-/}$T cells were stimulated for 2 hours in vitro with anti-CD3 and anti-CD28. The ability of the activated $\mathrm{T}$ cells to migrate in response to the chemoattractant, CCL19, was tested in a transwell migration assay. The percent of $D r a k 2^{-/} \mathrm{T}$ cells that migrated in response to CCL19 was significantly decreased compared to wildtype T cells

(Figure 5-4B). These data suggest that Drak2 plays a role in T cell migration. To determine if actin polymerization was altered in response to chemokine treatment, we cultured unstimulated wildtype and Drak2 $2^{-/}$T cells for 20 minutes in media, then added CCL19. Cells were harvested and fixed at various time points and phalloidin binding was examined. We found that F-actin expression was decreased in Drak2 ${ }^{-/} \mathrm{T}$ cells compared to wildtype T cells after treatment with CCL19 (Figure 5-4C). This difference was 
A

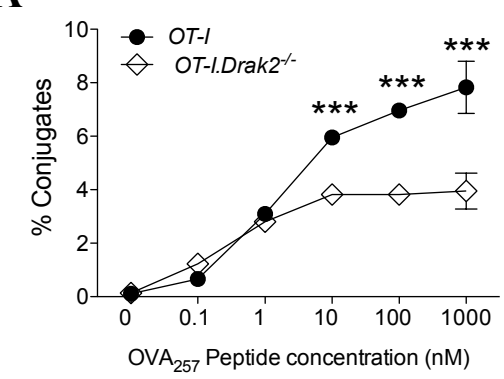

B

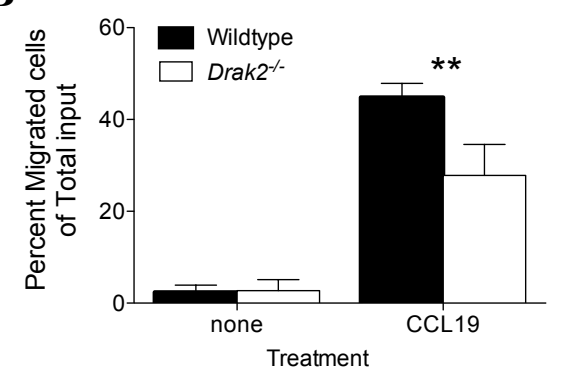

C
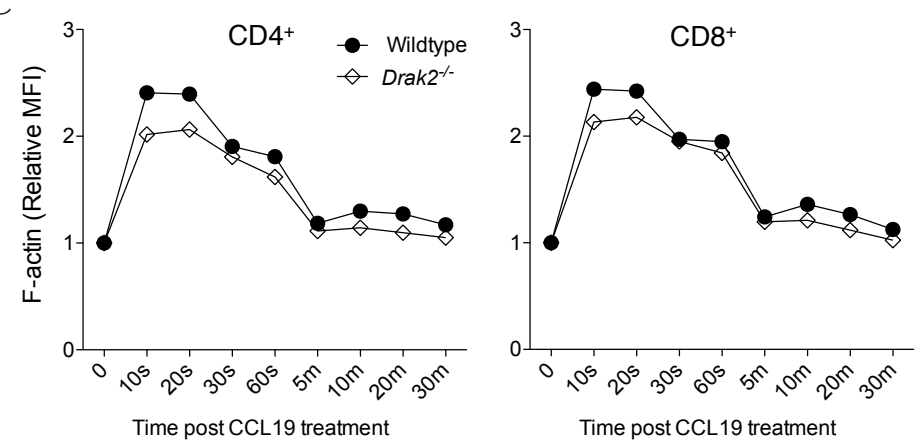

Figure 5-4. Actin-dependent $T$ cell functions are impaired in the absence of Drak2.

(A) Naïve $O T-I$ and $O T-I . D r a k 2^{-/} \mathrm{CD}^{+} \mathrm{T}$ cells were FACS sorted and co-cultured with CFSE-labeled, $\mathrm{OVA}_{257}$-loaded splenocytes for 10 minutes, then fixed. Cells were stained for antibodies specific for B220 and CD8, and analyzed by flow cytometry. The percent of total cells that formed conjugates $\left(\mathrm{B} 220^{+} \mathrm{CD} 8^{+}\right)$is shown for various $\mathrm{OVA}_{257}$ peptide concentrations. Samples represent two pooled mice per group and were tested in triplicate. Data were analyzed by two-way ANOVA with Bonferroni post-tests and error bars represent standard deviation. Data represent one experiment. (B) Negatively selected wildtype and Drak2 $2^{--} \mathrm{CD}^{+}$and $\mathrm{CD} 8^{+} \mathrm{T}$ cells were stimulated for 2 hours with anti-CD3 and anti-CD28. T cells were harvested, counted, and equal numbers were replated in a 96-transwell plate that held either media only or CCL19 chemokine. The percent of T cells that migrated by 2.5 hours into the receiver plate is shown. Samples represent three pooled mice per group and were tested in triplicate. Data were analyzed by two-way ANOVA with Bonferroni post-tests and error bars represent standard deviation. Data are representative of two experiments. (C) Negatively selected wildtype and Drak2 $^{--} \mathrm{CD}^{+}$and CD ${ }^{+} \mathrm{T}$ cells were rested at $37^{\circ} \mathrm{C}$ for 20 minutes. T cells were left untreated or treated with CCL19 for various time points, fixed, then stained with antibodies specific for CD4 and CD8. T cells were then permeabilized and stained with phalloidin. The MFI of F- phalloidin for CD4 and CD8 T cells at each time point is shown. Samples represent two pooled mice per group. Data represent one experiment. 
observed as early as 10-20 seconds after CCL19 treatment. These data demonstrate that Drak 2 modifies actin polymerization in response to chemoattractants, as well as TCR stimulation, and the absence of Drak2 impairs actin-mediated T cell functions.

\section{Active Rac-GTP expression is decreased in $\operatorname{Drak2}^{-/-} \mathbf{T}$ cells upon stimulation}

The activation of Rho GTPases, a family of proteins involved in the regulation of the actin cytoskeleton, is critical for several T cell functions, including activation, proliferation, and migration $[58,60]$. Interestingly, G1 to S phase transition during the cell cycle is also mediated by Rho GTPase proteins [57]. Therefore, we investigated the expression of active Rac, a member of the Rho GTPase family. T cells were purified from the lymph nodes of wildtype and $\mathrm{Drak}^{-/}$mice and stimulated in vitro for short periods of time by incubating the cells with biotin-conjugated anti-CD3 and anti-CD28 antibodies, followed by streptavidin crosslinking. Rac is active when bound to GTP, while GDP-bound Rac is inactive. Therefore, we measured the amount of active Rac by flow cytometry using an antibody that specifically binds to Rac-GTP. Following stimulation, Rac-GTP levels were significantly diminished in Drak2 ${ }^{-/}$CD4 and CD8 T cells compared to wildtype T cells (Figure 5-5A and 5-5B). Levels of Rac-GTP decreased in wildtype $\mathrm{T}$ cells after 2 minutes, but remained lower at all time points in Drak2 $^{--} \mathrm{T}$ cells. These data suggest that Drak2 directly or indirectly modifies the actin polymerization pathway either in collaboration with or upstream of Rac.

\section{Discussion}

$\operatorname{Drak}^{-/}$mice are resistant to $\mathrm{T}$ cell-mediated autoimmune diseases due to decreased accumulation of T cells in the target organ [23]. Previous studies showed that this decreased accumulation is due, at least in part, to enhanced death in Drak2 ${ }^{-/} \mathrm{T}$ cells following stimulation $[19,23]$. However, as T cell accumulation is a culmination of both survival and productive proliferation, Drak2 may also influence $\mathrm{T}$ cell proliferation. The data presented here show that defective proliferation does in fact, contribute to the decreased $\mathrm{T}$ cell accumulation observed in the absence of Drak2. We show that, following stimulation, Drak $2^{-/} \mathrm{T}$ cells exhibited abnormal morphology, reduced actin polymerization, and a block in the G1-S phase transition during cell cycle. Furthermore, actin-dependent $\mathrm{T}$ cell functions including APC:T cell conjugation and migration were decreased in the absence of Drak2. Interestingly, similar to Drak2 ${ }^{-/-} \mathrm{T}$ cells, T cells that are deficient in molecules involved in actin dynamics, such as Vav1 and WASP, also exhibit impaired $\mathrm{T}$ cell proliferation and migration [58], further implicating a direct or indirect role for Drak2 in actin polymerization. Finally, we show decreased levels of RacGTP, the active form of Rac, which is downstream of Vav1, in the absence of Drak2. Together these data suggest that Drak2 impacts actin polymerization upstream of Rac (Figure 5-6). Defects in cell cycle progression and proliferation may render Drak2 ${ }^{-/} \mathrm{T}$ cells more susceptible to death. Thus, reduced survival and accumulation of $\mathrm{Drak}^{-/} \mathrm{T}$ cells may be mediated by these faulty actin dynamics. 
A

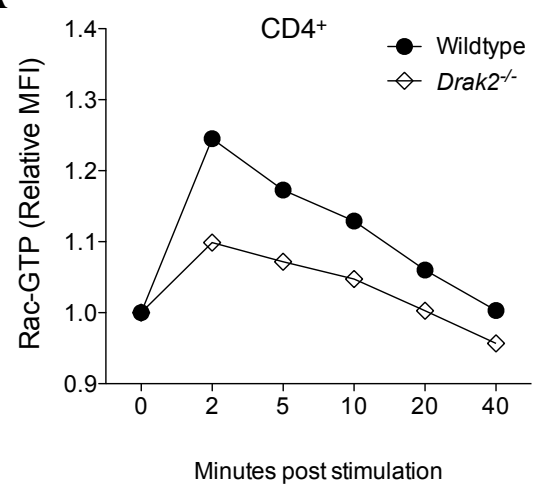

B

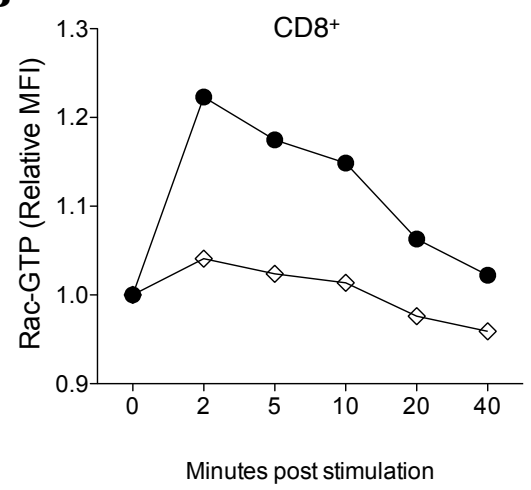

Figure 5-5. Active Rac-GTP expression is decreased in Drak2 ${ }^{-/-} \mathrm{T}$ cells upon stimulation.

Wildtype and Drak2 $2^{--} \mathrm{CD} 4^{+}$and $\mathrm{CD}^{+} \mathrm{T}$ cells were negatively selected and stimulated in vitro for the specified periods of time with biotin-conjugated anti-CD3 and anti-CD28 antibodies followed by streptavidin crosslinking. T cells were stained with anti-CD4 and anti-CD8, then fixed, permeabilized and stained with an anti-Rac-GTP antibody. The MFI of the Rac-GTP antibody in (A) $\mathrm{CD}^{+}$and (B) $\mathrm{CD}^{+} \mathrm{T}$ cells at each time point relative to the Rac-GTP antibody MFI in unstimulated wildtype or Drak2 ${ }^{-/-} \mathrm{T}$ cells is shown. Samples represent two pooled mice per group. Data represent one experiment. 


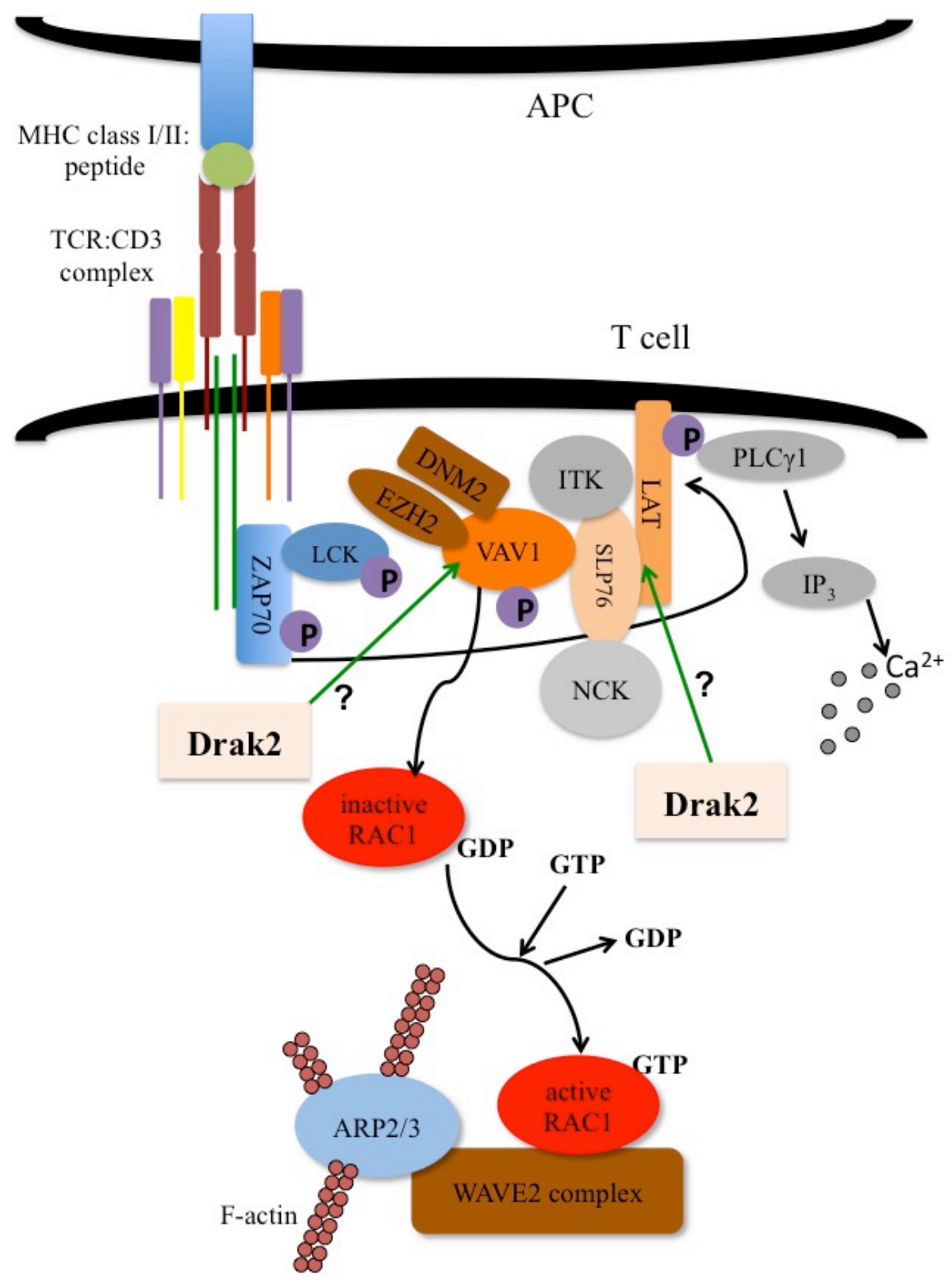

Figure 5-6. Proposed model of Drak2 function in actin polymerization.

Drak2 promotes actin polymerization, either directly or indirectly, upstream of Rac. Following TCR stimulation and activation of LCK, ZAP70, and LAT, Drak2 may function as a scaffold protein along with LAT and SLP76 for actin-regulatory proteins including VAV1, or may mediate activation of these proteins. The regulatory effects of Drak2 lead to enhanced actin polymerization and actin-mediated functions. 
The direct or indirect role of Drak2 in actin signaling may also account for many of the previously described phenotypes of Drak $2^{-/-} \mathrm{T}$ cells. For example, Drak $2^{-/-} \mathrm{T}$ cells are hyperproliferative to suboptimal TCR stimulation [2]. Productive TCR signaling requires an intact actin cytoskeleton to form a stable immunological synapse. The cytoskeletal components are also required to regulate the location of negative regulators of TCR signaling and to dissolve the synapse to prevent excessive signaling [59]. Thus, defects in actin polymerization could cause aberrant localization of key negative regulators or prolonged synapse formation, which would increase $\mathrm{T}$ cell activation and subsequent proliferation. For example, PKC- $\theta$ localization to the synapse, which is dependent on F-actin, has been shown to negatively regulate the stability of $\mathrm{T}$ cell synapses [61]. Therefore, if actin dynamics are decreased in the absence of Drak2, localization of PKC- $\theta$ to the synapse may also be decreased, which would lead to more stable synapse formation and enhanced signaling. The finding that there were fewer APC:T cell conjugates in the absence of Drak2 suggests that Drak2 may impact synapse formation and activation, although the role of Drak2 in actin-mediated immunological synapse formation requires further elucidation.

In addition, Drak2 is a negative regulator of $\mathrm{T}$ cell activation, and Drak2 ${ }^{-/-} \mathrm{T}$ cells exhibit increased calcium flux, augmented cytokine production, and enhanced IL-2 signaling, compared to wildtype T cells [4-6]. Several reports suggest an interdependence between calcium signaling and actin rearrangements; however, the factors that link these two processes remain elusive [62]. Inhibition of actin polymerization with cytochalasin $\mathrm{B}$ and latrunculin $\mathrm{B}$ led to elevated intracellular $\mathrm{Ca}^{2+}$ levels and increased cytokine production in T cells [63]. Thus, it is possible that decreased actin polymerization in Drak2 ${ }^{-/} \mathrm{T}$ cells mediates the increased calcium flux and increased IL-2 and IL-4 production observed in these cells after activation. While Drak2 has been shown to interact with several proteins involved in calcium signaling, including CHP, PKC- $\gamma$, and PKD, these interactions were not confirmed in primary $\mathrm{T}$ cells. Therefore, the exact mechanism by which Drak2 regulates calcium signaling in $\mathrm{T}$ cells is unclear. Thus, it is possible that decreased actin polymerization alters $\mathrm{T}$ cell activation in the absence of Drak2, which may contribute to augmented calcium signaling.

In addition to enhanced susceptibility to death and defects in proliferation, the reduced accumulation of Drak2 $2^{-/-} \mathrm{T}$ cells in the target organs during autoimmune disease could also be due to deficiencies in migration. Studies showed that wildtype and Drak2 $2^{-/}$ $\mathrm{T}$ cells exhibited similar expression levels of the adhesion molecules and chemokine receptors required for entry into the CNS [23], however it was not clear whether these receptors functioned similarly in the absence of Drak2. Furthermore, although the migration of T cells into nonlymphoid organs during delayed-type hypersensitivity, LCMV infection, and mouse hepatitis virus (MHV) was not altered in the absence of Drak2 [23,25], the mechanisms that mediate migration of T cells into non-lymphoid organs may vary between infection and autoimmunity. We showed that $\mathrm{T}$ cell migration in response to CCL19, a chemoattractant that is also expressed in the CNS, was decreased in the absence of Drak2. Therefore, decreased migration efficiency in the absence of 
Drak2 may also contribute to decreased accumulation in target organs during T1D and MS.

Together, the data presented here offer important insight into a novel role for Drak2 in actin polymerization via direct or indirect mechanisms. Further investigations to determine the expression and/or activation of additional actin proteins should be explored to determine more specifically if Drak2 functions directly within the actin polymerization pathway or if indirect effects mediate alterations observed in the absence of Drak2. We highlighted several previously described characteristics of Drak2 $2^{-/-} \mathrm{T}$ cells that could be caused by defects in actin polymerization. This leads to an intriguing hypothesis that Drak 2 modifies the actin pathway to mediate its downstream effects on $\mathrm{T}$ cell activation, proliferation, accumulation, cytokine production, migration, and possibly calcium signaling. Furthermore, perhaps these slight alterations in various processes synergize to lead to autoimmune disease resistance in the absence of Drak2. Whether Drak2 plays distinct roles in each of these pathways, or if there is interplay between these roles, wherein one factor precedes and mediates the others, remains to be determined. 


\section{CHAPTER 6. DISCUSSION AND CONCLUSIONS}

\section{Discussion}

Drak2 plays a key role in the induction of T1D and MS by promoting the accumulation of T cells after stimulation [23]. Consequently, Drak ${ }^{-/-}$mice are resistant to disease in models of MS and T1D. Yet, Drak2 ${ }^{-/-}$mice respond comparably to wildtype mice in several models of infection. In fact, the response is enhanced in the absence of Drak2 following infection with some pathogens [24-26] and (unpublished data).

Furthermore, Drak2 does not function as a tumor suppressor or an oncogene in various in vivo tumor models [32]. Based on these findings, Drak2 is an ideal target to inhibit for the treatment of T cell-mediated autoimmune diseases. While several studies show that Drak2 contributes to T1D and MS, the exact mechanism(s) by which Drak2 mediates autoimmunity is not clear. Therefore, the investigations performed in this dissertation aimed to examine and clarify more precise mechanisms by which Drak2 influences autoimmunity.

While it was established that Drak2 expression within the T cells during MS mediates disease resistance, the mechanism for resistance to T1D is less clear. One study showed that enhanced susceptibility to death within the T cells led to decreased $\mathrm{T}$ cell accumulation in the pancreas and the draining lymph nodes, and thus, disease resistance [23]. However, an alternative study suggested that T1D was mediated by Drak2 expression in the $\beta$-islet cells within the pancreas, which caused increased apoptosis and destruction of those cells [14]. Therefore, we investigated whether Drak2 expression in the T cells, $\beta$-islet cells, or a combination of both, contributes to T1D. Utilizing the NOD mouse model, we determined that resistance to T1D is due to the absence of Drak2 in the $\mathrm{T}$ cells, rather than the $\beta$-islet cells. This is evident because the resistance to T1D in NOD.Drak $2^{-/}$mice transferred with the T cells and was independent of Drak2 expression in islet cells. Importantly, enhanced $\mathrm{T}$ cell death was not the sole mediator of resistance, as regulatory T cells were also required to elicit T1D resistance in the absence of Drak2. Further studies showed an enhanced proportion of Treg cells in Drak2 $2^{-/}$mice compared to wildtype mice, and enhanced IL-2 signaling within Drak2 $2^{-/-}$thymocytes, compared to wildtype thymocytes. We further observed that enhanced IL-2 signaling and increased Stat5 phosphorylation mediated the increased proportion of Foxp3-epxressing Tregs in the absence of Drak2. These data suggest that the increase in Drak2 ${ }^{--}$Tregs, along with an increased susceptibility to death within $\operatorname{Drak2}^{-/-} \mathrm{T}$ cells both cooperate to prevent T1D. Furthermore, the enhanced expression of pStat5 in the absence of Drak2 suggests that Drak2 functions as a negative regulator of IL-2 signaling upstream of Stat5 activation. The exact mechanism by which Drak2 decreases pStat5-mediated Foxp3 induction warrants further exploration. In addition to mediating enhanced Foxp3 induction in Drak2 $2^{-/}$thymocytes, enhanced IL-2 signaling may also contribute to increased apoptosis or other downstream functional effects in mature, peripheral $\mathrm{T}$ cells that could contribute to autoimmune disease resistance in the absence of Drak2. These options should also be investigated. 
As T cells play pivotal roles in eliciting resistance to MS and T1D in the absence of Drak2, it is important to study the molecular mechanisms of Drak2 in primary T cells to further understand how Drak2 mediates autoimmunity. Therefore, we further explored $\mathrm{T}$ cell functions that could mediate this resistance. A recent investigation, utilizing several tumor cell lines, suggested that Drak 2 is a negative regulator of TGF- $\beta$ signaling [10]. TGF- $\beta$ elicits many effects on T cells that could suppress autoimmunity, including inhibition of proliferation, survival, and differentiation. If Drak2 were a negative regulator of TGF- $\beta$ signaling, then these processes should be enhanced in the absence of Drak2 and could mediate resistance to autoimmune diseases. However, T cells were not specifically investigated in the previous study. Therefore, we investigated if Drak2 functioned as a negative regulator of TGF- $\beta$ signaling in T cells. Our data show that Drak2 does not function as a negative regulator of this pathway in primary T cells. We did not observe enhanced Smad2/3 signaling after TGF- $\beta$ stimulation in Drak2 ${ }^{-/}$T cells compared to wildtype T cells. Furthermore, several TGF- $\beta$-mediated functional effects were similar between wildtype and Drak $2^{-/-} \mathrm{T}$ cells, including inhibition of naïve T cell proliferation, T cell accumulation and survival, and Treg induction. While Drak2 may serve as a negative regulator in tumor cell lines, possibly due to pathway alterations that may occur in response to mutations that lead to tumorigenesis, we contend that Drak2 does not function as a negative regulator of TGF- $\beta$ signaling in primary T cells. Furthermore, alterations in TGF- $\beta$ signaling do not mediate susceptibility to autoimmune disease in the absence of Drak2. Therefore, we continued our study to determine alternative molecular mechanism(s) by which Drak2 functions to promote autoimmune disease within T cells.

Decreased T cell accumulation in target organs during MS and T1D mediates disease resistance in the absence of Drak2 [23]. T cell accumulation is a result of efficient survival and proliferation. Although decreased survival of Drak2 ${ }^{-/} \mathrm{T}$ cells following stimulation has been shown to mediate, at least in part, this decreased accumulation $[19,23]$, detailed investigations to study proliferation had not been performed. Therefore, we investigated if there were proliferative alterations in the absence of Drak2. We found that defective proliferation, in addition to decreased survival, contributed to the decreased $\mathrm{T}$ cell accumulation observed in the absence of Drak2 in vitro. We also showed that following stimulation, Drak $2^{-/} \mathrm{T}$ cells exhibited abnormal morphology, altered cell proliferation, and a delay or block in G1-S phase transition during cell cycle. In addition, we observed decreases in actin polymerization, and actin-dependent $\mathrm{T}$ cell functions, including migration and APC:T cell conjugation, in the absence of Drak2. Therefore, we hypothesize that Drak2 modifies the actin polymerization pathway either directly or indirectly. Furthermore, the Rho family of GTPases have been shown to mediate G1 to S phase transition during the cell cycle. Interestingly, we observed decreased active RacGTP, a member of the Rho Family, in the absence of Drak2, suggesting that Drak2 impacts the actin polymerization pathway upstream of Rac activation. Rac activation via VAV1 is pivotal for the accumulation of F-actin at the immunological synapse, $\mathrm{T}$ cell activation, lamellipod formation, and other important actin-mediated functions [64]. Generally, the actin polymerization pathway and its associated proteins also mediate numerous other $\mathrm{T}$ cell functions, including cell cycle progression, proliferation, migration, and calcium dynamics. These data suggest that Drak2 contributes to T cell- 
mediated autoimmune diseases via its effects on actin polymerization by influencing small alterations within these processes.

Taken together, these findings suggest novel roles for Drak2 in IL-2 signaling and actin polymerization, either directly or indirectly. Interestingly, increased IL-2-mediated functions including enhanced Treg induction and augmented IL-2 mediated activationinduced $\mathrm{T}$ cell death, along with alterations in actin-mediated $\mathrm{T}$ cell functions, including altered immunological synapse formation, defective proliferation, and reduced migration could all potentially mediate disease resistance and decreased $\mathrm{T}$ cell accumulation in the pancreas and CNS during T1D and MS, respectively. Therefore, in the absence of Drak2, small alterations within these processes could collectively contribute to autoimmune disease. Interestingly, defects in actin polymerization also contribute to enhanced calcium signaling and increased cytokine signaling and production. Thus, our future studies will further elucidate whether Drak2 plays distinct roles within each pathway, or if it plays a direct role in actin polymerization to mediate calcium and IL-2 signaling.

\section{Future Studies}

\section{Drak2 and IL-2 signaling}

We showed that Drak2 negatively regulated IL-2 signaling in CD4 SP thymocytes and thus, reduced the development of Tregs. Enhanced phosphorylation of Stat 5 in the absence of Drak2 suggests that Drak2 blocks signaling upstream of Stat5 activation. There are several regulatory mechanisms by which Drak 2 could elicit this effect. Therefore, future studies will focus on identifying the exact mechanism by which Drak2 reduces IL-2 signaling. Drak2 may act as a scaffold protein to recruit other negative regulators, including SOCS1, SOCS3, or SHP-1, to the receptor complex or may mediate the activation of these proteins. Alternatively, Drak2 may function at the IL-2 receptor to dampen IL-2 signaling by blocking recruitment or activation of Jak1 or Jak3. Thus, studies to examine the levels of activated Jak1 and Jak3, which are downstream of the IL2 receptor, but upstream of Stat5 activation, will determine if Drak2 mediates negative regulatory effects at the receptor complex, or if its effects are elicited downstream of Jak activation. To further explore potential interactions and scaffold functions of Drak2, we will perform co-immunoprecipitation assays to identify possible Drak2 interactions with IL-2 signaling molecules, as well as the known negative regulators of the pathway. Interestingly, mass spectrometry data suggested that Drak2 interacts with Stat5a (unpublished data). Therefore, Stat5 will be the initial protein of interest.

Further studies will be conducted to determine if IL-2 signaling is enhanced in mature, peripheral T cells. Although previous data showed that Drak2 ${ }^{-/-} \mathrm{T}$ cells produce more IL-2 than wildtype T cells, detailed analysis of IL-2 signaling has not been investigated in peripheral $T$ cells. In addition, we will test if functions downstream of IL2 are altered in the absence of Drak2. Specifically, enhanced IL-2 signaling has been 
shown to enhance apoptosis in mature T cells [48]. Therefore, we will determine the effects of exogenous IL-2 treatment on Drak $2^{-/}$T cell survival.

\section{Drak2 and actin polymerization}

Our data show that Drak2 contributes to actin polymerization via direct or indirect mechanisms, and its absence leads to multiple defects in actin-mediated $\mathrm{T}$ cell functions. Notably, APC:T cell conjugation was decreased in the absence of Drak2, which has implications for altered immunological synapse dynamics and activation. Therefore, future studies will utilize lipid bilayers and fluorescent microscopy to explore immunological synapse formation and actin localization at the immunological synapse. These studies will allow us to determine if alterations in actin polymerization in the absence of Drak2 lead to either hyperstable or unstable synapses.

In addition, we determined that Drak2 likely functions upstream of Rac1 activation. Future studies will explore the expression, activation, and localization of actin proteins upstream of Rac-GTP in the actin polymerization pathway. Because several of the proteins upstream of Rac activation also possess scaffold functions, we will also perform co-immunoprecipitation assays to determine if Drak2 functions in the actin polymerization pathway via potential interactions with these proteins of interest, including LAT, SLP76, and VAV1.

\section{Conclusions}

It is important to investigate and determine potential molecular mechanisms by which Drak2 functions during autoimmunity to better understand the etiology of autoimmune diseases, as well as to validate the use of Drak2 as a target for therapeutic treatment of these diseases. Our investigations to determine the role of Drak2 in autoimmunity have revealed several novel findings for Drak2 in T cell function. First, we determined that Drak2 expression in T cells contributes to autoimmune disease in T1D, similar to what was previously shown for MS. Furthermore, enhanced death of these T cells was not the sole mediator for resistance, as Tregs were required. In addition, an enhanced proportion of Tregs in the absence of Drak2 was observed, which may also contribute to T1D resistance. The increase in Tregs was mediated by enhanced IL-2 signaling during Treg development in the thymus, and not due to enhanced TGF- $\beta$ mediated Treg induction in the periphery. In fact, TGF- $\beta$ signaling is not enhanced in the absence of Drak2, and TGF- $\beta$ functions are comparable to wildtype T cells. These data dispute the suggestion that Drak2 is a negative regulator of TGF- $\beta$ signaling, at least in primary T cells. Surprisingly, Drak2 also modifies actin polymerization, either directly or indirectly, upstream of Rac1 to elicit alterations in several T cell functions, including survival, proliferation, migration, and APC:T cell conjugation. Taken together, these findings offer an intriguing concept, in which slight modifications within several processes may collaborate and contribute to autoimmune disease resistance in the absence of Drak2. We are hopeful that these findings will benefit future studies to 
develop novel therapeutic treatments for autoimmune diseases. Furthermore, the fact that $\operatorname{Drak2}^{-{ }^{-}}$mice respond effectively to infectious pathogens and tumors highlights that the aforementioned modifications do not collaborate to mediate detrimental effects during productive immune responses, supporting the notion that slight modifications in certain pathways may be more detrimental for $\mathrm{T}$ cell responses during autoimmunity rather than during immunity to foreign agents and tumors. Most importantly, Drak2 remains a viable target to inhibit for therapeutic treatment during T-cell mediated autoimmune diseases. 


\section{LIST OF REFERENCES}

1. Bachmaier K, Krawczyk C, Kozieradzki I, Kong YY, Sasaki T, Oliveira-dos-Santos A, et al. Negative regulation of lymphocyte activation and autoimmunity by the molecular adaptor Cbl-b. Nature. 2000 Jan 13;403(6766):211-6.

2. Rangachari $M$, Penninger JM. Negative regulation of $T$ cell receptor signals. Curr Opin Pharmacol. 2004 Aug;4(4):415-22.

3. Suzuki A, Yamaguchi MT, Ohteki T, Sasaki T, Kaisho T, Kimura Y, et al. T cellspecific loss of Pten leads to defects in central and peripheral tolerance. Immunity. 2001 May;14(5):523-34.

4. McGargill MA, Wen BG, Walsh CM, Hedrick SM. A deficiency in Drak2 results in a $\mathrm{T}$ cell hypersensitivity and an unexpected resistance to autoimmunity. Immunity. 2004 Dec;21(6):781-91.

5. Friedrich ML, Wen BG, Bain G, Kee BL, Katayama C, Murre C, et al. DRAK2, a lymphoid-enriched DAP kinase, regulates the TCR activation threshold during thymocyte selection. Int Immunol. 2005 Nov;17(11):1379-90.

6. Friedrich ML, Cui M, Hernandez JB, Weist BM, Andersen H-M, Zhang X, et al. Modulation of DRAK2 autophosphorylation by antigen receptor signaling in primary lymphocytes. J Biol Chem. 2007 Feb 16;282(7):4573-84.

7. Sanjo H, Kawai T, Akira S. DRAKs, novel serine/threonine kinases related to deathassociated protein kinase that trigger apoptosis. J Biol Chem. 1998 Oct 30;273(44):29066-71.

8. Kögel D, Prehn JH, Scheidtmann KH. The DAP kinase family of pro-apoptotic proteins: novel players in the apoptotic game. Bioessays. 2001 Apr;23(4):352-8.

9. Matsumoto M, Miyake Y, Nagita M, Inoue H, Shitakubo D, Takemoto K, et al. A serine/threonine kinase which causes apoptosis-like cell death interacts with a calcineurin B-like protein capable of binding $\mathrm{Na}(+) / \mathrm{H}(+)$ exchanger. J Biochem. 2001 Aug;130(2):217-25.

10. Yang K-M, Kim W, Bae E, Gim J, Weist BM, Jung Y, et al. DRAK2 participates in a negative feedback loop to control TGF- $\beta /$ Smads signaling by binding to type I TGF- $\beta$ receptor. Cell Rep. 2012 Nov 29;2(5):1286-99.

11. Ye P, Zhao L, Gonda TJ. The MYB oncogene can suppress apoptosis in acute myeloid leukemia cells by transcriptional repression of DRAK2 expression. Leuk Res. 2013 May;37(5):595-601. 
12. Mao J, Qiao X, Luo H, Wu J. Transgenic drak2 overexpression in mice leads to increased $\mathrm{T}$ cell apoptosis and compromised memory T cell development. J Biol Chem. 2006 May 5;281(18):12587-95.

13. Mao J, Luo H, Wu J. Drak2 overexpression results in increased beta-cell apoptosis after free fatty acid stimulation. J Cell Biochem. 2008 Nov 1;105(4):1073-80.

14. Mao J, Luo H, Han B, Bertrand R, Wu J. Drak2 is upstream of p70S6 kinase: its implication in cytokine-induced islet apoptosis, diabetes, and islet transplantation. $\mathrm{J}$ Immunol. 2009 Apr 15;182(8):4762-70.

15. Kuwahara $\mathrm{H}$, Nakamura N, Kanazawa $H$. Nuclear localization of the serine/threonine kinase DRAK2 is involved in UV-induced apoptosis. Biol Pharm Bull. 2006 Feb;29(2):225-33.

16. Kuwahara H, Nishizaki M, Kanazawa H. Nuclear localization signal and phosphorylation of Serine350 specify intracellular localization of DRAK2. J Biochem. 2008 Mar;143(3):349-58.

17. Newton RH, Leverrier S, Srikanth S, Gwack Y, Cahalan MD, Walsh CM. Protein kinase D orchestrates the activation of DRAK2 in response to TCR-induced Ca2+ influx and mitochondrial reactive oxygen generation. J Immunol. 2011 Jan 15;186(2):940-50.

18. Kuwahara H, Kamei J, Nakamura N, Matsumoto M, Inoue H, Kanazawa H. The apoptosis-inducing protein kinase DRAK2 is inhibited in a calcium-dependent manner by the calcium-binding protein CHP. J Biochem. 2003 Aug;134(2):245-50.

19. Ramos SJ, Hernandez JB, Gatzka M, Walsh CM. Enhanced T cell apoptosis within Drak2-deficient mice promotes resistance to autoimmunity. J Immunol. 2008 Dec 1;181(11):7606-16.

20. Al-Qahtani A, Xu Z, Zan H, Walsh CM, Casali P. A role for DRAK2 in the germinal center reaction and the antibody response. Autoimmunity. 2008 Aug;41(5):341-52.

21. Weist BM, Hernandez JB, Walsh CM. Loss of DRAK2 signaling enhances allogeneic transplant survival by limiting effector and memory $\mathrm{T}$ cell responses. Am J Transplant. 2012 Aug;12(8):2220-7.

22. Gatzka M, Newton RH, Walsh CM. Altered thymic selection and increased autoimmunity caused by ectopic expression of DRAK2 during T cell development. J Immunol. 2009 Jul 1;183(1):285-97.

23. McGargill MA, Choy C, Wen BG, Hedrick SM. Drak2 regulates the survival of activated $\mathrm{T}$ cells and is required for organ-specific autoimmune disease. J Immunol. 2008 Dec 1;181(11):7593-605. 
24. Wang S, Welte T, McGargill M, Town T, Thompson J, Anderson JF, et al. Drak2 contributes to West Nile virus entry into the brain and lethal encephalitis. J Immunol. 2008 Aug 1;181(3):2084-91.

25. Ramos SJ, Hardison JL, Stiles LN, Lane TE, Walsh CM. Anti-viral effector T cell responses and trafficking are not dependent upon DRAK2 signaling following viral infection of the central nervous system. Autoimmunity. 2007 Feb;40(1):54-65.

26. Schaumburg CS, Gatzka M, Walsh CM, Lane TE. DRAK2 regulates memory T cell responses following murine coronavirus infection. Autoimmunity. 2007 Nov;40(7):483-8.

27. Michie AM, McCaig AM, Nakagawa R, Vukovic M. Death-associated protein kinase (DAPK) and signal transduction: regulation in cancer. FEBS J. 2010 Jan;277(1):74-80.

28. Inbal B, Cohen O, Polak-Charcon S, Kopolovic J, Vadai E, Eisenbach L, et al. DAP kinase links the control of apoptosis to metastasis. Nature. 1997 Nov $13 ; 390(6656): 180-4$.

29. Raveh T, Droguett G, Horwitz MS, DePinho RA, Kimchi A. DAP kinase activates a p19ARF/p53-mediated apoptotic checkpoint to suppress oncogenic transformation. Nat Cell Biol. 2001 Jan;3(1):1-7.

30. Doherty GA, Byrne SM, Austin SC, Scully GM, Sadlier DM, Neilan TG, et al. Regulation of the apoptosis-inducing kinase DRAK2 by cyclooxygenase- 2 in colorectal cancer. Br J Cancer. 2009 Aug 4;101(3):483-91.

31. Hartmann TB, Mattern E, Wiedemann N, van Doorn R, Willemze R, Niikura T, et al. Identification of selectively expressed genes and antigens in CTCL. Exp Dermatol. 2008 Apr;17(4):324-34.

32. Edwards BA, Harris TL, Floersh H, Lukens JR, Zaki MH, Vogel P, et al. Drak2 is not required for tumor surveillance and suppression. Int Immunol. 2015 Mar;27(3):161-6.

33. Leonczak P, Gao L-J, Ramadori AT, Lescrinier E, Rozenski J, De Jonghe S, et al. Synthesis and structure-activity relationship studies of $2-(1,3,4-$ oxadiazole- $2(3 \mathrm{H})-$ thione)-3-amino-5-arylthieno[2,3-b]pyridines as inhibitors of DRAK2. ChemMedChem. 2014 Nov;9(11):2587-601.

34. Gao L-J, Kovackova S, Sála M, Ramadori AT, De Jonghe S, Herdewijn P. Discovery of dual death-associated protein related apoptosis inducing protein kinase 1 and 2 inhibitors by a scaffold hopping approach. J Med Chem. 2014 Sep 25;57(18):7624-43. 
35. Barnden MJ, Allison J, Heath WR, Carbone FR. Defective TCR expression in transgenic mice constructed using cDNA-based alpha- and beta-chain genes under the control of heterologous regulatory elements. Immunol Cell Biol. 1998 Feb;76(1):34-40.

36. Gorelik L, Flavell RA. Abrogation of TGFbeta signaling in T cells leads to spontaneous T cell differentiation and autoimmune disease. Immunity. 2000 Feb;12(2):171-81.

37. Zeng H, Yang K, Cloer C, Neale G, Vogel P, Chi H. mTORC1 couples immune signals and metabolic programming to establish T(reg)-cell function. Nature. 2013 Jul 25;499(7459):485-90.

38. Vignali DAA, Collison LW, Workman CJ. How regulatory T cells work. Nat Rev Immunol. 2008 Jul;8(7):523-32.

39. Lyons AB, Blake SJ, Doherty KV. Flow cytometric analysis of cell division by dilution of CFSE and related dyes. Curr Protoc Cytom. 2013;Chapter 9:Unit9.11.

40. Morley SC, Wang C, Lo W-L, Lio C-WJ, Zinselmeyer BH, Miller MJ, et al. The actin-bundling protein L-plastin dissociates CCR7 proximal signaling from CCR7induced motility. J Immunol. 2010 Apr 1;184(7):3628-38.

41. Burbach BJ, Srivastava R, Ingram MA, Mitchell JS, Shimizu Y. The pleckstrin homology domain in the SKAP55 adapter protein defines the ability of the adapter protein ADAP to regulate integrin function and NF-kappaB activation. J Immunol. 2011 Jun 1;186(11):6227-37.

42. Yopp AC, Ochando JC, Mao M, Ledgerwood L, Ding Y, Bromberg JS. Sphingosine 1-phosphate receptors regulate chemokine-driven transendothelial migration of lymph node but not splenic T cells. J Immunol. 2005 Sep 1;175(5):2913-24.

43. Pearson JA, Wong FS, Wen L. The importance of the Non Obese Diabetic (NOD) mouse model in autoimmune diabetes. J Autoimmun. 2016 Jan;66:76-88.

44. Burchill MA, Yang J, Vang KB, Moon JJ, Chu HH, Lio C-WJ, et al. Linked T cell receptor and cytokine signaling govern the development of the regulatory $\mathrm{T}$ cell repertoire. Immunity. 2008 Jan;28(1):112-21.

45. Lio C-WJ, Hsieh C-S. A two-step process for thymic regulatory T cell development. Immunity. 2008 Jan;28(1):100-11.

46. Huynh A, Zhang R, Turka LA. Signals and pathways controlling regulatory T cells. Immunol Rev. 2014 Mar;258(1):117-31.

47. Yi Z, Lin WW, Stunz LL, Bishop GA. The adaptor TRAF3 restrains the lineage determination of thymic regulatory $\mathrm{T}$ cells by modulating signaling via the receptor for IL-2. Nat Immunol. 2014 Sep;15(9):866-74. 
48. Malek TR. The Biology of Interleukin-2. Annual Review of Immunology. 2008;26(1):453-79.

49. Hulme MA, Wasserfall $\mathrm{CH}$, Atkinson MA, Brusko TM. Central role for interleukin2 in type 1 diabetes. Diabetes. 2012 Jan;61(1):14-22.

50. Roncarolo MG, Zoppo M, Bacchetta R, Gabiano C, Sacchetti C, Cerutti F, et al. Interleukin-2 production and interleukin-2 receptor expression in children with newly diagnosed diabetes. Clin Immunol Immunopathol. 1988 Oct;49(1):53-62.

51. Rubtsov YP, Rudensky AY. TGFbeta signalling in control of T-cell-mediated selfreactivity. Nat Rev Immunol. 2007 Jun;7(6):443-53.

52. Harris TL, McGargill MA. Drak2 Does Not Regulate TGF- $\beta$ Signaling in T Cells. PLoS ONE. 2015;10(5):e0123650.

53. McKarns SC, Schwartz RH. Distinct effects of TGF-beta 1 on CD4+ and CD8+ T cell survival, division, and IL-2 production: a role for T cell intrinsic Smad3. J Immunol. 2005 Feb 15;174(4):2071-83.

54. Sanjabi S, Mosaheb MM, Flavell RA. Opposing effects of TGF-beta and IL-15 cytokines control the number of short-lived effector CD8+ T cells. Immunity. 2009 Jul 17;31(1):131-44.

55. Oh SA, Li MO. TGF- $\beta$ : guardian of T cell function. J Immunol. 2013 Oct 15;191(8):3973-9.

56. Itoh $\mathrm{S}$, ten Dijke P. Negative regulation of TGF-beta receptor/Smad signal transduction. Curr Opin Cell Biol. 2007 Apr;19(2):176-84.

57. Heng Y-W, Koh C-G. Actin cytoskeleton dynamics and the cell division cycle. Int J Biochem Cell Biol. 2010 Oct;42(10):1622-33.

58. Billadeau DD, Nolz JC, Gomez TS. Regulation of T-cell activation by the cytoskeleton. Nat Rev Immunol. 2007 Feb;7(2):131-43.

59. Kumari S, Curado S, Mayya V, Dustin ML. T cell antigen receptor activation and actin cytoskeleton remodeling. Biochim Biophys Acta. 2014 Feb;1838(2):546-56.

60. Rougerie P, Delon J. Rho GTPases: masters of T lymphocyte migration and activation. Immunol Lett. 2012 Feb 29;142(1-2):1-13.

61. Sims TN, Soos TJ, Xenias HS, Dubin-Thaler B, Hofman JM, Waite JC, et al. Opposing effects of PKCtheta and WASp on symmetry breaking and relocation of the immunological synapse. Cell. 2007 May 18;129(4):773-85. 
62. Joseph N, Reicher B, Barda-Saad M. The calcium feedback loop and T cell activation: how cytoskeleton networks control intracellular calcium flux. Biochim Biophys Acta. 2014 Feb;1838(2):557-68.

63. Rivas FV, O'Keefe JP, Alegre M-L, Gajewski TF. Actin cytoskeleton regulates calcium dynamics and NFAT nuclear duration. Mol Cell Biol. 2004 Feb;24(4):1628-39.

64. Tybulewicz VLJ. Vav-family proteins in T-cell signalling. Curr Opin Immunol. 2005 Jun;17(3):267-74. 


\section{VITA}

Tarsha L. Harris was born in 1981 in Charleston, MS. She graduated from West Tallahatchie High School in 2000. Tarsha matriculated at Tougaloo College, near Jackson, MS, and graduated with a Bachelor of Science in Biology in 2005. After graduation, she gained laboratory experience as a Lab Technician at the University of Mississippi (MS) Medical Center, then later as a Laboratory Technologist at the MS State Health Department's Public Health Laboratory. Fueled by her thirst for knowledge, Tarsha enrolled in the Integrated Program of Biomedical Sciences in the Microbiology, Immunology, and Biochemistry track (formerly the Microbial Pathogenesis, Immunology, and Inflammation track) at the University of Tennessee Health Science Center in the Fall of 2010. In the Spring of 2011, Tarsha joined Dr. Maureen McGargill's Immunology Lab at St. Jude Children's Research Hospital. Upon joining the lab, Tarsha's dissertation research focused on determining the role of Drak2 in T cell function and autoimmunity. Tarsha successfully defended her Ph.D. dissertation research in April 2016. 